\title{
Coordinating Cytoskeleton and Molecular Traffic in T Cell Migration, Activation, and Effector Functions
}

\author{
Marta Mastrogiovanni 1,2, Marie Juzans' ${ }^{1}$, Andrés Alcover ${ }^{1}$ and Vincenzo Di Bartolo ${ }^{1 *}$ \\ 1 Ligue Nationale Contre le Cancer - Equipe Labellisée LIGUE 2018, Lymphocyte Cell Biology Unit, INSERM-U1221, \\ Department of Immunology, Institut Pasteur, Paris, France, ${ }^{2}$ Collège Doctoral, Sorbonne Université, Paris, France
}

\section{OPEN ACCESS}

Edited by:

Enrique Aguado,

University of Cádiz, Spain

Reviewed by:

Noa B. Martin-Cofreces, University Hospital of La Princesa,

Spain

Cosima T. Baldari,

University of Siena, Italy

*Correspondence:

Vincenzo Di Bartolo

vincenzo.di-bartolo@pasteur.fr

Specialty section:

This article was submitted to

Signaling,

a section of the journal

Frontiers in Cell and Developmental

Biology

Received: 04 August 2020 Accepted: 24 September 2020

Published: 21 October 2020

Citation:

Mastrogiovanni M, Juzans M, Alcover A and Di Bartolo V (2020)

Coordinating Cytoskeleton and Molecular Traffic in T Cell

Migration, Activation, and Effector

Functions.

Front. Cell Dev. Biol. 8:591348. doi: 10.3389/fcell.2020.591348
Dynamic localization of receptors and signaling molecules at the plasma membrane and within intracellular vesicular compartments is crucial for $T$ lymphocyte sensing environmental cues, triggering membrane receptors, recruiting signaling molecules, and fine-tuning of intracellular signals. The orchestrated action of actin and microtubule cytoskeleton and intracellular vesicle traffic plays a key role in all these events that together ensure important steps in $T$ cell physiology. These include extravasation and migration through lymphoid and peripheral tissues, $\mathrm{T}$ cell interactions with antigen-presenting cells, $\mathrm{T}$ cell receptor (TCR) triggering by cognate antigen-major histocompatibility complex (MHC) complexes, immunological synapse formation, cell activation, and effector functions. Cytoskeletal and vesicle traffic dynamics and their interplay are coordinated by a variety of regulatory molecules. Among them, polarity regulators and membrane-cytoskeleton linkers are master controllers of this interplay. Here, we review the various ways the T cell plasma membrane, receptors, and their signaling machinery interplay with the actin and microtubule cytoskeleton and with intracellular vesicular compartments. We highlight the importance of this fine-tuned crosstalk in three key stages of $T$ cell biology involving cell polarization: T cell migration in response to chemokines, immunological synapse formation in response to antigen cues, and effector functions. Finally, we discuss two examples of perturbation of this interplay in pathological settings, such as HIV-1 infection and mutation of the polarity regulator and tumor suppressor adenomatous polyposis coli (Apc) that leads to familial polyposis and colorectal cancer.

Keywords: TCR, signaling molecules, actin, microtubules, molecular transport, HIV-1, immunological synapse, polarity regulators

\section{INTRODUCTION}

Dynamic compartmentation of receptors and signaling molecules is key for $\mathrm{T}$ cells to sense environmental cues, trigger membrane receptors, and transduce and fine-tune intracellular signals controlling T cell migration, activation, and effector functions. This molecular compartmentation is ensured by the interplay between the plasma membrane, cytoskeleton networks, and intracellular organelles.

At the plasma membrane, dynamic assemblies of lipids and proteins form nano- to micro-scale domains that may become platforms for receptor signaling (i.e., cholesterol- and sphingolipidenriched membrane domains or lipid rafts). These domains may facilitate either segregation or 
interaction between receptors (e.g., chemokine receptors and $\mathrm{T}$ cell receptors [TCRs]) and signaling molecules, conditioning their state of activation and preventing or facilitating receptor triggering and signaling (Lillemeier et al., 2006; Viola and Gupta, 2007; Simons and Gerl, 2010; Swamy et al., 2016). In addition, specific membrane phosphoinositides, transiently generated by enzymatic activation during chemokine receptor or TCR signaling, form different domains that target signaling effectors (e.g., Pleckstrin homology $(\mathrm{PH})$ domain-containing proteins) at sites of receptor stimulation (Courtney et al., 2018).

The cortical actin cytoskeleton contributes to plasma membrane organization by generating areas of differential mobility of lipids and proteins. Thus, membrane-associated cytoskeletal fences shape the lateral distribution of membrane components involved in cell adhesion or receptor activation (Sako and Kusumi, 1995), adding a level of membrane organization cooperative with lipid microdomain partitioning. Furthermore, actin dynamics contribute to cell reorganization in response to chemokine or antigen stimulation needed for $\mathrm{T}$ cell migration, activation, and effector functions (Viola and Gupta, 2007; Nicolson, 2014; Niedergang et al., 2016). Although cortical actin and plasma membrane domains are often considered two-dimensional entities, three-dimensional membrane-cytoskeletal structures, such as microvilli, may form sensing exploratory extensions displaying receptor signaling components and adhesion molecules located within flexible subcellular areas distant from the cell body (Singer et al., 2001; Cai et al., 2017; Ghosh et al., 2020).

Several cellular organelles, including the Golgi apparatus and the endosomal and lysosomal compartments, continuously exchange with the plasma membrane. They contribute to lipid and protein sorting to subcellular areas involved in cell migration, activation, or secretion (Bretscher and Aguado-Velasco, 1998; Griffiths et al., 2010; Niedergang et al., 2016). Moreover, the endoplasmic reticulum (ER) and mitochondria contribute not only to protein synthesis and metabolism but also to $\mathrm{T}$ cell signaling (Quintana and Hoth, 2012).

Microtubules are crucial for intracellular transport and subcellular localization of molecules, vesicles, and organelles. They form a network that interacts with the nucleus, the cortical actin cytoskeleton, the plasma membrane, and various organelles, including endo-lysosomal compartments, the ER, and the Golgi apparatus. Microtubules coordinate the localization of proteins and organelles by means of their associated molecular motors, dynein, and kinesins. In this way, they ensure the dynamic relocalization of a variety of cellular components during $\mathrm{T}$ cell migration, activation, and effector functions (VicenteManzanares and Sanchez-Madrid, 2004; Niedergang et al., 2016; Martin-Cofreces and Sanchez-Madrid, 2018).

Intermediate filaments are the third major element of the cytoskeleton displaying different stabilities and mechanical properties from actin and microtubules. They cooperate with actin and microtubules in cellular architecture being important for cell polarization during migration, nuclear positioning, cellular mechanics, and cell adhesion-mediated mechanotransduction in various cell types (Etienne-Manneville, 2018). Their role in $\mathrm{T}$ cell biology remains poorly explored. In circulating $\mathrm{T}$ cells, vimentin intermediate filaments display a spherical pattern that relocalizes to a juxtanuclear area in chemokine-induced polarized cells. T cell rigidity (Brown et al., 2001), lymphocyte adhesion, transendothelial migration, and homing depend on intact intermediate filaments (Nieminen et al., 2006). In regulatory $\mathrm{T}$ cells (Tregs), vimentin intermediate filaments contribute to PKC $\theta$ localization at the distal pole of TCR-stimulated cells and to the control of Treg activity (McDonald-Hyman et al., 2018). In addition, vimentin regulates apoptosis in T cells during inflammation (Su et al., 2019). Septins are an additional component of the cytoskeleton in eukaryotic cells. These GTP-binding proteins assemble into hetero-oligomers that further associate forming higher order structures (e.g., filaments, bundles, and circles; Mostowy and Cossart, 2012). Recently, they have been shown to regulate several aspects of $\mathrm{T}$ cell biology, including signaling, differentiation, and cell division (Lassen et al., 2013; Sharma et al., 2013; Mujal et al., 2016). In particular, their role in regulating amoeboid $\mathrm{T}$ cell motility has been recently characterized (Tooley et al., 2009). Septins have been shown to regulate cortical rigidity and membrane dynamics. Their knockdown in $\mathrm{T}$ cells results in membrane blebbing and abnormal structure of both the leading edge and the uropod. These defects make $\mathrm{T}$ cell motility uncoordinated and poorly persistent (Tooley et al., 2009). The interplay of intermediate filaments and septins with actin and microtubules in $\mathrm{T}$ cells is not well defined, and it will not be further discussed in this review.

Among the most striking features of $\mathrm{T}$ cells is their capacity to rapidly change shape and profoundly reorganize their cellular interior leading to differential cell polarization in response to chemokine or antigenic stimuli (Figure 1). These cues induce coordinated changes in actin and microtubule cytoskeletons, membrane receptors, adhesion molecules, and various organelles that prepare the $\mathrm{T}$ cell to migrate in response to chemokines or to generate a signaling platform, the immunological synapse, in response to antigenic stimulation. Chemokine stimulation makes $\mathrm{T}$ cells to adopt a bipolar organization, with a lamellipodium at the migration front and a protruding uropod in the back differing in shape, cytoskeleton, and membrane component organization (Figures 1A,B). Such a remodeling prepares $\mathrm{T}$ cells to adhere and migrate through lymphoid organs and inflamed peripheral tissues (del Pozo et al., 1996). In turn, the encounter of $\mathrm{T}$ cells with antigen-presenting cells displaying cognate peptide antigen-major histocompatibility complex (MHC) complexes at their surface stabilizes the interaction between the two cells and triggers the formation of a highly organized and dynamic cell-cell interface named the immunological synapse (Figure 1C). Actin and microtubule cytoskeletons reorganize at the immunological synapse, together with TCR, co-stimulatory receptors, signaling molecules, and adhesion receptors. In addition, several organelles, such as the Golgi apparatus, the endosomal compartment, and the mitochondria, polarize to the immunological synapse releasing their cargo or retrieving membrane receptors and signaling molecules (Figures 1D,E). Altogether, the reorganization of molecular components at the immunological synapse ensures the control of $\mathrm{T}$ cell activation and effector functions (Niedergang et al., 2016). 


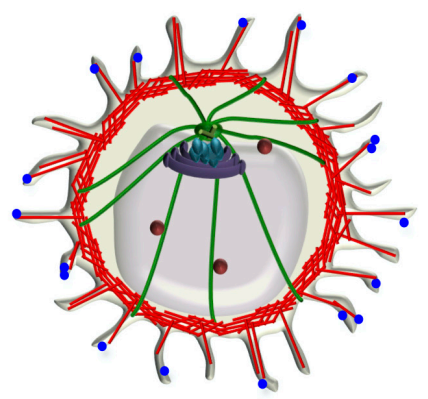

+ Chemokine

E

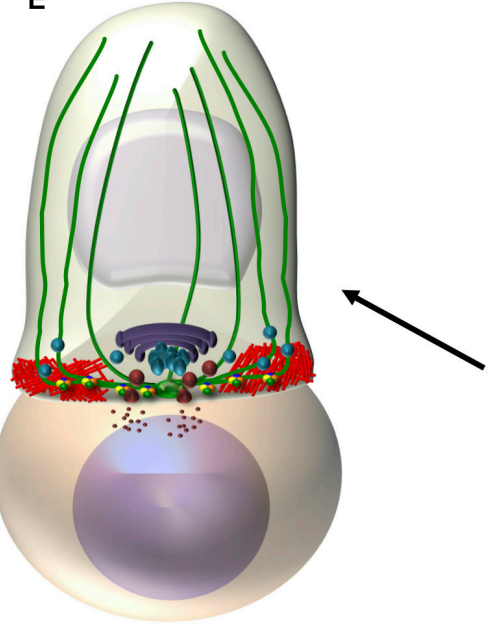

D

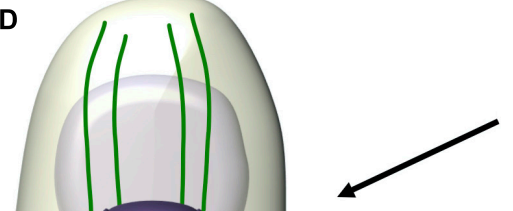

+ Antigen

Front (lamellipodium)

B
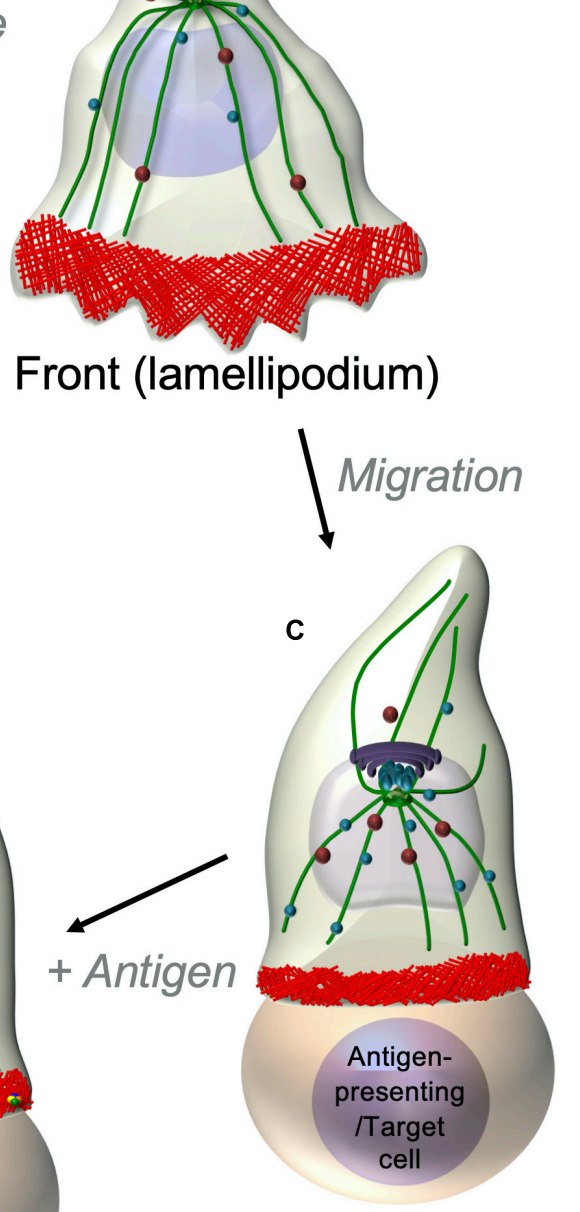

\begin{tabular}{|c|c|c|c|c|}
\hline (ब) & Centrosome & 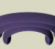 & Golgi apparatus & - Lytic granule \\
\hline r & Microtubule & ○ & Endosome & $\therefore$ Granzyme/cytokine \\
\hline$x^{n-1}: k$ & F-actin & 2 & Signaling complex & - TCR \\
\hline
\end{tabular}

FIGURE 1 | T cell polarization during T cell migration and immunological synapse formation. (A,B) Resting T cells, displaying microvilli at their surface (A), polarize and start migrating in response to chemokines. A lamellipodium in which robust actin cytoskeleton dynamics takes place appears at the front edge, whereas a protrusion, named the uropod, forms at the back (B). The centrosome is positioned between the nucleus and the uropod (see also Figure 3). Following chemokine gradients, $T$ cells migrate through lymphoid organs or peripheral tissues where they meet antigen-presenting cells or target cells expressing their cognate antigen in complex with MHC proteins. (C-E) Upon antigen recognition, TCR signaling induces the coordinated polarization of actin and microtubule cytoskeletons. This is characterized by strong actin polymerization at the cell-cell contact site and the reorganization of the microtubule network that moves the centrosome toward the contact site (C). Centrosome-associated organelles, such as the Golgi apparatus, endosomes, or lytic granules, move together with microtubules toward the contact site. Actin reorganizes while the T cell spreads at the contact site, forming a peripheral F-actin-enriched ring and a central F-actin poor area, where the centrosome and microtubule-associated organelles approach the cell-cell interface (D). A final cytoskeleton-coordinated reorganization of the contact area generates the immunological synapse, where a concentration and dynamic clustering of TCRs, signaling and adhesion molecules, and co-signaling receptors occurs, thus ensuring sustained and controlled TCR signaling (further developed in Figure 4). In effector T cells, this is an area where cytokines or lytic granules are secreted (E). 
The tight interplay between receptors and their signaling machineries, the actin and microtubule cytoskeleton, and intracellular molecular transport enables $\mathrm{T}$ cells to perform their functions, namely, sense environmental cues, polarize, migrate and patrol through lymphoid organs, recognize cognate antigen, and get activated to accomplish clonal expansion and differentiation into helper, regulatory, or cytotoxic T cells. Finally, it allows $\mathrm{T}$ cell effector functions, such as polarized secretion of cytokines to help B cells, and cytotoxic granules to eliminate infected or transformed cells. Various pivotal proteins facilitate the interplay between membrane, cytoskeletal, and organelle components. Among them, membrane-cytoskeleton linkers, such as the ezrin-radixin-moesin (ERM) family of proteins, talin, and several polarity regulators, play important roles at the different stages of $\mathrm{T}$ cell migration and immunological synapse formation (Krummel and Macara, 2006; Lasserre and Alcover, 2010; Garcia-Ortiz and Serrador, 2020).

Ezrin-radixin-moesin proteins bind plasma membrane components, such as phosphatidylinositol (4,5)-bisphosphate $\left(\mathrm{PIP}_{2}\right)$ and transmembrane proteins, via their N-terminal FERM domain, and the cortical actin cytoskeleton via its threoninephosphorylated C-terminal domain (Figure 2). Thus, ERMs help localizing membrane proteins at particular subcellular areas in various cell types (Arpin et al., 2011). T cells express ezrin and moesin that are important for confining TCRs and some of its signaling proteins to microvilli (Jung et al., 2016; Ghosh et al., 2020) and several adhesion proteins (i.e., intercellular adhesion molecules [ICAMs] and P-selectin glycoprotein ligand [PSGL])

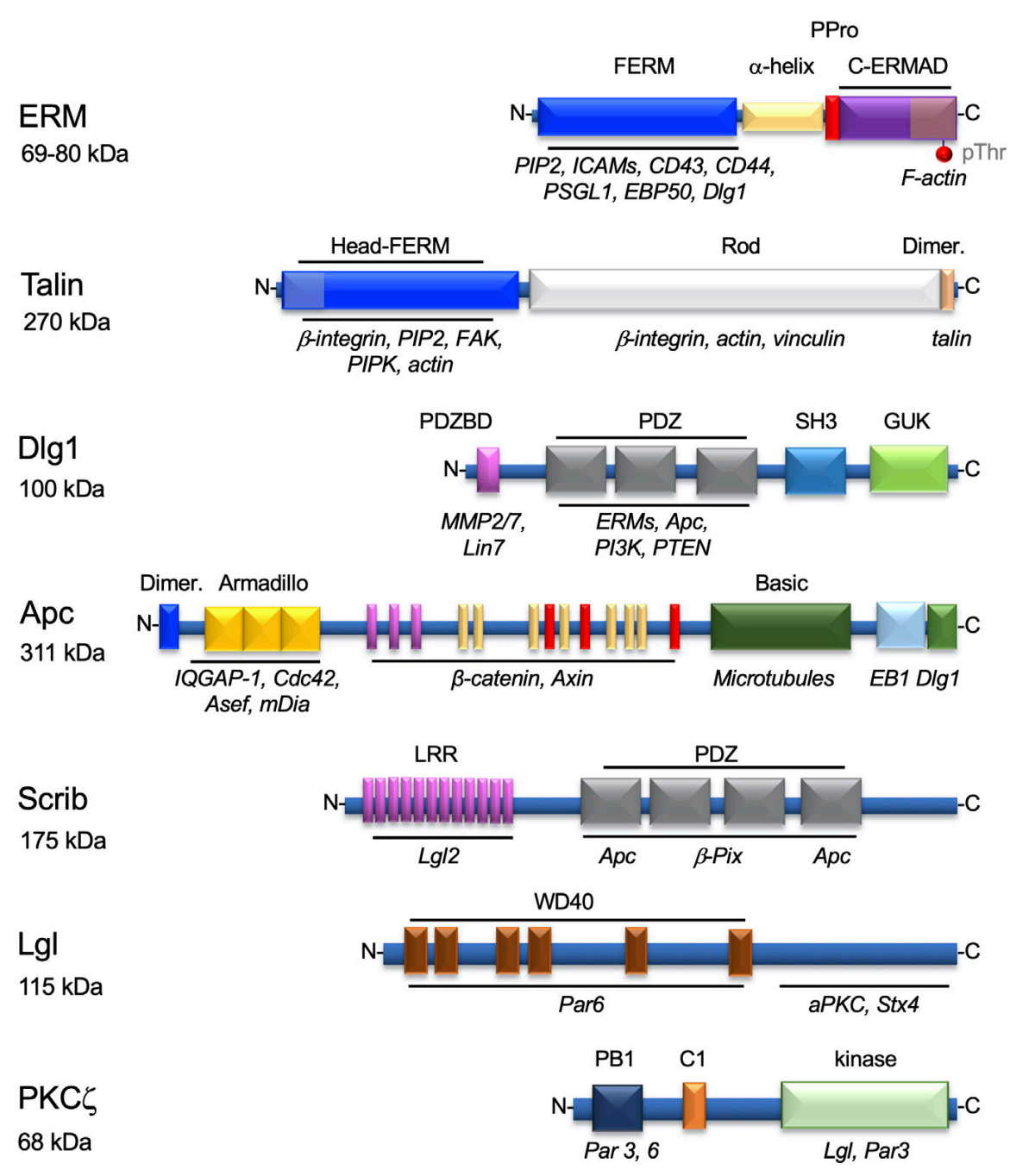

FIGURE 2 | Proteins involved in the interplay between the plasma membrane components and the cytoskeleton in T cells. Structural organization of proteins regulating the interplay between membrane components and the actin and microtubule cytoskeletons. The modular domains involved in their interactions with lipids or other proteins are highlighted. Each domain, named on top, is shown in a different color and its interacting molecules depicted below in italics. ERMs and talin are mostly involved in the localization of adhesion proteins to particular areas of the plasma membrane, as the uropod (ERMs), or the immunological synapse periphery (talin). Dlg1, Apc, Scrib, Lgl, and PKC $\zeta$ are polarity regulators involved in T cell migration and/or immunological synapse formation. For ERM, the phosphorylatable regulatory threonine residue (pThr) in the C-terminal domain is also shown. Molecular weights in kDa are show below each protein name. 
to the uropod of migrating cells (Serrador et al., 1997, 1998, 2002). They can also link cortical actin with membrane rafts (Itoh et al., 2002). Finally, ezrin and moesin are key for immunological synapse formation and function (Allenspach et al., 2001; Delon et al., 2001; Roumier et al., 2001; Itoh et al., 2002; Faure et al., 2004; Shaffer et al., 2009; Lasserre et al., 2010). Other proteins also ensure the interplay between the plasma membrane and the actin cytoskeleton. For instance, talin and vinculin anchor adhesion proteins of the integrin family to the cortical actin cytoskeleton in areas of the cell in contact with integrin ligands in migrating cells and at the periphery of the immunological synapse (Jankowska et al., 2018; Figure 2).

Polarity regulators are multifunctional proteins displaying a variety of protein-protein interaction domains. These domains (e.g., PDZ domains) ensure interactions between polarity regulators themselves and with cytoskeleton components, cytoskeleton regulators (e.g., Cdc42), and membranecytoskeleton linkers, such as ERMs (Figure 2). Polarity regulators act in complexes. Several of them, such as Scribble, Dlg1, Lgl, PKC $\zeta$, Crumbs, PAR, and adenomatous polyposis coli (Apc), have been shown to control $\mathrm{T}$ cell polarization during migration, immunological synapse formation, or activation (Xavier et al., 2004; Ludford-Menting et al., 2005; Krummel and Macara, 2006; Real et al., 2007; Round et al., 2007; Bertrand et al., 2010; Lasserre et al., 2010; Aguera-Gonzalez et al., 2017).

In this review, we summarize the available knowledge on how the interplay between membrane receptor dynamics and signaling, the cytoskeleton, and intracellular vesicular compartments modulates three main aspects of $\mathrm{T}$ cell biology: $\mathrm{T}$ cell migration, immunological synapse formation in response to antigen stimulation, and effector functions. Finally, we describe two examples of perturbation of this interplay in pathological settings, i.e., HIV-1 infection and mutation of the polarity regulator and tumor suppressor Apc in familial polyposis and colorectal cancer.

\section{CYTOSKELETON INTERPLAY IN REGULATING T CELL POLARIZATION AND MIGRATION}

$\mathrm{T}$ cells are activated in lymph nodes, where they acquire the expression of specific tissue-homing receptors, such as adhesion and chemokine receptors, that sense information from the environment and lead $\mathrm{T}$ cell trafficking. Driven by the presence or the absence of these signals, $\mathrm{T}$ cells leave central lymphoid organs and undergo bloodstream navigation reaching peripheral lymph nodes or inflamed tissues. Their spherical shape facilitates the blood flux to push them forward. Moreover, the presence of thin protrusions on their surface, named microvilli, where some chemokine receptors, such as CXCR4, and adhesion molecules, such as L-selectins, are concentrated (Berlin et al., 1995; Singer et al., 2001) promotes sensing of the environment and the attachment necessary for them to slow down navigation and dock at a destination site. Once $\mathrm{T}$ cells have adhered to the blood vessel wall, chemokine stimulation induces the transient collapse of microvilli, and integrin activation leads to firm arrest, lymphocyte polarization, and transmigration through the vascular endothelial cell layer (Brown et al., 2003; Nijhara et al., 2004).

In the tissues, $\mathrm{T}$ cells modify their shape and adopt a different motility based on adhesion and on contact with the surrounding cells and the extracellular matrix. This allows them to migrate through tissues of different architecture and to interact with antigen-presenting cells (Moreau et al., 2018). This plasticity is fine-tuned by cytoskeleton structures, whose dynamics and interplay with molecular adaptors, such as cell polarity regulators, is essential for processes required for efficient $\mathrm{T}$ cell migration, including polarization, adhesion, and vesicle trafficking.

$\mathrm{T}$ cell polarization, an inherent requirement for migration, implies the formation of specialized subcellular areas, a lamellipodium at the leading edge and a uropod at the trailing edge (Figure 3). The leading edge, being enriched in chemokine receptors, guides the displacement, whereas the adhesive uropod supports cell-cell interactions. T cell migration relies on the mechanical cyclicity of lamellipodium extension and uropod retraction (Lauffenburger and Horwitz, 1996; Sánchez-Madrid and del Pozo, 1999).

\section{Cytoskeleton Rearrangements Shaping T Cell Polarization}

The Rho family GTPases Cdc42, Rac1, and RhoA regulate actin and microtubules specialized dynamics at the front and the rear by transducing signals from surface receptors (Rougerie and Delon, 2012; Saoudi et al., 2014). At the cell front, chemokine stimulation induces the activation of Cdc42 and Rac1/2 via the phosphorylation of their guanine nucleotide exchange factors (GEFs), such as Vav1. These, in turn, engage several actin-binding proteins, trigger actin nucleation, and modulate the stability of filamentous actin (F-actin)-rich protrusions (reviewed in Dupre et al., 2015). In particular, Cdc42 and Rac1/2 induce the extension of filopodia and lamellipodia, respectively (Ridley et al., 2003; Dupre et al., 2015). Their function involves the activation of the WASP and WAVE proteins, followed by the activation of the Arp2/3 effector complex, that ensure actin polymerization and branching necessary for lamellipodium extension. Thus, defects in the Arp3 subunit are sufficient to affect the lamellipodium formation and the migratory behavior of CD8 T cells (Obeidy et al., 2020). In addition, the RhoA-ROCK pathway-dependent stimulation of actomyosin contraction is both responsible for the actin retrograde flow, on which lamellipodium extension and migration persistence rely on (Maiuri et al., 2015; Moreau et al., 2018), and essential for the detachment from the substrate (Alblas et al., 2001).

The precise control of microtubule organization in migrating lymphocytes is not fully understood, but their disassembly by nocodazole treatment disrupts cell polarity (Takesono et al., 2010). Events of microtubule growth and catastrophe may occur as described in other cell types (Hui and Upadhyaya, 2017). Interestingly, while migrating astrocytes or fibroblasts orient their centrosome between the nucleus and the front lamellipodium, migrating lymphocytes have their centrosome 
A

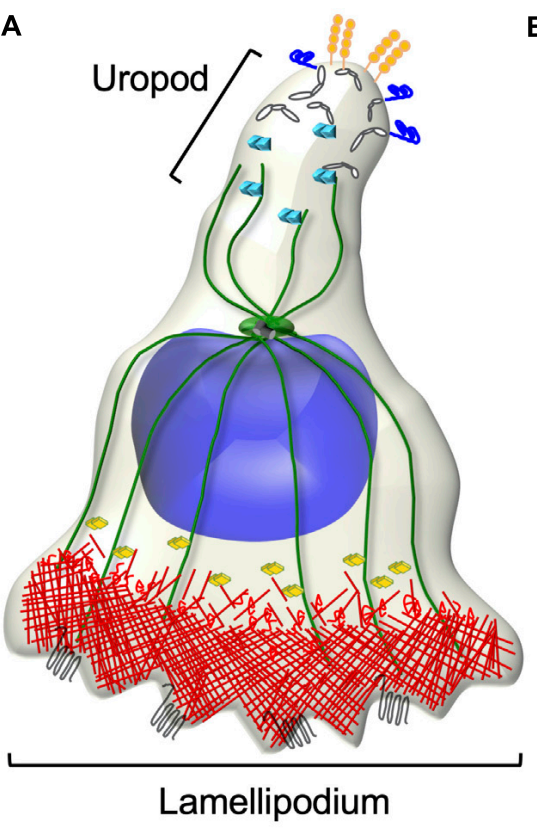

B

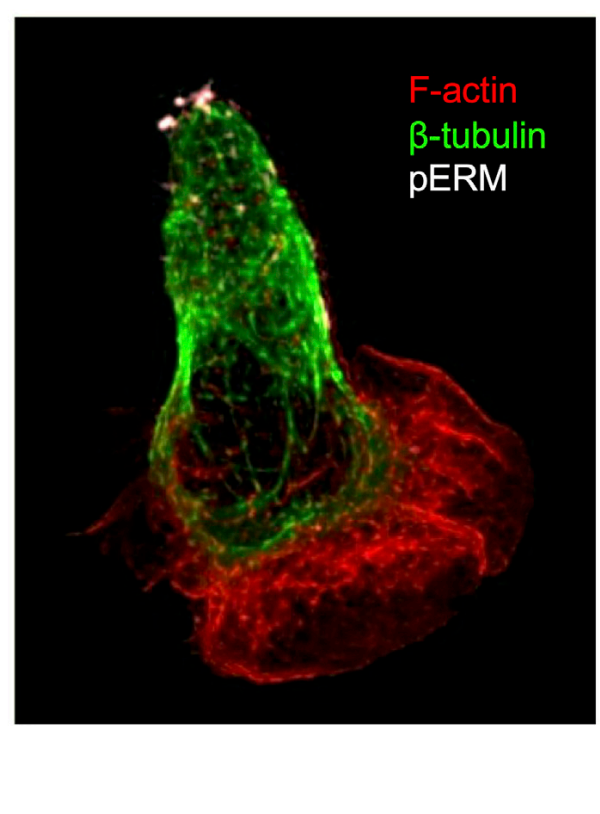

$\begin{array}{llll}\text { Centrosome } & \text { \& ERMs } & \text { wod Chemokine rec. } \\ \text { Microtubule } & \text { Arp2/3 } & \text { \& CD43, CD44 } \\ \text { \& } & \text { RhoA } & \text { ICAM-1,-2,-3 }\end{array}$

FIGURE 3 | Cytoskeleton rearrangements during T cell migration. (A) Schematic representation of migrating T cell polarization involving the orchestrated rearrangement of both the actin and the microtubule cytoskeletons. At the cell front, chemokine stimulation induces the activation of the Arp2/3 effector complex that leads to actin polymerization and branching necessary for lamellipodium extension. At the rear, RhoA-dependent phosphorylation of ERM proteins induces their selective segregation to the uropod, where they recruit transmembrane adhesion molecules. (B) Fluorescence confocal microcopy image of a CEM T cell polarized in response to the chemokine SDF-1. F-actin (red), microtubules (green), and phosphorylated ERMs (white) are shown.

behind the nucleus (Ratner et al., 1997; Serrador et al., 1997; Lee et al., 2004; Figure 3). This positioning likely reflects some functional peculiarities of lymphocytes that need to be dissected.

In astrocytes and other non-leukocyte cell types, microtubule plus-end growth at the leading edge contributes to the lamellipodium activity by participating to the F-actin-membrane protrusion formation (Etienne-Manneville, 2004, 2013). Thus, microtubules drive vesicle exocytosis necessary for membrane extension (Bretscher, 1996), and their growth favors the increase in Rac1-GTP amounts, promoting the Racl signaling cascade (Liao et al., 1995; Waterman-Storer et al., 1999). In turn, Rac1/PAK1 activation may promote microtubule growth by inhibiting the microtubule-destabilizing protein Op18/stathmin (Wittmann et al., 2004). These features have only been partly described in T cells or leukocytes.

Microtubules contribute to RhoA activation at the rear of $\mathrm{T}$ cells. This involves the RhoGEF H1, which is sequestered by microtubules (Meiri et al., 2012), and the subsequent activation of the RhoA-ROCK pathway and phosphorylation of myosin light chain, which induces uropod contraction (Chang et al., 2008; Kaverina and Straube, 2011; Yoo et al., 2012). The RhoAROCK pathway also contributes to activate the formin mDia, an actin nucleator that regulates peripheral actin flow (Otomo et al., 2005). Hence, microtubule dynamics in the front contributes to the persistence of the actin flow (Park and Doh, 2015), whereas microtubule stability at the rear is required for myosin light chain-dependent uropod contraction, providing the mechanical force necessary for effective cell locomotion.

Ezrin-radixin-moesin proteins, which ensure interactions between cortical actin and membrane components, are key for chemokine-induced $\mathrm{T}$ cell polarization. Chemokines induce transient ERMs de-phosphorylation, dissociation from the plasma membrane and the actin cytoskeleton, and release of GEF proteins that in turn activate Rac1 and Cdc42. This supports F-actin polymerization at the protrusive leading edge (Hao et al., 2009; Garcia-Ortiz and Serrador, 2020). Then, RhoA-dependent re-phosphorylation of ERMs induces their selective segregation to the uropod, where they recruit adhesion molecules, such as ICAM-1, -2, -3, CD44, and PSGL-1 (Figure 3). Ezrin and moesin FERM domains interact with a consensus sequence in the intracellular region of these adhesion molecules. Phosphorylated ERMs constitute a functional polar cap in the rear pole via their cooperation with lipid raft-associated flotillins (Lee et al., 2004; Martinelli et al., 2013) where they re-activate 
RhoA and myosin, modulating contractility at the uropod in a positive feedback loop.

\section{Membrane-Cytoskeleton Interactions During T Cell Adhesion and Migration}

Cell membrane components participate to adhesion and migration, acting as sensors of the environment and converting external signals into biochemical messages for the cell. Lipid rafts of different composition redistribute during $\mathrm{T}$ cell polarization in response to chemokines, being enriched in the ganglioside GM3 at the leading edge and in GM1 in the uropod (Gomez-Mouton et al., 2001). This contributes to the spatial segregation of chemokine receptors or adhesion molecules and to their interaction with cytoskeleton structures and/or signaling complexes, thus influencing their spatiotemporal activation (reviewed in Dustin et al., 2004; Manes and Viola, 2006). While front GM3-enriched rafts mainly concentrate chemokine receptors, such as CXCR4 and CCR5, GM1-enriched rafts colocalize with the adhesion protein $\mathrm{CD} 44$ at the uropod, where ERM-associated flotillins are found as well (Gomez-Mouton et al., 2001). Integrin activation depends on their localization in ganglioside GM1-containing rafts (Gomez-Mouton et al., 2001). Integrins are present not only in the uropod of polarized $\mathrm{T}$ cells but also in a larger zone in contact with their ligands (GomezMouton et al., 2001; Leitinger and Hogg, 2002; Smith et al., 2005). Indeed, integrins move laterally within lipid rafts, and their activation state may result in the localization in different cell compartments, including the leading edge (Hogg et al., 2003; Hyun et al., 2009).

Integrins represent the main class of adhesion molecules responsible for interactions with both the extracellular matrix and neighboring cells. They are heterodimeric proteins whose activation relies on their reversible conformational changes triggered by surface receptors, including the TCR and chemokine receptors, or by their own binding to multivalent ligands (reviewed by Baker and Koretzky, 2008; Abram and Lowell, 2009). In addition, both lipid raft microenvironment and cytoskeleton interactions shape integrin activation by controlling single hotspots of integrins in the membrane and their clustering in larger plasma membrane domains (Stewart et al., 1998; Leitinger and Hogg, 2002; Cairo et al., 2006; van Zanten et al., 2009). Integrin clustering selectively provides higher avidity for ligands (Stewart and Hogg, 1996; van Kooyk et al., 1999), although it does not change their affinity (Kim et al., 2004; Luo et al., 2005). It results from the TCR-mediated signaling (Abram and Lowell, 2009) and may be negatively regulated by GTPases. Indeed, inhibition of the RhoA-ROCK pathway induces clustering of lymphocyte function-associated antigen1 (LFA-1), followed by the induction of adhesion to its ligand, ICAM-1 (Rodriguez-Fernandez et al., 2001).

Integrin activation state in turn influences the composition of the surrounding environment, thus impacting the downstream signaling and enabling cytoskeleton remodeling (Schwartz, 2010; Byron et al., 2015). Whereas active $\beta 1$ integrins are mainly found in complexes with actin and microtubule-associated proteins, such as talin and kindlin, inactive integrins form complexes with molecules involved in adhesion and cytoskeleton organization (Rho and Ras GTPase family members) or in membrane trafficking (Arf and Rab GTPases) in K562 leukemic cells, which may resemble to $\mathrm{T}$ cells for their adhesion pattern (Byron et al., 2015).

Interestingly, the link between integrins and the cytoskeleton is bidirectional, and their functions are reciprocally modulated (Vicente-Manzanares et al., 2009). For instance, LFA-1 activation during cell migration is modulated by physical forces on its $\beta$ subunit applied by the actin cytoskeleton (Nordenfelt et al., 2016). Moreover, the inhibition of actin polymerization by cytochalasin D prevents the formation of new nascent adhesions (Choi et al., 2008), whereas microtubule regrowth after nocodazole washout correlates with adhesive structure disassembly (Kaverina et al., 1998; Ezratty et al., 2005).

$\mathrm{T}$ cell adhesion to the substrate and subsequent changes on the physical properties of their membranes are also sensed by BAR domain-containing proteins that translate these signals into cytoskeleton remodeling. Substrate attachment of the adhesive uropod of neutrophils induces a membrane curvature critical for the activation of the SRGAP2 BAR protein, in keeping with the notion of phospho-ERMs asymmetrical segregation at the uropod during $\mathrm{T}$ cell migration (Ren et al., 2019). Hence, the rear membrane curvature would be responsible for the activation of specific BAR proteins and then kinases, determining the local phosphorylation of ERMs and their membrane binding at the rear (Ren et al., 2019). It is noteworthy that the BAR protein CIP4, involved in membrane deformation during endocytosis, is also crucial for integrin-dependent activation of WASP. Indeed, T cells from CIP4 ${ }^{-/-}$mice present defects in adhesive interactions, impairing transmigration across endothelial cell monolayers (Koduru et al., 2010).

\section{Intracellular Traffic in T Cell Adhesion and Migration}

Intracellular trafficking may promote the polarization of motile lymphocytes by allowing the dynamic turnover of membrane and the delivery of cargos, such as chemokine or cytokine receptors and integrins, to specific subcellular localizations. Cargos are transported along actin and microtubule structures via myosin, kinesin, and dynein molecular motors, respectively, and may be associated with vesicles. Integrins continuously cycle between the plasma membrane and endosomal compartments (Paul et al., 2015). Clustering of integrins in lipid rafts may contribute to their internalization and recycling, possibly facilitating integrin targeting at the leading edge (Hyun et al., 2009) where they would establish adhesion during migration. These processes are poorly elucidated in T cells, and most of the information is on LFA- 1 . In the uropod of T cells migrating on ICAM-1, LFA-1 undergoes a caveolar endocytosis, which is regulated by G-protein-coupled receptor, mediated for instance by Gaq/11 (Svensson et al., 2012). Partitioning into lipid rafts is likely pivotal for LFA-1 to undergo a caveolae-dependent endocytic pathway (Upla et al., 2004; Fabbri et al., 2005). Moreover, inhibition of the small GTPases Rab13, a key regulator of intracellular membrane trafficking, could reduce LFA-1-dependent adhesion on ICAM-1 and the formation of 
micro-adhesion rings of LFA-1 at the contact site with antigenpresenting cells (Nishikimi et al., 2014), essential for $\mathrm{T}$ cell activation (Hashimoto-Tane et al., 2016) (see section “ActinMicrotubule Interplay Shaping T Cell Effector Functions”).

\section{T CELL SENSING OF ANTIGEN CUES, TCR TRIGGERING, AND IMMUNOLOGICAL SYNAPSE FORMATION}

\section{Topological Distribution of the TCR}

Once in the lymph nodes or in peripheral tissues, $\mathrm{T}$ cells scan antigen-presenting cells searching for cognate peptide-MHC complexes. The localization of the TCR and some of its proximal signaling molecules on microvilli may enhance the sensing capacity of T cells.

Mapping TCRs localization relative to the 3D membrane topology demonstrated that TCRs are segregated on the tips of microvilli in fixed resting and effector T cells (Jung et al., 2016). $\mathrm{CD} 3 \varepsilon$ follows the same distribution than TCR, and both proteins significantly colocalize with L-selectin, further confirming their localization at microvilli tips. This approach has been recently extended to analyze the distribution of additional membrane receptors and signaling proteins in human effector $\mathrm{T}$ cells and the Jurkat $\mathrm{T}$ cell line (Ghosh et al., 2020). It has been shown that the majority of the $\mathrm{CD} 3 \zeta$ subunit, the co-receptor $\mathrm{CD} 4$, and the adhesion protein CD2 are localized to microvilli. The protein kinase Lck and the adaptor LAT are also enriched in microvilli, although a significant fraction of these molecules is found outside these structures. This observation agrees with Lck and LAT being partially associated with intracellular vesicular compartments (Soares et al., 2013; see also "Alterations of T Cell Cytoskeleton and Molecular Traffic in Pathological Settings" section). On the contrary, the protein tyrosine phosphatase CD45, which inhibits TCR/CD3 complex phosphorylation, is segregated from the TCR, hence mostly excluded from microvilli (Razvag et al., 2018; Ghosh et al., 2020).

The structural integrity of microvilli requires an intact actin cytoskeleton, and the confinement of proteins into microvilli is dependent on membrane-cytoskeleton linker proteins of the ERM family (Ghosh et al., 2020). Indeed, phosphorylated ERMs are concentrated into microvilli where they co-localize with F-actin and TCRs. Additionally, overexpression of a dominant-negative form of the ERM member ezrin in Jurkat $\mathrm{T}$ cells results in the disappearance of membrane protrusions and redistributions of microvilli-associated proteins throughout plasma membrane. These modifications correlate with a reduction of TCR-dependent signaling, as measured by the inhibition of the phosphorylation of ERK kinases (Ghosh et al., 2020).

Studies of microvillar dynamics in live $\mathrm{T}$ cells indicated that most microvilli undulate and move laterally, allowing a faster and more efficient scanning of the antigen-presenting cell surface (Cai et al., 2017). Microvillar dynamics is slowed down once the contact with the antigen-presenting cells is stabilized, likely as a consequence of TCR engagement by peptide-MHC complexes and integrin activation. Further analyses demonstrated that signaling complexes containing the TCR and the ZAP70 protein kinase colocalized in areas corresponding to microvillar tips (Cai et al., 2017), suggesting that the geometry and dynamics of signaling protein complexes or pre-existing "protein islands" described before (Lillemeier et al., 2010) are actually influenced by membrane 3D topology.

Collectively, these data indicate that concentration of TCRs, associated co-receptors, and signaling proteins at microvilli tips plays a critical role in antigen recognition and early activation steps. Indeed, this organization and the mobility of membrane protrusions would allow a "topological scan" of antigen-presenting cell surface, increasing speed and efficiency of antigen search (Cai et al., 2017). Moreover, focusing TCR and its signaling machinery to microvilli increase the avidity of interaction of antigen receptors with peptide-MHC complexes and facilitate early signal transduction. However, at later steps of activation, ERMs dephosphorylation may lead to microvilli resorption (Ghosh et al., 2020), thus favoring mixing of signaling proteins with TCRs and centripetal movement of signaling complexes, followed by their internalization and/or dissociation.

It is worth noting that microvilli might also have additional functions, such as the recently described generation of extracellular organelles or "immunological synaptosomes," through a mechanism similar to trogocytosis (Kim et al., 2018). These entities may carry various signals to the antigen-presenting cells (e.g., TCR/CD3 complexes, co-stimulatory proteins, and cytokines) and are probably related to the extracellular vesicles previously detected at the center of the immunological synapse (Choudhuri et al., 2014).

\section{Immunological Synapse Formation}

The early consequence of a productive TCR engagement by its cognate antigen displayed on the surface of an antigenpresenting cell is twofold. First, the T cell stops or slows down its movement, and then it starts polarizing toward the antigenpresenting cell. These initial events, driven by rearrangements of the actin and microtubule cytoskeletons, result in the formation of the immunological synapse. This specialized interface allows the communication between the two cells involved, ensuring efficient TCR signal transduction leading to $\mathrm{T}$ cell activation, clonal expansion, and differentiation.

The immunological synapse is characterized by intensive F-actin polymerization at the interface with the antigenpresenting cell. Once the synapse is stabilized, F-actin clears from the center of the synapse leaving an actin-rich peripheral ring (Bunnell et al., 2001; Ritter et al., 2015). Microtubules also reorganize at the immunological synapse, some irradiating from the centrosome and oriented toward the periphery of the synapse where some appear to anchor and bend (Kuhn and Poenie, 2002; Lasserre et al., 2010; Aguera-Gonzalez et al., 2017). Concomitantly, the centrosome translocates toward the center of the synapse, beneath the plasma membrane, within a minute after F-actin clearance (Geiger et al., 1982; Kupfer et al., 1986; Stinchcombe et al., 2006; Ueda et al., 2011; Ritter et al., 2015; Figure 4). The exact molecular mechanism moving 


\section{A}

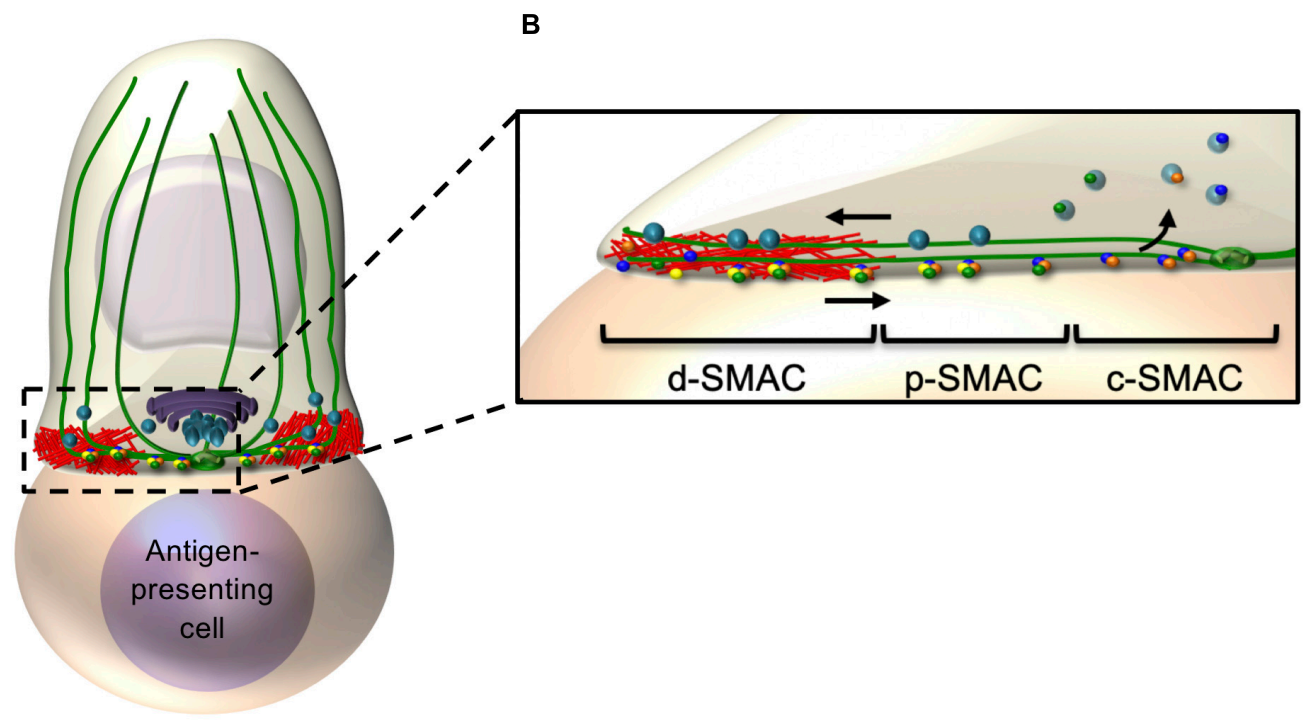

C

c
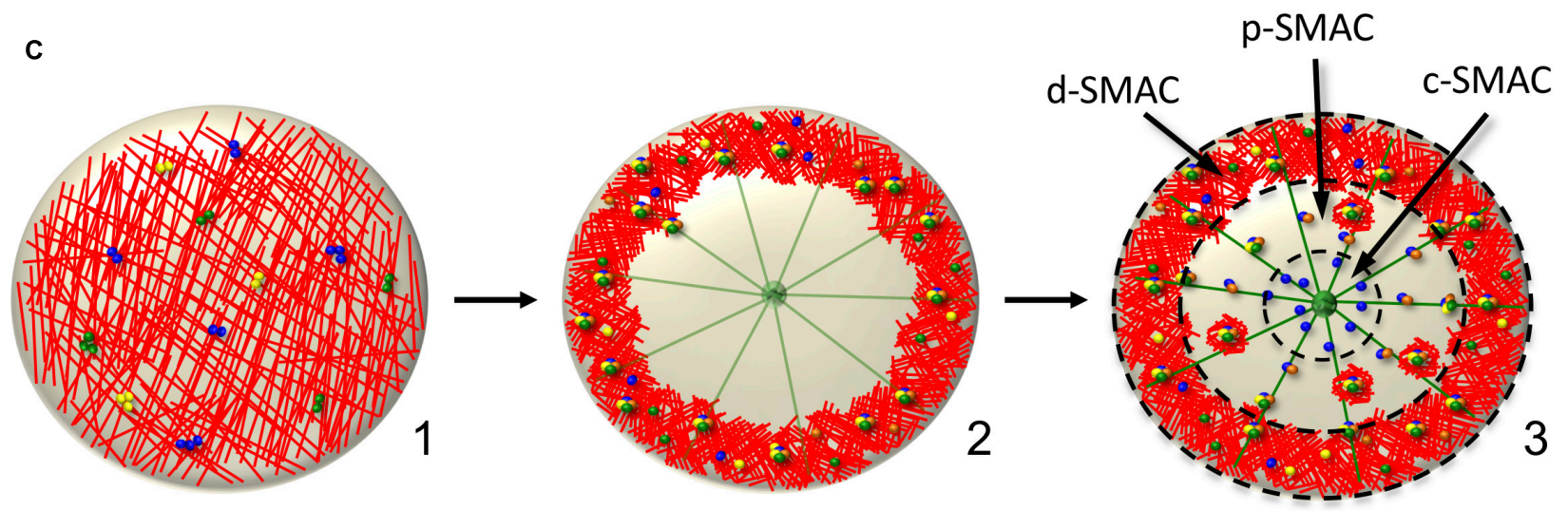

\begin{tabular}{lllll} 
Centrosome & Gicrotubule & Golgi apparatus & TCR \\
F-actin & 0 & Signaling proteins & Actin foci \\
\hline
\end{tabular}

FIGURE 4 | Interplay between actin and microtubule cytoskeleton controls signaling microcluster dynamics at the immunological synapse. (A,B) Schematic representation of cellular and molecular rearrangements leading to immunological synapse formation. This involves actin and microtubule rearrangements and organelle polarization, driving to the generation of dynamic signaling microclusters. The latter form in the d-SMAC, at the periphery of the immunological synapse (B), then centripetally move to the center in an actin- and microtubule-dependent manner. Some molecules (e.g., the TCR) coalesce in the center generating the C-SMAC, whereas others are internalized or disassembled in the p-SMAC during their centripetal movement. (C) En-face view of an immunological synapse showing the kinetics of its reorganization. F-actin, which is initially disseminated throughout the synapse (1), redistributes and concentrates in the peripheral area, whereas microtubules adopt a radial organization from the centrosome to the periphery (2). Signaling microclusters form at the synapse periphery and move centripetally (2,3), first by retrograde actin waves, then by the microtubule-based motors dynein. Adhesion rings (not shown) and F-actin foci transiently surround signaling microclusters, reminiscent of "micro-synapses" (3). Dashed circles in (3) separate d-SMAC, p-SMAC, and c-SMAC.

the centrosome to the synapse is still not clear. Interaction of microtubules with the actin cortex at the synapse periphery via ezrin and Dlg1 appears to facilitate centrosome polarization (Lasserre et al., 2010). A process of microtubule bending at the synapse periphery mediated by the motor dynein has been proposed to facilitate microtubule tension and centrosome docking close at the synapse center (Kuhn and Poenie, 2002). Decreased F-actin polymerization at the centrosome could also 
allow its detachment from the nucleus and its translocation, as shown in B cells (Obino et al., 2016). In turn, microtubules and the centrosome could control the F-actin remodeling at the synapse, as centriole depletion impairs actin clearance (Tamzalit et al., 2020). By converging toward the centrosome at the center of the synapse, microtubules guide polarized transport of vesicular components and organelles, such as the Golgi and several endosomes and secretory lysosomes (Kupfer and Dennert, 1984; Das et al., 2004; Chemin et al., 2012). The clearance of F-actin at the center of the synapse may be related to the localization of this secretory machinery. For instance, nitric oxide synthase-mediated post-translational modifications of actin may remodel the actin cytoskeleton by controlling polymerization/depolymerization (Garcia-Ortiz et al., 2017).

T cells can form simultaneously multiple synapses, integrating signal from several antigen-presenting cells, but polarize their cytokine secretory machinery mainly toward the one displaying the strongest stimulus (Depoil et al., 2005). In some instances, the $\mathrm{T}$ cell does not completely stop and forms asymmetric and not stabilized synapses, while it continues to move over the antigen-presenting cell. In this case, the cell-cell contact zone is called immunological kinapse. As in migrating cells, T cell presents an F-actin-rich lamellipodium, and the centrosome and vesicular components are localized at the uropod (reviewed by Fooksman et al., 2010). Interestingly, kinapses still permit durable interactions and TCR signal integration (Skokos et al., 2007; Moreau et al., 2012; Mayya et al., 2018). T cells may cycle between synapse and kinapse in vitro and in vivo, depending on the stimulation level, which may facilitate $\mathrm{T}$ cell interaction with several antigen-presenting cells (Sims et al., 2007; Moreau et al., 2015).

\section{TCR Signaling Drives Cytoskeleton Reorganization}

The initial TCR signaling occurring during the immunological synapse formation proceeds through serial reactions to control cytoskeleton reorganization. TCR-associated CD3 subunits are phosphorylated in their cytoplasmic regions on tyrosinecontaining signaling motifs named immunoreceptor tyrosinebased activation motifs (ITAMs) (Barber et al., 1989; Reth, 1989). ITAM phosphorylation by Lck, a membrane-associated protein kinase of the Src family, induces ZAP70 recruitment to CD3 and its activation (Iwashima et al., 1994). Then, ZAP70 phosphorylates LAT, which in turn recruits SLP76 (Finco et al., 1998; Yablonski et al., 1998b; Zhang et al., 1998). Centrosome and microtubule repositioning requires efficient recruitment and activation of all these proteins (LowinKropf et al., 1998; Kuhné et al., 2003; Tsun et al., 2011). Phosphorylated SLP76 binds the GEF Vav and the adaptor protein Nck (Wu et al., 1996; Wunderlich et al., 1999). The second signal received by $\mathrm{T}$ cells through the co-stimulatory molecule CD28 also allows the recruitment of Nck and Vav that bind to CD28 and can be activated in a TCR-independent manner upon CD28 engagement (Acuto et al., 2008). Vav activates the Rho family GTPases Racl and Cdc42 that together with Nck recruit and activate WAVE2 and WASP. As in migrating cells, WAVE2 and WASP then stimulate Arp2/3 ensuring actin polymerization and branching (Blumenthal and Burkhardt, 2020). Interestingly, WASP, together with PKC $\theta$, controls the conversion of kinapses into synapses, as WASP ${ }^{-/-}$ $\mathrm{T}$ cells cannot reform symmetric stable interaction with stimulatory surfaces after a cycle of migration (Sims et al., 2007). Vav, Rac1, Arp2/3, and formins have been involved in centrosome translocation, likely regulating the interplay between actin and microtubule networks (Ardouin et al., 2003; Gomez et al., 2007; Randzavola et al., 2019). TCR-induced signaling recruits at the synapse and activates actin cytoskeleton regulators involved in its polarization, cortical reorganization, and maintenance, such as dynamin 2, the cortactin homologue HS1, and the polarity regulator Dlg1 (Gomez et al., 2005, 2006; Round et al., 2005). Finally, clathrin accumulation at the synapse recruits the actin-polymerization machinery, indicating a relationship between the endocytic machinery and actin dynamics (Calabia-Linares et al., 2011).

Initial TCR triggering modifies the membrane phospholipid composition that controls F-actin organization at the synapse. LAT recruits PLC $\gamma 1$, which metabolizes $\mathrm{PIP}_{2}$, generating the second messengers diacyl glycerol (DAG) and inositol $(1,4,5)$-trisphosphate $\left(\mathrm{IP}_{3}\right)$, that respectively activate PKCs and calcium release from intracellular stores. CD28 recruits the phosphoinositide-3-kinase (PI3K), which converts $\mathrm{PIP}_{2}$ into phosphatidylinositol $(3,4,5)$-trisphosphate $\left(\mathrm{PIP}_{3}\right)$. Both $\mathrm{PIP}_{2}$ and $\mathrm{PIP}_{3}$ regulate $\mathrm{F}$-actin localization at the immunological synapse. Indeed, F-actin depletion from the center of the synapse correlates with a reduction of $\mathrm{PIP}_{2}$ at the plasma membrane (Ritter et al., 2015; Gawden-Bone et al., 2018), whereas generation and maintenance of the actin-rich ring is controlled by the annular accumulation of $\mathrm{PIP}_{3}$ at the synapse periphery (Le Floc'h et al., 2013).

DAG plays an important role in centrosome polarization (Quann et al., 2009; Liu et al., 2013; Chauveau et al., 2014). The mechanisms involved in microtubule anchoring at the synapse periphery and centrosome reorientation are complex and regulated by various effectors, underscoring the interplay between actin and microtubule cytoskeleton. These include membrane-microfilament linkers, such as ezrin, molecular motors, such as dynein, and polarity regulators, such as Dlg1 and Apc (Combs et al., 2006; Stinchcombe et al., 2006; Gomez et al., 2007; Martin-Cofreces et al., 2008; Bertrand et al., 2010; Lasserre et al., 2010; Liu et al., 2013; Aguera-Gonzalez et al., 2017). However, the interplay between these effectors is poorly understood.

\section{Signaling Complexes Assembly and Regulation by the Cytoskeleton}

Early TCR and co-stimulatory molecule signaling is responsible for bringing the actin polymerization machinery, regulators of its organization, and the centrosome and microtubules to the immunological synapse (Figure 4). However, a positive feedback loop exists since actin and microtubule cytoskeletons are in turn necessary for maintaining TCR signaling. They regulate the spatiotemporal organization of the signaling machinery, not only 
reinforcing and sustaining signaling but also driving TCR signal downregulation (Nguyen et al., 2008; Lasserre et al., 2010).

Initially, TCRs, signaling and adhesion molecules, as well as cytoskeleton structures, are not uniformly distributed at the plasma membrane, possibly reflecting their distribution in microvilli (Jung et al., 2016; Cai et al., 2017; Ghosh et al., 2020). Then, they coalesce into concentric supramolecular activation clusters (SMACs) (Monks et al., 1998; Grakoui et al., 1999). A central-SMAC (c-SMAC) is enriched in TCR and associated proteins, such as $\mathrm{CD} 3$, co-signaling receptors, such as $\mathrm{CD} 2$ and $\mathrm{CD} 28$, inhibitory receptors, such as CTLA-4 and PD1, and their downstream signaling proteins (reviewed in Dustin and Choudhuri, 2016). Surrounding the c-SMAC, the peripheral SMAC (p-SMAC), containing integrins, such as LFA-1, and its cytoskeleton linkers as talin (Monks et al., 1998; Grakoui et al., 1999), stabilizes the synapse (Comrie et al., 2015). Finally, the distal SMAC (d-SMAC) contains large proteins, such as the protein tyrosine phosphatase CD45 (Davis and van der Merwe, 2006; Cordoba et al., 2013). The d-SMAC also corresponds to the peripheral actin ring and is enriched in microtubule linkers (e.g., IQGAP-1 and ezrin) (Roumier et al., 2001; Watanabe et al., 2004; Stinchcombe et al., 2006; Lasserre et al., 2010). This SMAC-type organization was mostly observed in vitro on stimulatory surfaces made of planar bilayers displaying ICAM-1 and MHC-peptide antigen molecules or using B cells as antigen-presenting cells. Indeed, when reducing the concentration of antigenic peptide or costimulatory molecules or studying different physiological conditions (e.g., $\mathrm{T}$ cells in different differentiation states and/or interacting with different antigen-presenting cells), the spatiotemporal pattern is highly diverse (reviewed in Thauland and Parker, 2010). For instance, in the case of the asymmetrical contacts formed in kinapses, the molecular organization at the uropod is reminiscent of the c-SMAC (reviewed in Dustin, 2008).

Upon initial TCR triggering, Lck, ZAP70, SLP76, and LAT are recruited at the plasma membrane close to the area of TCR stimulation (see "Alterations of T Cell Cytoskeleton and Molecular Traffic in Pathological Settings" section). Some of these molecules (e.g., TCR and LAT) are pre-clustered in separate stable domains before TCR stimulation that mix upon TCR engagement (Lillemeier et al., 2010; Beck-Garcia et al., 2015). Studying immunological synapse formation using activating planar bilayers as surrogate antigen-presenting cells and live cell TIRF microscopy revealed that once at the plasma membrane, these signaling molecules nucleate into dynamic microclusters in the d-SMAC where they are phosphorylated (Lee et al., 2002) and rapidly engage into a centripetal movement (Bunnell et al., 2002; Campi et al., 2005; Yokosuka et al., 2005; Varma et al., 2006; Kaizuka et al., 2007). The F-actin-rich ring acts as a scaffold for microcluster assembly and stabilization (Campi et al., 2005), whereas the microtubules seem to be dispensable for microcluster formation but needed for their centripetal movement (Lasserre et al., 2010; Hashimoto-Tane et al., 2011; Figures 4B,C).

Signaling microclusters have been shown to be surrounded by adhesion molecules similar to the p-SMAC and by F-actin enrichments, called foci (Kumari et al., 2015; Hashimoto-Tane et al., 2016; Figure 4C). The adhesion ring formation depends on LFA-1 signaling and actin dynamics, whereas actin foci are regulated by WASP (Kumari et al., 2015; Hashimoto-Tane et al., 2016). These observations suggest the existence of transient "micro-synapses" within the immunological synapse with similar structure but at a smaller scale. They likely provide scaffolds for TCR and signaling molecules clustering, promoting efficient signaling (Pageon et al., 2016).

Impairing actin cytoskeleton meshwork alters microcluster formation and TCR signaling. For instance, TCR and SLP76 microclusters do not form in $\mathrm{T}$ cell treated with latrunculinA that depolymerizes F-actin (Campi et al., 2005; Babich et al., 2012). Furthermore, impairing F-actin dynamics, with jasplakinolide that stabilizes filaments, alters the centripetal movement of SLP76 microclusters, which cannot reach the c-SMAC (Babich et al., 2012). Accordingly, downstream events, such as calcium flux, NFAT1 activation, and interleukin (IL)2 transcription, are also altered by actin inhibitors, although with differential effects depending on the dose used (Nolz et al., 2007). Similarly, to the events taking place in $\mathrm{T}$ cell migration, F-actin continuously pulls forces on the plasma membrane and the antigen-presenting cell due to contraction dependent on the molecular motor myosin II. Additionally, actin polymerization pushes forces and drives the retrograde flow of the actin network.

Microtubules have been recently involved in the regulation of these forces. Indeed, $\mathrm{T}$ cell treated with nocodazole displayed more sustained actin flow on activating planar bilayers (Hui and Upadhyaya, 2017). Together, these forces stabilize the actin cytoskeleton meshwork, allow the formation of the integrinrich P-SMAC, and maintain the radial symmetry of the immunological synapse (Campi et al., 2005; Nguyen et al., 2008; Ilani et al., 2009; Hashimoto-Tane et al., 2011; Husson et al., 2011; Babich et al., 2012; Comrie et al., 2015). Mechanical forces and waves of actin polymerization also initiate the centripetal movement of signaling microclusters toward the p-SMAC (Campi et al., 2005; Yokosuka et al., 2005; Nguyen et al., 2008; Ilani et al., 2009; Yi et al., 2012; Comrie et al., 2015; Murugesan et al., 2016) and their segregation into the c-SMAC where signaling terminates (Lee et al., 2003; Varma et al., 2006; Kumari et al., 2012). Some signaling molecules (e.g., SLP76, LAT, and ZAP70) are downregulated in the p-SMAC, before reaching the c-SMAC (Yokosuka et al., 2005; Lasserre et al., 2011), whereas the TCR is downregulated in the c-SMAC by internalization (Lee et al., 2002, 2003; Varma et al., 2006; Vardhana et al., 2010) or by accumulation into extracellular vesicles (Choudhuri et al., 2014; Saliba et al., 2019).

Impairing the microtubule cytoskeleton alters microcluster centripetal movement (Bunnell et al., 2002; Lasserre et al., 2010; Hashimoto-Tane et al., 2011). For instance, SLP76 microclusters do not move to the c-SMAC in T cells silenced for ezrin or the polarity regulators Dlg1 and Apc that display altered microtubule network organization at the synapse (Lasserre et al., 2010; Aguera-Gonzalez et al., 2017). Likewise, perturbing the microtubule-associated molecular motor dynein impairs centripetal TCR microcluster movement 
(Hashimoto-Tane et al., 2011). In addition, knockdown of the microtubule end-binding protein 1 (EB1) alters TCR dynamics at the immunological synapse and downstream signaling (Martin-Cofreces et al., 2012).

Importantly, impairing or slowing down microcluster movement toward the center of the synapse correlates with enhanced T cell signaling (e.g., higher level of phosphorylated LAT at the synapse and higher activation of Erk1/2), indicating that microcluster dynamics is linked to TCR signal downregulation (Mossman et al., 2005; Nguyen et al., 2008; Lasserre et al., 2010; Hashimoto-Tane et al., 2011). The molecular mechanisms involved in signaling complex deactivation and their relationship with microcluster centripetal movement are not fully understood. Several mechanisms may coexist at the synapse, including tyrosine dephosphorylation in the c-SMAC by the presence of the CD45 phosphatase (Varma et al., 2006) or post-translational modifications of signaling complexes facilitating their disaggregation (Lasserre et al., 2011).

In conclusion, while dynamic F-actin first initiates the formation of signaling microclusters, it subsequently leads to signaling molecule deactivation by targeting them to the c-SMAC, in close cooperation with the microtubule network. Therefore, a fine-tuned interplay between both cytoskeletons is key for sustaining TCR signaling and for conditioning its intensity and duration.

\section{Vesicle Traffic Controls TCR Signaling and the Cytoskeleton}

Targeting of organelles and intracellular vesicular compartments to the immunological synapse regulates $\mathrm{T}$ cell signaling and effector functions, as well as participates to the communication between $\mathrm{T}$ cells and antigen-presenting cells. Indeed, TCR-CD3 and two of its proximal signaling molecules, Lck and LAT, not only are localized at the plasma membrane, in part in microvilli, but also are present in endosomal and Golgi compartments. These molecules partition differently between plasma membrane and intracellular compartments, and their targeting to the immunological synapse is uniquely regulated. Targeting of vesicles carrying $\mathrm{CD} 3 \zeta$, Lck, and LAT to the immunological synapse follows TCR triggering and the formation of early microclusters containing phosphorylated forms of these proteins (Blanchard et al., 2002a; Ehrlich et al., 2002; Bonello et al., 2004; Balagopalan et al., 2013, 2018). This is consistent with the role of plasma membrane pools of these molecules in the initial signal triggering and of vesicular pools in signal amplification by fueling additional signaling molecules to the immunological synapse.

TCR-CD3 components exchange between the plasma membrane and recycling endosomes. Interestingly, although part of the same multi-subunit TCR-CD3 complex, the CD3 $\zeta$ chain has a different turnover, and it is more concentrated in the endosomal compartment than in other subunits (reviewed in Alcover et al., 2018). Clustering of TCR-CD3 complexes at the synapse is maintained by microtubule-dependent polarized vesicle traffic (Blanchard et al., 2002a; Das et al., 2004; Soares et al., 2013) and controlled by several regulatory proteins. These include intraflagellar transport proteins and the microtubulebinding protein EB1, which interact with microtubules and TCR-CD3 components (Finetti et al., 2009; Martin-Cofreces et al., 2012), several Rab GTPases, and vesicle fusion regulators, such as the SNAREs VAMP-3, SNAP-23, syntaxin-4, and the calcium sensor synaptotagmin-7 (Das et al., 2004; Patino-Lopez et al., 2008; Finetti et al., 2009, 2015; Soares et al., 2013; Onnis et al., 2015). Altered expression of some of these regulators results in reduced TCR signaling and $\mathrm{T}$ cell activation (Finetti et al., 2009; Martin-Cofreces et al., 2012). Intraflagellar transport proteins are key for the formation of the primary cilium, a sensory structure present in many cell types. Although T cells lack primary cilia, they use the same molecular machinery, including IFT20, IFT57, and IFT88 proteins, to transport TCRCD3 complexes to the synapse (Finetti et al., 2009). Likewise, $\mathrm{T}$ cells express and utilize SNARE proteins involved in vesicle fusion in other secretory cellular systems (Sudhof and Rizo, 2011) to control polarized traffic to the immunological synapse (Das et al., 2004; Soares et al., 2013; Finetti et al., 2015). Proteins controlling actin polymerization and branching, such as ARPC2 (Zhang et al., 2017) or WASH (Piotrowski et al., 2013), can also modulate TCR endosomal trafficking and its polarization, thus affecting $\mathrm{T}$ cell homeostasis and function.

Lck is partly associated with endosomes, and contrary to $\mathrm{CD} 3 \zeta$ and LAT, its plasma membrane pool is bigger than the endosomal one (Soares et al., 2013). Intracellular Lck is mainly localized in the $\mathrm{Rab}_{1} 1^{+}$recycling endosomal compartment (Soares et al., 2013; Bouchet et al., 2017). It constitutively recycles between the plasma membrane and pericentrosomal endosomes, and it is targeted to the immunological synapse soon after TCR engagement via endosomal polarization (Ehrlich et al., 2002; Anton et al., 2008). The Rab11 effector FIP3 (Rab11 family interacting protein-3) controls Lck subcellular localization, its clustering at the immunological synapse, and its signaling functions. FIP3 links Rab11 with microtubule molecular motors, such as dynein and kinesin, and with components of the exocyst complex controlling endosomal traffic (Horgan and McCaffrey, 2009). Interestingly, FIP3-mediated Lck localization conditions both basal and TCR-mediated phosphorylation of Lck substrates and intracellular calcium (Bouchet et al., 2017). Moreover, perturbing Lck endosomal localization by FIP3 silencing impairs constitutive $\mathrm{CD} 3 \zeta$ phosphorylation and leads to increased total amount of $\mathrm{CD} 3 \zeta$ and higher TCR-CD3 cell surface expression (Bouchet et al., 2017). This is consistent with the described effect of Lck-mediated phosphorylation on $\mathrm{CD} 3 \zeta$ turnover (D'Oro et al., 2002). Therefore, Lck endosomal localization is key for a variety of Lck functions. Interestingly, Unc119, an adapter protein that activates Rab11 and recruits the actin-based molecular motor myosin 5B, controls Lck traffic in an opposite manner than FIP3. Unc119 also associates to CD3 and CD4 and facilitates Lck activation (Gorska et al., 2004; Gorska et al., 2009). Unc119A cooperates with the ciliary ARL-3 GTPase and its GEF ARL-13B to transfer active Tyr394-phosphorylated Lck to the immunological synapse (Stephen et al., 2018). Lck is associated with membrane rafts (Rodgers and Rose, 1996; Drevot et al., 2002). In this context, Lck localization is also regulated by MAL (Anton et al., 2008, 2011), a small tetraspanin associated 
with membrane rafts and controlling their polarized intracellular traffic (Martin-Belmonte et al., 2003). Finally, the late endosomal transporter CD222 regulates Lck localization, intracellular traffic, and activation (Pfisterer et al., 2014). Interestingly, these different Lck traffic regulators seem to balance the anterograde (MAL, Unc119, and CD222) and retrograde (FIP3) Lck transport, key to regulate Lck function in $\mathrm{T}$ cell activation.

LAT cycles between the plasma membrane, endosomes, and the Golgi. The intracellular LAT compartment is polarized to the immunological synapse concomitantly with those of $\mathrm{CD} 3 \zeta$ and Lck. Particular amino acid residues control LAT association to intracellular vesicle pools and its targeting to the synapse (Bonello et al., 2004). Intracellular LAT contributes to the synapse as a second wave, following the formation of microclusters derived from plasma membrane LAT (Bonello et al., 2004; Balagopalan et al., 2018). Several intracellular traffic regulators control LAT localization. Some are common with $\mathrm{CD} 3 \zeta$, such as flagellar transport proteins (Vivar et al., 2016), or vesicle docking and fusion regulators, such as the SNARE VAMP7 or the calcium sensor synaptotagmin-7 (Larghi et al., 2013; Soares et al., 2013). In addition, LAT undergoes retrograde transport from the plasma membrane and endosomes to the Golgi under the control of the Rab6 GTPase, the tSNARE syntaxin-16, and the golgin GMAP210 (Carpier et al., 2018; Zucchetti et al., 2019), which together facilitate LAT delivery to the immunological synapse and subsequent $\mathrm{T}$ cell activation. It is likely that a continuous traffic between the plasma membrane and endosomal and Golgi compartments takes place and is modified upon T cell contact with antigen-presenting cells. However, the spatiotemporal organization, sequence of events, and regulation of these events are still ill defined.

The mechanisms described above are thought to target TCR-CD3 complexes and Lck and LAT signaling molecules to the immunological synapse, fueling the formation of signaling microclusters at the plasma membrane. After their dynamic trip within microclusters, TCRs and some of its proximal signaling molecules may be internalized and either recycled back to the plasma membrane to participate in additional cycles of signaling, restored in the vesicular compartment, or degraded to downregulate TCR signaling. This may be modulated by post-transcriptional modifications, such as phosphorylation and ubiquitination (Cenciarelli et al., 1992; D’Oro et al., 1997; Valitutti et al., 1997; Wang et al., 2001; Bonello et al., 2004; Balagopalan et al., 2007, 2011; Huang et al., 2010; Ivanova and Carpino, 2016). Worth noting, the existence of a transient endosomal/Golgi compartment where signaling may continue has been inferred from the presence of active kinases and phosphorylated signaling molecules associated with intracellular compartments after TCR engagement (Luton et al., 1997; Yudushkin and Vale, 2010; reviewed in Alcover et al., 2018; Saveanu et al., 2019; Evnouchidou et al., 2020).

As described above, Racl and Cdc42 GTPases transduce TCR signals driving actin cytoskeleton remodeling during immunological synapse formation. These molecules were shown to be associated with vesicles in other cellular types (Phuyal and Farhan, 2019). Interestingly, we observed that a minor fraction of Rac1 in T cells colocalizes with Rab11 ${ }^{+}$recycling endosomes, whereas most of the Racl protein seems to be associated with the plasma membrane or diffused in the cytosol. Interestingly, perturbing recycling endosome dynamics by overexpressing the Rab11 effector FIP3 concentrates Rac1 in pericentrosomal endosomes, whereas FIP3 silencing disperses endosomal Rac1 all over the cytoplasm. Importantly, FIP3 silencing releases the tight control of Rac1 on the actin cytoskeleton, inducing $\mathrm{T}$ cell overspreading on stimulatory surfaces (i.e., anti-CD3-coated) or on poly-L-lysine-coated surfaces. Moreover, FIP3-silenced cells form larger and asymmetrical immunological synapses. These shape changes could be due, at least in part, to a reduction of $\mathrm{T}$ cell rigidity. Therefore, Rac1 association and traffic via Rab11 endosomes is key to balance basal versus TCR-stimulated actin cytoskeleton rearrangements, perhaps by the differential compartmentalization of Rac1 and its regulatory molecules, such as the GEFs Vav1 or Tiam1. Finally, Rac1 endosomal traffic is required for the regulation of $\mathrm{T}$ cell activation leading to cytokine production (Bouchet et al., 2016, 2018).

Vesicle traffic to the synapse may also be involved in the termination of $\mathrm{T}$ cell activation, as the inhibitory receptor CTL4, which competes with CD28 co-stimulatory receptor, is also associated with an endo-lysosomal vesicular compartment, which is released at the synapse in a LYST-regulated manner (Linsley et al., 1996; Shiratori et al., 1997; Barrat et al., 1999; Iida et al., 2000).

Finally, $\mathrm{T}$ cells forming immunological synapses produce extracellular microvesicles containing TCRs, CD40L, ICOS, and tetraspanins (Blanchard et al., 2002b; Choudhuri et al., 2014; Saliba et al., 2019), as well as RNA and DNA (Mittelbrunn et al., 2011; Torralba et al., 2018). Extracellular vesicle protein and nucleic acid components undergo a process of molecular sorting, since extracellular vesicles are enriched in some components while lacking others (Villarroya-Beltri et al., 2013; Yanez-Mo et al., 2015; Saliba et al., 2019). They accumulate at the synaptic cleft, by a budding process regulated by ESCRT proteins (Choudhuri et al., 2014), where they may play a dual role: first, to reduce TCR cell surface expression to control T cell activation and second, to contribute to dendritic cell priming and maturation and B cell help. This may occur in two ways, by binding MHC-peptide antigen or stimulatory molecules on antigen-presenting cells, such as CD40 or ICOSL (Saliba et al., 2019), and by fusing and transferring their microRNA or DNA content (Mittelbrunn et al., 2011; Torralba et al., 2018).

Therefore, a complex balance of exchanges between the plasma membrane and intracellular vesicular compartments, involving the TCR, several signaling molecules, and an array of traffic regulatory proteins ensures TCR signal transduction and actin cytoskeleton remodeling. Distinct spatiotemporal localization of these various proteins may ensure the fidelity of TCR triggering and sustained $\mathrm{T}$ cell activation. Finally, the production of extracellular vesicles plays a key role on antigen-presenting cells regulation contributing to dendritic cell priming and maturation or B cell help. Importantly, some of these mechanisms may be altered by pathogen infections or specific genetic disorders. For instance, HIV-1 hijacks these processes to ensure viral replication and transmission and escape from the immune system (see "Alterations of 
T Cell Cytoskeleton and Molecular Traffic in Pathological Settings" section).

\section{Role of the Cytoskeleton in Signaling to the Nucleus}

One of the consequences of antigen stimulation is the nuclear translocation of several transcription factors, such as nuclear factor of activated T cells (NFAT), nuclear factor kappa B (NFkB), and activator protein 1 (AP1), that play a central role in $\mathrm{T}$ cell activation, differentiation, and effector functions. Recent work has highlighted the involvement of the cytoskeleton in controlling this step, particularly in the case of NFAT.

The NFAT family of transcription factors encompasses five different members, two of them being expressed in T cells: NFAT1 (NFATc2 or NFATp) and NFAT2 (NFATc1 or NFATc) (Muller and Rao, 2010). A third member, NFAT4 (NFATc3 or NFATx), is preferentially expressed in thymocytes (Oukka et al., 1998). The expression of these factors may be differentially regulated: for instance, NFAT1 is constitutively expressed in T cells, whereas NFAT2 is induced upon T cell stimulation (Northrop et al., 1994; Lyakh et al., 1997).

In unstimulated $\mathrm{T}$ cells, NFAT transcription factors are phosphorylated on a series of serine residues that expand over the nuclear localization signal. Phosphorylation prevents NFAT nuclear translocation, ensuring cytoplasmic localization in resting T cells. NFAT activation is initiated by TCR-induced PLC $\gamma 1$-dependent production of IP3 and consequent release of $\mathrm{Ca}^{2+}$ from ER stores (reviewed in Hogan et al., 2003). Low $\mathrm{Ca}^{2+}$ concentration in the ER lumen triggers the multimerization on ER membranes of the single transmembrane domain protein STIM that contacts the pore-forming ORAI proteins on the plasma membrane. As a result, $\mathrm{Ca}^{2+}$ influx from the extracellular space is stimulated (Zhang et al., 2005; Prakriya et al., 2006; Penna et al., 2008). The rise of intracellular $\mathrm{Ca}^{2+}$ leads to the rapid activation of the Ser/Thr-specific phosphatase calcineurin that binds to and dephosphorylates cytosolic NFAT proteins, leading to their nuclear import (Hogan et al., 2003). Once in the nucleus, NFAT usually acts together with other transcription factors. For instance, it interacts with AP1, FOXP3, or GATA family members (Macian et al., 2001; Monticelli et al., 2004; Wu et al., 2006) and functionally cooperates with NFkB to regulate the transcription of multiple cytokine genes (e.g., IL-2, IL-4, interferon gamma [IFN $\gamma]$, and IL-17), transcription factors (e.g., FOXP3), or other receptors (e.g., CD25 and CTLA-4) (Muller and Rao, 2010). Notably, NFAT can also act alone to induce CD8 T cell exhaustion (Martinez et al., 2015).

Inactivation of NFAT and its nuclear export depends on the activity of multiple kinases, such as casein kinase 1 (CK1), glycogen synthase kinase 3 (GSK3), and the dualspecificity tyrosine-phosphorylation-regulated kinase (DYRK), that phosphorylate specific motifs in the conserved N-terminal regulatory region (Okamura et al., 2004; Gwack et al., 2006). These kinases have been found to be constitutively associated with NFAT in a large cytoplasmic RNA-protein scaffold complex, which also contains the GTPase IQGAP and the noncoding RNA NRON (Sharma et al., 2011). Dephosphorylation of NFAT requires the dissociation of this complex and results in masking the nuclear export sequence (NES) in NFAT, exposing its nuclear localization sequences (NLS), as well as promoting its transcriptional activity (Okamura et al., 2000).

Once the NLSs are exposed, NFAT may reach nuclear pore complexes by simple diffusion in the cytoplasm, before its import into the nucleus. However, several data suggest a potential implication of the microtubule cytoskeleton in this process. Initial findings in neuroblast cells showed that treatments altering tubulin polymerization, such as decreasing cellular zinc or exposure to colchicine or vinblastine, prevent NFAT transport to the nucleus (Mackenzie and Oteiza, 2007). Further studies revealed that NFAT nuclear translocation depends on importin$\beta$ and requires tubulin acetylation (Ishiguro et al., 2011). Interestingly, our recent work (Aguera-Gonzalez et al., 2017) has revealed that endogenous NFATc2 forms discrete clusters juxtaposed to microtubules in unstimulated $\mathrm{T}$ cells. These clusters move closer to the immunological synapse surface at early time points after activation and then progressively move to the perinuclear region. Moreover, NFAT clusters progressively move away from microtubules, correlating with NFAT shuttling to the nucleus (Aguera-Gonzalez et al., 2017). Hence, these data suggest that the association of NFAT with the microtubule network could facilitate concentration of this transcription factor around the nucleus and/or its interaction with nuclear pores. In agreement with a functional link between NFAT and the microtubules, we have also observed that knockdown of several proteins that control the appropriate organization of the microtubule network, such as the polarity regulators Apc and Dlg1 and the actincytoskeleton linker ezrin, impairs NFAT nuclear translocation and transcriptional activity (Lasserre et al., 2010; AgueraGonzalez et al., 2017; Juzans et al., 2020). Altogether, these data underscore the involvement of microtubules in driving NFAT nuclear localization.

The role of actin cytoskeleton in NFAT activation is less clear. Indeed, treatment of cells with actin polymerization inhibitors has been shown to affect the $\mathrm{Ca}^{2+} / \mathrm{NFAT}$ pathway; however, the effects were positive or negative depending on the cell type, dose, and/or stimulation protocol (Rivas et al., 2004; Mackenzie and Oteiza, 2007). This is likely due to the multiple roles of actin that is implicated in regulating $\mathrm{T}$ cell/antigen-presenting cell interactions, receptor triggering, and signaling complex dynamics at the immunological synapse (see "T Cell Sensing of Antigen Cues, TCR Triggering, and Immunological Synapse Formation" section). Several regulators of the actin cytoskeleton have been implicated in NFAT activation. These include the actin nucleators WASP and WAVE2 (Silvin et al., 2001; Nolz et al., 2006), the Ser/Thr kinase PAK1 (Yablonski et al., 1998a), the GTPase RhoG (Vigorito et al., 2003), and the GEF SLAT (Becart et al., 2008). However, in most cases, these proteins do not affect directly NFAT but act on upstream signaling proteins and/or $\mathrm{Ca}^{2+}$ influx. On the other hand, the aforementioned role of ezrin, which binds to actin and can act in concert with Dlg1 to organize the microtubule network at the immunological synapse (Lasserre et al., 2010), suggests that proper crosstalk between actin and microtubule cytoskeletons is required for NFAT nuclear translocation. Importantly, ezrin and Dlg1 may also control 
NFAT activation via Dlg1 interaction with the p38 MAP kinase, indicating an influence of these cytoskeleton crosstalk regulators in TCR signaling (Round et al., 2007; Lasserre et al., 2010).

It is worth noting that both actin and microtubule cytoskeletons are involved in the reorganization of the $\mathrm{ER}$ and mitochondria in activated $\mathrm{T}$ cells, which is key to regulate TCR-induced $\mathrm{Ca}^{2+}$ signaling (reviewed in Babich and Burkhardt, 2013). As mentioned above, the ER has to move toward the plasma membrane in order to allow the contact between STIM oligomers and ORAI and trigger extracellular $\mathrm{Ca}^{2+}$ influx. This movement may directly involve microtubules (Grigoriev et al., 2008). On the other hand, the mitochondria have to be repositioned close to membrane $\mathrm{Ca}^{2+}$ channels to buffer $\mathrm{Ca}^{2+}$ concentration locally and keep these channels active (Ishii et al., 2006; Baixauli et al., 2011; Quintana et al., 2011; Quintana and Hoth, 2012). Polarization of both ER and mitochondria in this setting depends on the coordinated action of actin and microtubules and associated molecular motors (Babich and Burkhardt, 2013).

Finally, another structural link between the nucleus and immunological synapse modulating $\mathrm{T}$ cell functions involves A-type lamins. These proteins that belong to the intermediate filaments family and form the nuclear lamina have been shown to indirectly connect with actin and microtubules and affect $\mathrm{T}$ cell activation. Indeed, lamin $\mathrm{A}$ defective $\mathrm{T}$ cells have impaired actin and microtubule dynamics, altered signaling, and a lower ability to form immunological synapses (Gonzalez-Granado et al., 2014).

\section{ACTIN-MICROTUBULE INTERPLAY SHAPING T CELL EFFECTOR FUNCTIONS}

The cooperation between actin and microtubules is also key for $\mathrm{T}$ cell effector functions occurring at the synapse, such as lytic granule release or polarized cytokine secretion.

\section{Lytic Granule Release}

When cytotoxic $\mathrm{T}$ cells recognize target cells, lytic granules rapidly move along microtubules, cluster around the moving centrosome, and then polarize with it at the immunological synapse. Centrosome translocation and actin clearance at the synapse have been proposed to be key for lytic granule docking and fusion at the membrane and target cell killing (Stinchcombe et al., 2006; Ritter et al., 2015; Figure 5), although this seems not to be the sole mechanism (Bertrand et al., 2013; Tamzalit et al., 2020). Conversely, actin recovery terminates cytotoxic granule release (Ritter et al., 2017). At the plasma membrane, the centrosome defines a precise secretory domain next to the c-SMAC, concentrating perforin and granzymes in the synaptic cleft (Stinchcombe et al., 2001, 2006). Perforin and granzymes then induce target cell apoptosis. Interestingly, granule movement involves multiple molecular motors. Initially, dynein-dependent retrograde transport on microtubules brings lytic granules to the centrosome (Stinchcombe et al., 2006). Then, granules travel to the immunological synapse, together with the centrosome, and may be positioned close to the plasma membrane by microtubule-based anterograde movement-dependent kinesin motors (Kurowska et al., 2012) or just by the sole proximity of the centrosome to the synapse (Stinchcombe et al., 2006).

The alteration of any of these steps results in impaired lytic granule release. Indeed, the deficiency of several polarity and cytoskeleton regulators impacts both cytoskeleton and centrosome translocation. For instance, silencing of Dlg1 or Apc results in impaired F-actin remodeling, microtubule disorganization, and impaired centrosome and $\mathrm{CD} 3$ polarization at the synapse (Round et al., 2005; Lasserre et al., 2010; Humphries et al., 2012; Aguera-Gonzalez et al., 2017; Juzans et al., 2020). Therefore, Dlg1 and Apc modulate CTL immunological synapse formation and function, consequentially influencing both the lytic granule delivery to the synapse and the ability to kill target cells (Silva et al., 2015; Juzans et al., 2020). In addition, the impairment of actin regulators, such as WASP or the Arp2/3 complex, results in altered target cell elimination (De Meester et al., 2010; Randzavola et al., 2019). However, this does not affect lytic granule secretion, assessed by Lamp1 cell surface expression, but impair immunological synapse symmetry and stability (De Meester et al., 2010; Houmadi et al., 2018; Randzavola et al., 2019). Actin dynamics is thus necessary for efficient killing, while apparently not essential for lytic granule release. However, we have recently shown that Lamp1 cell surface measurement could not be sensitive enough to discriminate small secretion differences (Juzans et al., 2020).

Interestingly, several mechanisms of CTL killing may exist, and plasticity could be an attribute of cytotoxic immunological synapses. On the one hand, a mechanism has been described involving centrosome and cytotoxic granule polarization to a well-structured immunological synapse in which actin and microtubule dynamics orchestrate lytic granule delivery to target cells. On the other hand, various examples challenge this rule, questioning the importance of centrosome docking. For instance, the polarity regulator $\mathrm{PKC} \zeta$ is required for centrosome polarization in CD8 $\mathrm{T}$ cells, but not for efficient lytic granule release and target cell killing (Ludford-Menting et al., 2005; Bertrand et al., 2013). Its potential role in actin reorganization at the synapse has not been addressed to date, but it has been shown to control F-actin dynamics in migrating $\mathrm{T}$ cells (Real et al., 2007; Crespo et al., 2014). Lytic granule translocation to the cytotoxic synapse may occur in the absence of centrosome polarization, and CTLs may simultaneously kill several target cells (Wiedemann et al., 2006; Bertrand et al., 2013). Conversely, human B cells, by inducing weak CD2 signaling, may trigger non-polarized granule exocytosis by the CTLs, although the centrosome is at the synapse (Kabanova et al., 2016; Zurli et al., 2020). Finally, centriole deletion has no effect on lytic granule polarized secretion, but reduces killing efficiency by impairing lytic granule biogenesis and actin-induced forces at the synapse (Tamzalit et al., 2020).

Altering cytoskeleton organization and the interplay between cortical actin and microtubules affects synapse symmetry and stability (Ludford-Menting et al., 2005; Lasserre et al., 2010; Juzans et al., 2020). For instance, we have recently shown 
A Normal conditions

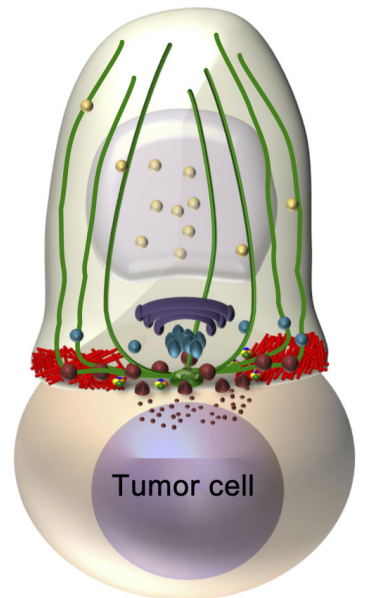

B Apc deticiency

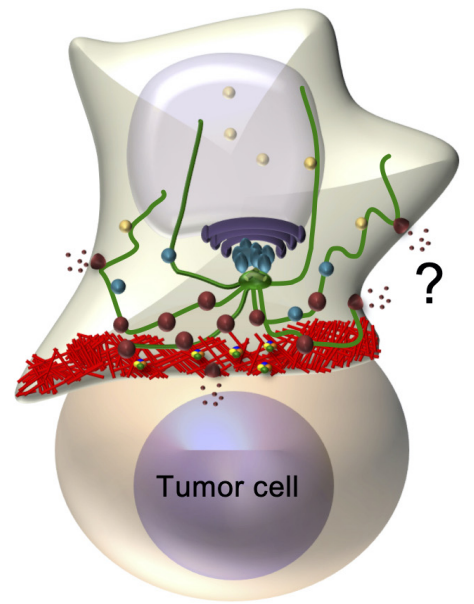

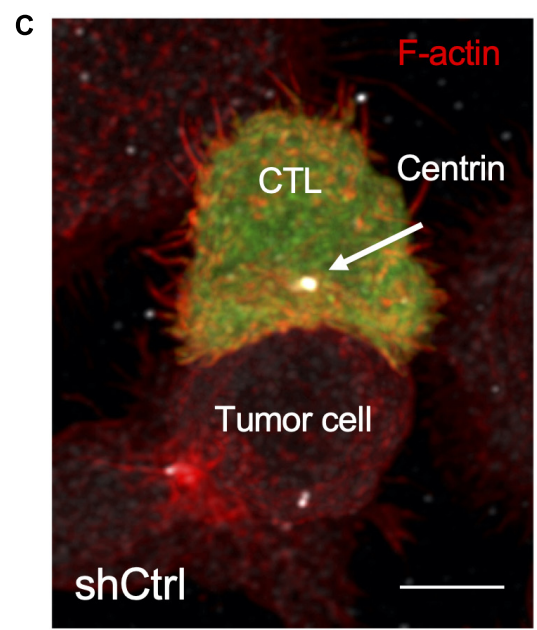

E

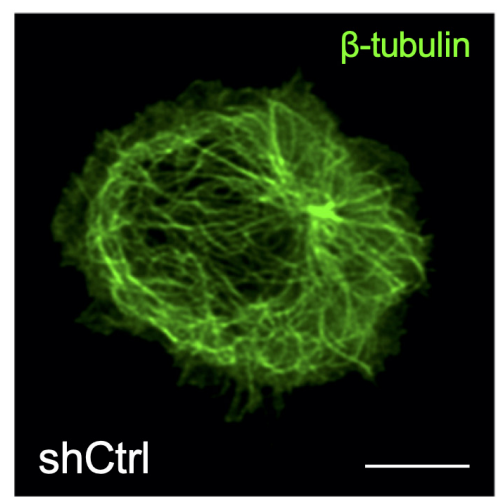

D

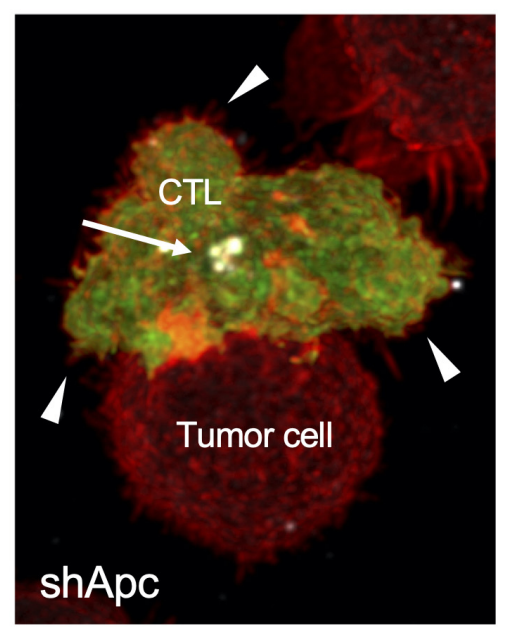

$\mathbf{F}$

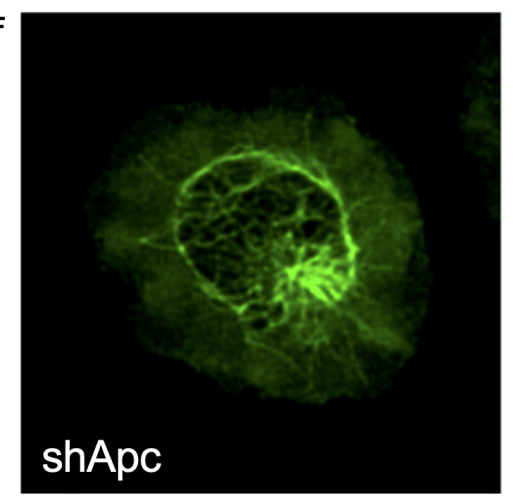


FIGURE 5 | Defects of the polarity regulator and tumor suppressor Apc impair CTL function. (A,B) Schematic representation of CTL polarization leading to lytic granule release and killing of a tumor target cell (A). Apc defects impair actin and microtubule reorganization at the immunological synapse, NFAT nuclear translocation, centrosome polarization, immunological synapse symmetry and stability, and lytic granule polarized release leading to tumor target cell killing (B). Granule release is not completely hampered, and it might occur in an unpolarized manner. (C,D) Fluorescence confocal microscopy of a control (C) or Apc-silenced (D) human CTL encountering a tumor target cell coated with an anti-CD3 Ab. Arrows point to the centrosome and arrowheads to large membrane protrusions. Control CTL appears symmetric with the centrosome close to the center of the synapse, whereas Apc-deficient CTL appears dissymmetric with large membrane protrusions and the centrosome distant from the synapse. (E,F) Fluorescence confocal microscopy of control (E) or Apc-silenced (F) human CTLs stimulated anti-CD3-coated coverslips to form immunological pseudo-synapses. Alteration of the microtubule network is evident in Apc-silenced compared with control cells. Confocal images are from Juzans et al. (2020). Bar $=5 \mu \mathrm{m}$.

that Apc silencing results in altered synapse shape, symmetry, and stability (Juzans et al., 2020; Figures 5A-D). Interestingly, cytotoxic synapses may not require to be fully formed and stable to efficiently kill. Indeed, CTLs exhibit low TCR stimulation threshold to induce lytic granule release compared with the one required for efficient TCR signal transduction to the nucleus (Faroudi et al., 2003). Killing may occur with only three TCRpMHC interactions, whereas stable synapse formation requires at least 10 interactions (Purbhoo et al., 2004). Finally, the formation of a mature synapse with typical SMAC pattern and CD2 enrichment is not always necessary for efficient cytotoxic granule release (Faroudi et al., 2003; Depoil et al., 2005; O'Keefe and Gajewski, 2005). Therefore, synapse stability may not be necessary for killing, but could increase its efficiency. Indeed, lytic granule release has been spatiotemporally correlated with the forces exerted by CTLs against target cell surfaces. These forces, due to the pushing-pulling action of the actin cytoskeleton, increase target cell membrane tension, which in turn enhances the perforin pore-forming activity (Basu et al., 2016; Tamzalit et al., 2019).

Therefore, actin and microtubule cytoskeleton mechanical properties are crucial for efficient target cell killing, but the extracellular environment may also play a key role. Since the conflicting results described above were most (if not all) obtained in vitro, it is possible that the in vivo requirements for an effective immune response are more stringent. Indeed, in vivo, CTLs act in a crowded environment of healthy or pathological tissues that generate strong forces and interact simultaneously with several cells. Detailed analyses in vivo will help to better understand cytotoxicity mechanisms in health and diseases (Boulch et al., 2019).

\section{Cytokine Secretion}

As perforin and granzymes, cytokine secretion involves the Golgi apparatus and the transit through secretory vesicles. Both Golgi and vesicles polarize with the centrosome and facilitate cytokine secretion at the immunological synapse, on a time scale of hours rather than minutes as for lytic granules (Kupfer et al., 1991, 1994; Huse et al., 2006). Interestingly, cytokine polarization is under the control of $\mathrm{PKC} \zeta$, which is not involved in lytic granule secretion (Bertrand et al., 2010, 2013). Additionally, CD4 T cells can release cytokines in a multidirectional manner (Huse et al., 2006). This could facilitate the dispersion of local signals and the recruitment of target cells. Polarized and multidirectional pathways involve different molecular effectors and could depend on the secreted cytokine, e.g., IL-2, IL-10, and IFN $\gamma$ are released at the synapse, whereas IL-4 and tumor necrosis factor alpha
(TNF $\alpha)$ multi-directionally (Huse et al., 2006). However, this distinction may not be strict, since other authors reported polarized release of IL-4 and TNF $\alpha$ (Depoil et al., 2005; Hivroz et al., 2012). Different experimental setups may explain these differences, suggesting that in vivo, cytokine polarization may depend on the stimuli.

The importance of actin clearance from the center of the synapse has been much less addressed for cytokine secretion than for lytic granule release. The impairment of actin dynamics and clearance in Cdc42-silenced or WASP-deficient CD4 T cells significantly decreases IFN $\gamma$ secretion, without altering its production (Morales-Tirado et al., 2004; Chemin et al., 2012). Interestingly, Cdc42 silencing also inhibits TNF secretion. However, in the setup used by the authors, $\mathrm{TNF} \alpha$ is polarized at the synapse and does not appear to be secreted in a multidirectional manner (Chemin et al., 2012; Hivroz et al., 2012). As for lytic granule release (Ritter et al., 2015), impaired actin clearance from the secretion site could act as a physical barrier restraining the access of vesicles to the plasma membrane (Chemin et al., 2012). In addition, in WASP-deficient cells, disorganization of the cis-Golgi morphology appears to take place and could contribute to impaired secretion (MoralesTirado et al., 2004). Interestingly, impaired actin clearance induced by Apc silencing in CTLs that correlates with reduced lytic granule release does not alter IFN $\gamma$ nor TNF secretion (Juzans et al., 2020). Hence, the effects of Apc silencing on F-actin appear less significant than those of Cdc42 or WASP deficiency, and Apc may be replaced by another polarity regulator.

The microtubule cytoskeleton seems to play a specific role in the polarized secretion of cytokines. Indeed, nocodazole or vinblastine treatment, which impairs microtubule polymerization and centrosome polarization, alters IFN $\gamma$ and IL-2 concentrations at the synapse and their polarized secretion. These cytokines are then secreted in a multidirectional manner, likely due to Rab relocalization (Huse et al., 2006; Ueda et al., 2015). On the contrary, nocodazole treatment of CD4 $\mathrm{T}$ cells has no effect on multidirectional secretion of $\mathrm{TNF} \alpha$ (Huse et al., 2006). Therefore, microtubules would be crucial for cytokinespecific targeting at the synapse but not for their release. Importantly, their alteration could reorient cytokine polarized secretion to a multidirectional one (Huse et al., 2006; Ueda et al., 2015).

The expression of a truncated mutant of ezrin lacking F-actin binding domain that inhibits cortical interaction with the plasma membrane and microtubules leads to defective production of 
IFN $\gamma$ and IL-2, but not of TNF (Allenspach et al., 2001). This suggests that the microtubule role and their interplay with the actin are more significant for cytokine secretion in a polarized manner. However, little is known on the actin and microtubule cytoskeleton interplay in cytokine secretion.

Similarly, to what has been observed for lytic granule release, cytokine secretion may not require a well-structured immunological synapse. Indeed, IFN $\gamma$ production is poorly correlated with extensive TCR clustering in CD4 T cells and depends on the stimulation conditions (Blanchard et al., 2004). However, IFN $\gamma$ production still requires higher antigen stimulation of CTLs than lytic granule release (Valitutti et al., 1996; Faroudi et al., 2003). Moreover, in vivo secretion could be less stringent. Indeed, naive CD4 $\mathrm{T}$ cells interact successively with several antigen-presenting cells and undergo synapse-kinapse cycles, promoting IL-2 and IFN $\gamma$ production (Celli et al., 2005; Sims et al., 2007). Therefore, CD4 T cells could form fewer stable synapses than expected. Interactions with several targets may provide signal integration and facilitate amplification of the immune response or target cell elimination. Furthermore, polarized secretion could still induce signal spreading as the immunological synapse does not spatially restrict IFN $\gamma$ secretion by CTLs, allowing IFN $\gamma$ bystander activity important to alter tumor environment (Sanderson et al., 2012; Hoekstra et al., 2020; Thibaut et al., 2020).

\section{ALTERATIONS OF T CELL CYTOSKELETON AND MOLECULAR TRAFFIC IN PATHOLOGICAL SETTINGS}

As mentioned above, infection of $\mathrm{T}$ cells by specific pathogens or genetic alterations may result in dysregulation of the cytoskeleton, endosomal trafficking, and/or their crosstalk, thus impairing TCR signaling, T cell activation, and effector functions. Two examples are described below, i.e., HIV-1 infection of $\mathrm{T}$ cells and inherited mutations of the Apc gene in familial adenomatous polyposis.

\section{HIV-1 Subverts the Interplay Between Endosomal Traffic, TCR Signaling, and Actin Cytoskeleton}

HIV-1 infects CD4 $\mathrm{T}$ cells hijacking $\mathrm{T}$ cell physiology to produce new viral particles and spread to other cells. Viral infection eventually leads to chronic infection and the production of viral reservoirs that escape host immune control. HIV-1 encodes several "accessory" proteins mediating the subversion of various cellular processes. Among these proteins, Nef is key for in vivo viral replication and AIDS pathogenesis. Nef is expressed soon upon infection and has pleiotropic effects in $\mathrm{T}$ cells, modifying the intracellular environment to enhance virus replication, while reducing host immunity (Fackler et al., 2007). Nef expression subverts endosomal traffic, actin cytoskeleton regulators, and $\mathrm{T}$ cell signaling effectors in infected $\mathrm{T}$ cells. As a consequence, HIV-1 infection: (i) modifies cell surface expression of several $\mathrm{T}$ cell molecules, including CD4, CD28, and MHC class I and II (Pereira and Dasilva, 2016); (ii) reduces actin accumulation at the synapse and alters related features, such as $\mathrm{T}$ cell shape, membrane protrusions, cell spreading, and T cell motility (Fackler et al., 1999, 2000; Haller et al., 2006; Rauch et al., 2008; Nobile et al., 2010; Stolp et al., 2010, 2012; Lehmann et al., 2011); and (iii) modulates T cell activation by affecting various signaling pathways, including those controlling activation and apoptosis (Fackler et al., 2007; Abraham et al., 2012; Markle et al., 2013).

The action of Nef on actin cytoskeleton occurs at different levels and appears to affect different stages of the virus life cycle, including virus entry and viral particle assembly, and egress from infected cells and transmission to other cells (Stolp and Fackler, 2011; Bracq et al., 2018). In addition, Nef modifies some intracellular vesicle traffic pathways and as a consequence cellular processes depending on protein transport (Pereira and Dasilva, 2016). Interestingly, Nef perturbs endosomal recycling and hijacks Lck and Rac1 endosomal traffic leading to their concentration in partially overlapping intracellular compartments, thus preventing the formation and signaling function of the immunological synapse (Figure 6; Thoulouze et al., 2006; Del Rio-Iniguez et al., 2018). Nef also limits the communication between LAT and SLP76 adaptors, reducing their capacity to form signaling complexes at the immunological synapse (Abraham et al., 2012). Hence, HIV-1 infection interferes with a key intracellular regulatory hub that ensures the interplay between vesicle traffic, T cell signaling, and actin cytoskeleton remodeling (Bouchet et al., 2016, 2017). Moreover, by concentrating Lck in recycling endosomes, HIV-1 may generate an endosomal signaling compartment, which concentrates Lck in its active form (phosphorylated on Tyr394, see Figure 6), together with tyrosine phosphorylated (i.e., active) species of other

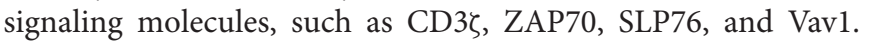
In contrast, LAT, associated with different endosomes than Lck, is not concentrated in this compartment. The Nef-induced endosomal compartment likely generates $\mathrm{T}$ cell activation signals since a concomitant upregulation of early activation and cytokine genes was observed in the absence of TCR stimulation (Pan et al., 2012; Del Rio-Iniguez et al., 2018). Indeed, impairing the formation of the Nef-induced Lck compartment, by interfering with the endosomal transport regulator FIP3, prevented the upregulation of Nef-induced genes (Del Rio-Iniguez et al., 2018). Interestingly, Nef also extensively sequesters Racl in an intracellular compartment partially overlapping with that of Lck. In this manner, Nef modulates Rac1-dependent actin cytoskeleton remodeling and reduces $\mathrm{T}$ cell spreading. Thus, by hijacking the endosomal traffic of Lck and Rac1, Nef modulates signaling and actin cytoskeleton-mediated processes in infected $\mathrm{T}$ cells (Del Rio-Iniguez et al., 2018).

Therefore, HIV has evolved to subtly modify several regulatory cellular processes at key points of their crosstalk via the expression of the viral protein Nef. This may contribute to active steps of virus cycle leading to its replication (Fackler et al., 2007; Pan et al., 2012). It 


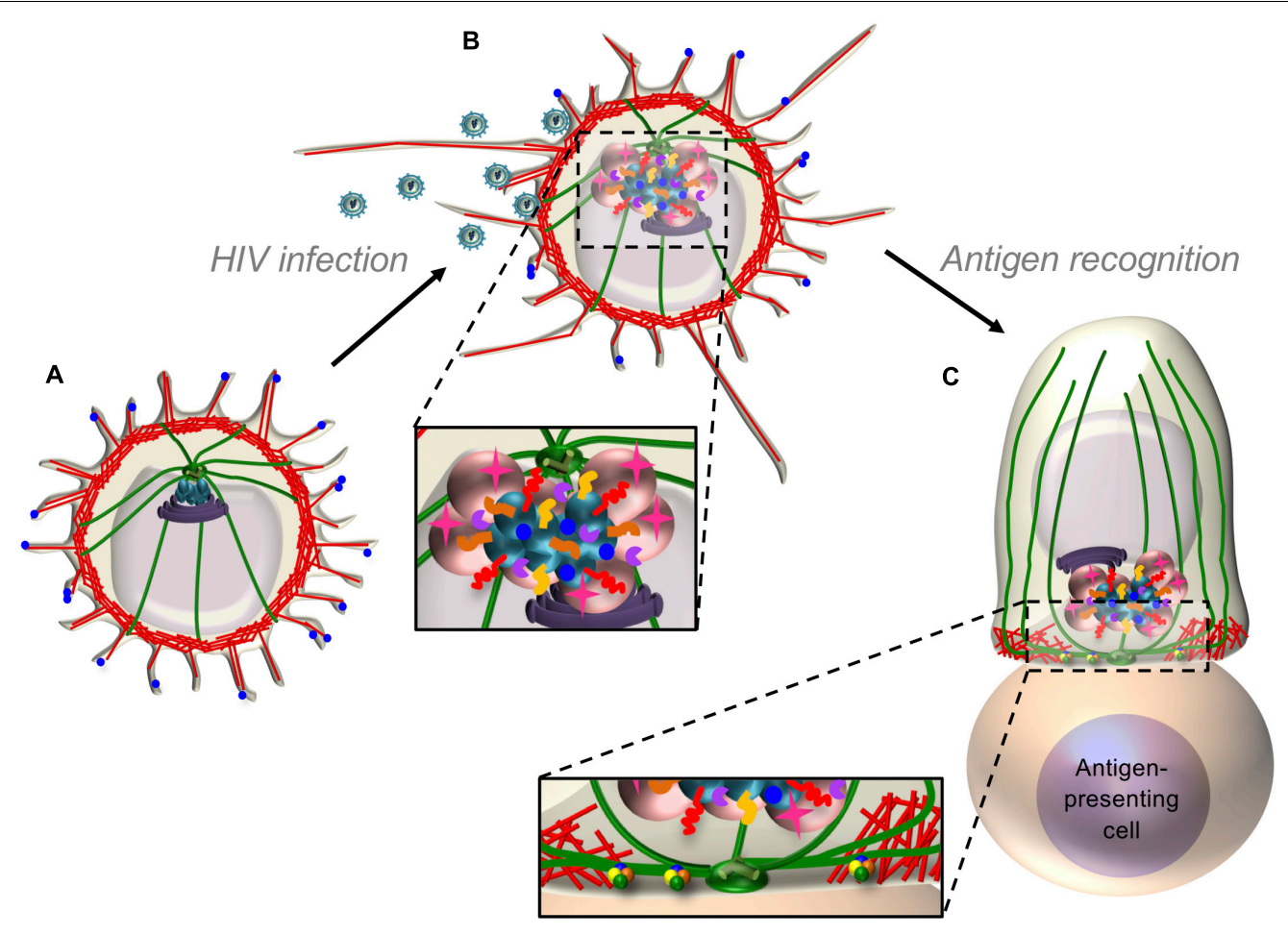

\begin{tabular}{|c|c|c|c|c|}
\hline 8 & Centrosome & - Endosomes & - TCR & \& p-Lck \\
\hline r & Microtubule & Nef compartement & $p-C D 3 \zeta$ & C Rac1 \\
\hline$X_{0}^{11}$ & $\begin{array}{l}\text { F-actin } \\
\text { Golgi apparatus }\end{array}$ & $\begin{array}{l}\text { Signaling complex } \\
\text { () HIV }\end{array}$ & p-ZAP70 & + Nef \\
\hline
\end{tabular}

FIGURE 6 | HIV-1 subverts endosomal traffic, TCR signaling, and actin cytoskeleton. (A,B) Upon HIV-1 infection, the expression of the viral protein Nef induces pleiotropic effects in the infected T cell, including changes in actin cytoskeleton dynamics and intracellular vesicle traffic. Actin cytoskeleton changes are likely responsible for cell shape modifications (e.g., infected T cells produce less ruffles and longer filopodia), whereas hijacking of endosomal traffic drives changes in the expression of several cell surface molecules and the concentration close to the centrosome of active phosphorylated forms of several proximal TCR signaling molecules, including Lck ( $p$-Lck), the CD3 $\zeta$ subunit ( $(\mathrm{C}-\mathrm{CD} 3 \zeta)$, the tyrosine kinase ZAP-70 ( $p$-ZAP-70), the adapter SLP76, and the cytoskeleton regulators Vav1 and Rac1 (only some depicted here and not depicted in (A) because their pattern is diffuse). This Nef-induced "endosomal signaling compartment" (depicted in light blue), which partially overlaps with a larger intracellular compartment containing Nef (in pink), appears to drive the expression of several activation genes, independently of TCR engagement. (C) Nef-induced perturbation of signaling molecules and actin cytoskeleton leads to the generation of defective immunological synapses that display fewer signaling complexes and contain a separate endosomal signaling compartment that impairs the TCR signaling cascade (compare with Figure 1E).

could also be important for inducing latency of infected $\mathrm{T}$ cells that favors virus reservoirs and avoids host immune control.

\section{The Tumor Suppressor Apc in T Cell Physiology and Pathology}

Apc is a cell polarity regulator and tumor suppressor whose mutations are associated with familial adenomatous polyposis and colorectal cancer development. Patients suffering from familial polyposis develop hundreds to thousands of polyps in their colon and/or rectum that finally turn into carcinomas if not removed by surgery (Lesko et al., 2014).
Thanks to its multiple binding domains (Figure 2), this large $(310-\mathrm{kDa})$ protein is involved in several cell functions. The central region of Apc contains short peptide motifs that bind the transcriptional co-activator $\beta$-catenin and three sets of SAMP (Ser-Ala-Met-Pro) domains that bind Axin to regulate $\beta$-catenin (Rubinfeld et al., 1993). Due to its involvement in a protein complex controlling $\beta$-catenin degradation, Apc is mostly known for its implication in the Wnt/ $\beta$-catenin signaling pathway that is essential during embryonic development and crucial for intestinal epithelium homeostasis.

Apc N-terminal portion contains a dimerization domain and an armadillo repeat domain. The latter interacts with many 
cytoskeleton regulators as the actin and microtubule regulator IQGAP-1, the Rho GTPase Cdc42, the Rho GTPase regulator Asef, or kinesin regulators (Kawasaki et al., 2000; Jimbo et al., 2002; Watanabe et al., 2004; Sudhaharan et al., 2011). The C-terminal portion contains domains binding other cytoskeleton regulators, including the microtubule plus-end binding protein EB1 and Dlg1, but also a basic domain directly interacting with microtubules and modulating their elongation and stability and cell polarity (Munemitsu et al., 1994; Nakamura et al., 2001). This basic domain stimulates F-actin nucleation and filament bundling (Moseley et al., 2007; Okada et al., 2010). Finally, Apc has been shown to interact directly and indirectly with nuclear pore and nuclear transport proteins and apoptosis- or mitosisrelated proteins (Nelson and Nathke, 2013).

Although Apc involvement in familial adenomatous polyposis and colorectal cancer has been extensively investigated, most studies concern how and why the epithelium is altered to form premalignant lesions, without questioning if Apc mutations could also alter immunosurveillance processes. Some studies conducted in Apc mutant mice have shown altered control of inflammation by Tregs (Akeus et al., 2014; Chae and Bothwell, 2015). These cells present impaired expression and/or activity of transcription factors key for their effector function regulation, such as FoxP3 and Gata-3, and as a consequence, their differentiation and production of anti-inflammatory cytokines, such as IL-10, are decreased (Gounaris et al., 2009; AgueraGonzalez et al., 2017). Interestingly, some studies showed that Apc mutant Tregs start to produce the pro-inflammatory cytokine IL-17 (Gounaris et al., 2009; Chae and Bothwell, 2015), described to promote tumor progression (Chae et al., 2010; Chae and Bothwell, 2015).

Variable alterations of $\mathrm{T}$ cell development and survival were observed in mouse models according to the extent and timing of Apc defects. For instance, conditional deletion of Apc in CD4 T cells induced Wnt pathway activation and apoptosis of mature cells leaving the thymus, resulting in lymphopenia (Wong et al., 2015). Likewise, thymocyte-specific Apc loss leads to extensive thymic atrophy due to a blockade of $\mathrm{T}$ cell development at the double negative stage (Gounari et al., 2005). Conversely, we observed in $\mathrm{Apc}^{\mathrm{Min} /+}$ mice, bearing a heterozygous mutation in the Apc gene, increased lymphocyte numbers in the spleen and lymph nodes.

Few studies have questioned if Apc loss or mutation directly affects $\mathrm{T}$ cell functions at the molecular level. We recently unveiled a direct involvement of Apc in T cell biology and the molecular mechanism responsible for the altered inflammatory control in Apc mutant mice intestine. As mentioned above, Apc loss impairs microtubule organization at the immunological synapse and centrosome reorientation toward the cell contact area in human CD4 T cells (Aguera-Gonzalez et al., 2017). Moreover, we observed that the NFAT transcription factor forms microclusters along microtubules. Therefore, Apc-dependent alteration of the microtubule network impairs NFAT nuclear translocation and its transcriptional activity. Intestinal Tregs from Apc mutant mice appear particularly affected, since they undergo altered differentiation and produce lower amount of the anti-inflammatory cytokine IL-10 (Aguera-Gonzalez et al., 2017), suggesting a dysregulation of the intestinal microenvironment at precancerous stages.

Recently, we showed that Apc is involved in cytoskeleton remodeling at the immunological synapse of CTLs. Indeed, Apc depletion impairs both microtubule and actin cytoskeletons, and as a consequence, it alters the morphology and stability of cytotoxic synapses formed by ex vivo differentiated CTLs. Additionally, polarized targeting and dynamics of lytic granules, as well as their fusion at the plasma membrane, are affected, thus diminishing the efficiency of tumor target cell killing by Apc-defective CTLs (Juzans et al., 2020) (see Figure 5). This phenotype shares some similarities with the one of CTLs from Wiscott-Aldrich Syndrome patients, who carry mutations in the gene encoding WASP and present actin cytoskeleton defects (De Meester et al., 2010; Houmadi et al., 2018) reducing their tumor cell killing ability.

Collectively, these data highlight how functional defects of the polarity regulator Apc may have a dual impact on familial adenomatous polyposis and colorectal cancer development, first, by altering the intestinal epithelial homeostasis, and second, by impairing $\mathrm{T}$ cell surveillance functions, further favoring the development of precancerous lesions and tumor growth.

\section{CONCLUDING REMARKS}

As we reviewed here, the fine interplay between actin and microtubule cytoskeleton and intracellular vesicle traffic is crucial for $\mathrm{T}$ cell functions, from migration to TCR signaling, immunological synapse formation, $\mathrm{T}$ cell activation, and effector functions. The detailed molecular mechanism of this crosstalk is not fully understood. An array of molecules linking cytoskeletal structures and their regulatory molecules, together with those linking plasma membrane-anchored proteins with the cytoskeleton, is key for this regulation, and their specific action needs further investigation. Likewise, novel cellular features needing cytoskeleton interplay are currently being unveiled. For instance, the role of mechanical forces in $\mathrm{T}$ cell physiology is becoming a field of active investigation, and the role of cytoskeletal crosstalk needs its further integration in these processes. In vivo, $\mathrm{T}$ cells continuously move in a crowded environment from which they may receive mechanical cues. In this sense, intermediate filaments, a third important component of the cell cytoskeleton, appear to play a key role in other cells in ensuring mechanical cell stability, as well as mechanotransduction from the cell surface to the nucleus. Intermediate filament dynamics, function, and interplay with various cell components are still poorly investigated in $\mathrm{T}$ cells and will be an interesting field of investigation. Interesting, polarity regulators as Apc ensure the interplay between the three cytoskeletal structures.

\section{AUTHOR CONTRIBUTIONS}

$\mathrm{MM}$ and $\mathrm{MJ}$ created the figures. $\mathrm{AA}$ and $\mathrm{VDB}$ edited the figures. All authors contributed equally in writing and editing the manuscript and read and approved the submitted version. 


\section{FUNDING}

Our laboratory was supported by grants from the Ligue Nationale contre le Cancer, Equipe Labellisée 2018, and institutional grants from the Institut Pasteur and INSERM. MM was a scholar of the Pasteur Paris University International Doctoral Program, supported by the Institut Pasteur, the European Union Horizon 2020 Research and Innovation Programme under the Marie Skłodowska-Curie grant agreement 665807 (COFUND-PASTEURDOC), and by a Ligue Nationale Contre

\section{REFERENCES}

Abraham, L., Bankhead, P., Pan, X., Engel, U., and Fackler, O. T. (2012). HIV-1 Nef Limits Communication between Linker of Activated T Cells and SLP-76 To Reduce Formation of SLP-76-Signaling Microclusters following TCR Stimulation. J. Immunol. 189, 1898-1910. doi: 10.4049/jimmunol. 1200652

Abram, C. L., and Lowell, C. A. (2009). The ins and outs of leukocyte integrin signaling. Annu. Rev. Immunol. 27, 339-362. doi: 10.1146/annurev.immunol. 021908.132554

Acuto, O., Di Bartolo, V., and Michel, F. (2008). Tailoring T-cell receptor signals by proximal negative feedback mechanisms. Nat. Rev. Immunol. 8, 699-712. doi: $10.1038 /$ nri2397

Aguera-Gonzalez, S., Burton, O. T., Vazquez-Chavez, E., Cuche, C., Herit, F., Bouchet, J., et al. (2017). Adenomatous Polyposis Coli Defines Treg Differentiation and Anti-inflammatory Function through Microtubule-Mediated NFAT Localization. Cell Rep. 21, 181-194. doi: 10.1016/j.celrep.2017.09.020

Akeus, P., Langenes, V., Von Mentzer, A., Yrlid, U., Sjoling, A., Saksena, P., et al. (2014). Altered chemokine production and accumulation of regulatory $\mathrm{T}$ cells in intestinal adenomas of APC(Min/+) mice. Cancer Immunol. Immunother. 63, 807-819. doi: 10.1007/s00262-014-1555-6

Alblas, J., Ulfman, L., Hordijk, P., and Koenderman, L. (2001). Activation of Rhoa and ROCK are essential for detachment of migrating leukocytes. Mol. Biol. Cell 12, 2137-2145. doi: 10.1091/mbc.12.7.2137

Alcover, A., Alarcon, B., and Di Bartolo, V. (2018). Cell Biology of T Cell Receptor Expression and Regulation. Annu. Rev. Immunol. 36, 103-125. doi: 10.1146/ annurev-immunol-042617-053429

Allenspach, E. J., Cullinan, P., Tong, J., Tang, Q., Tesciuba, A. G., Cannon, J. L., et al. (2001). ERM-dependent movement of CD43 defines a novel protein complex distal to the immunological synapse. Immunity 15, 739-750. doi: 10.1016/s1074-7613(01)00224-2

Anton, O. M., Andres-Delgado, L., Reglero-Real, N., Batista, A., and Alonso, M. A. (2011). MAL Protein Controls Protein Sorting at the Supramolecular Activation Cluster of Human T Lymphocytes. J. Immunol. 186, 6345-6356. doi: 10.4049/jimmunol.1003771

Anton, O., Batista, A., Millan, J., Andres-Delgado, L., Puertollano, R., Correas, I., et al. (2008). An essential role for the MAL protein in targeting Lck to the plasma membrane of human T lymphocytes. J. Exp. Med. 205, 3201-3213. doi: 10.1084/jem.20080552

Ardouin, L., Bracke, M., Mathiot, A., Pagakis, S. N., Norton, T., Hogg, N., et al. (2003). Vav1 transduces TCR signals required for LFA-1 function and cell polarization at the immunological synapse. Eur. J. Immunol. 33, 790-797. doi: 10.1002/eji.200323858

Arpin, M., Chirivino, D., Naba, A., and Zwaenepoel, I. (2011). Emerging role for ERM proteins in cell adhesion and migration. Cell Adh. Migr. 5, 199-206. doi: $10.4161 /$ cam.5.2.15081

Babich, A., and Burkhardt, J. K. (2013). Coordinate control of cytoskeletal remodeling and calcium mobilization during T-cell activation. Immunol. Rev. 256, 80-94. doi: 10.1111/imr.12123

Babich, A., Li, S., O'connor, R. S., Milone, M. C., Freedman, B. D., and Burkhardt, J. K. (2012). F-actin polymerization and retrograde flow drive sustained PLCgammal signaling during T cell activation. J. Cell Biol. 197, 775-787. doi: $10.1083 /$ jcb. 201201018 le Cancer Doctoral Fellowship. MJ was supported by a Ligue Nationale Contre le Cancer Doctoral Fellowship and the Institut Pasteur.

\section{ACKNOWLEDGMENTS}

We thank the other members of the Lymphocyte Cell Biology Unit for helpful discussions and their help in performing some of the experimental work mentioned herein.

Baixauli, F., Martin-Cofreces, N. B., Morlino, G., Carrasco, Y. R., Calabia-Linares, C., Veiga, E., et al. (2011). The mitochondrial fission factor dynamin-related protein 1 modulates T-cell receptor signalling at the immune synapse. Embo. J. 30, 1238-1250. doi: 10.1038/emboj.2011.25

Baker, R. G., and Koretzky, G. A. (2008). Regulation of T cell integrin function by adapter proteins. Immunol. Res. 42, 132-144. doi: 10.1007/s12026-008-8047-8

Balagopalan, L., Ashwell, B. A., Bernot, K. M., Akpan, I. O., Quasba, N., Barr, V. A., et al. (2011). Enhanced T-cell signaling in cells bearing linker for activation of T-cell (LAT) molecules resistant to ubiquitylation. Proc. Natl. Acad. Sci. U S A. 108, 2885-2890. doi: 10.1073/pnas.1007098108

Balagopalan, L., Barr, V. A., Kortum, R. L., Park, A. K., and Samelson, L. E. (2013). Cutting edge: cell surface linker for activation of T cells is recruited to microclusters and is active in signaling. J. Immunol. 190, 3849-3853. doi: 10.4049/jimmunol.1202760

Balagopalan, L., Barr, V. A., Sommers, C. L., Barda-Saad, M., Goyal, A., Isakowitz, M. S., et al. (2007). c-Cbl-mediated regulation of LAT-nucleated signaling complexes. Mol. Cell Biol. 27, 8622-8636. doi: 10.1128/mcb.00467-07

Balagopalan, L., Yi, J., Nguyen, T., Mcintire, K. M., Harned, A. S., Narayan, K., et al. (2018). Plasma membrane LAT activation precedes vesicular recruitment defining two phases of early T-cell activation. Nat. Commun. 9:2013. doi: 10. 1038/s41467-018-04419-x

Barber, E. K., Dasgupta, J. D., Schlossman, S. F., Trevillyan, J. M., and Rudd, C. E. (1989). The CD4 and CD8 antigens are coupled to a protein-tyrosine kinase (p56lck) that phosphorylates the CD3 complex. Proc. Natl. Acad. Sci. U S A. 86, 3277-3281. doi: 10.1073/pnas.86.9.3277

Barrat, F. J., Le Deist, F., Benkerrou, M., Bousso, P., Feldmann, J., Fischer, A., et al. (1999). Defective CTLA-4 cycling pathway in Chediak-Higashi syndrome: a possible mechanism for deregulation of T lymphocyte activation. Proc. Natl. Acad. Sci. U S A. 96, 8645-8650. doi: 10.1073/pnas.96.15.8645

Basu, R., Whitlock, B. M., Husson, J., Le Floc'h, A., Jin, W., Oyler-Yaniv, A., et al. (2016). Cytotoxic T Cells Use Mechanical Force to Potentiate Target Cell Killing. Cell 165, 100-110. doi: 10.1016/j.cell.2016.01.021

Becart, S., Balancio, A. J., Charvet, C., Feau, S., Sedwick, C. E., and Altman, A. (2008). Tyrosine-phosphorylation-dependent translocation of the SLAT protein to the immunological synapse is required for NFAT transcription factor activation. Immunity 29, 704-719. doi: 10.1016/j.immuni.2008.08.015

Beck-Garcia, K., Beck-Garcia, E., Bohler, S., Zorzin, C., Sezgin, E., Levental, I., et al. (2015). Nanoclusters of the resting T cell antigen receptor (TCR) localize to non-raft domains. Biochim. Biophys. Acta 1853, 802-809. doi: 10.1016/j. bbamcr.2014.12.017

Berlin, C., Bargatze, R. F., Campbell, J. J., Von Adrian, U. H., Szabo, M. C., Hasslen, S. R., et al. (1995). a4 integrins mediate lymphocyte attachment and rolling under physiological flow. Cell 80, 413-422. doi: 10.1016/0092-8674(95)90491-3

Bertrand, F., Esquerre, M., Petit, A. E., Rodrigues, M., Duchez, S., Delon, J., et al. (2010). Activation of the ancestral polarity regulator protein kinase C zeta at the immunological synapse drives polarization of Th cell secretory machinery toward APCs. J. Immunol. 185, 2887-2894. doi: 10.4049/jimmunol.1000739

Bertrand, F., Muller, S., Roh, K. H., Laurent, C., Dupre, L., and Valitutti, S. (2013). An initial and rapid step of lytic granule secretion precedes microtubule organizing center polarization at the cytotoxic T lymphocyte/target cell synapse. Proc. Natl. Acad. Sci. U S A. 110, 6073-6078. doi: 10.1073/pnas.1218640110

Blanchard, N., Decraene, M., Yang, K., Miro-Mur, F., Amigorena, S., and Hivroz, C. (2004). Strong and durable TCR clustering at the T/dendritic cell immune synapse is not required for NFAT activation and IFN-gamma production in 
human CD4+ T cells. J. Immunol. 173, 3062-3072. doi: 10.4049/jimmunol.173. 5.3062

Blanchard, N., Di Bartolo, V., and Hivroz, C. (2002a). In the immune synapse, ZAP-70 controls $\mathrm{T}$ cell polarization and recruitment of signaling proteins but not formation of the synaptic pattern. Immunity 17, 389-399. doi: 10.1016/ s1074-7613(02)00421-1

Blanchard, N., Lankar, D., Faure, F., Regnault, A., Dumont, C., Raposo, G., et al. (2002b). TCR activation of human T cells induces the production of exosomes bearing the TCR/CD3/zeta complex. J. Immunol. 168, 3235-3241. doi: 10.4049/ jimmunol.168.7.3235

Blumenthal, D., and Burkhardt, J. K. (2020). Multiple actin networks coordinate mechanotransduction at the immunological synapse. J. Cell Biol. 219:e201911058. doi: 10.1083/jcb.201911058

Bonello, G., Blanchard, N., Montoya, M. C., Aguado, E., Langlet, C., He, H. T., et al. (2004). Dynamic recruitment of the adaptor protein LAT: LAT exists in two distinct intracellular pools and controls its own recruitment. J. Cell Sci. 117, 1009-1016. doi: $10.1242 /$ jcs. 00968

Bouchet, J., Del Río-Iñiguez, I., Lasserre, R., Agüera-Gonzalez, S., Cuche, C., Danckaert, A., et al. (2016). Rac1-Rab11-FIP3 regulatory hub coordinates vesicle traffic with actin remodeling and T-cell activation. EMBO J. 35, 1160 1174. doi: 10.15252/embj.201593274

Bouchet, J., Del Rio-Iniguez, I., Vazquez-Chavez, E., Lasserre, R., Aguera-Gonzalez, S., Cuche, C., et al. (2017). Rab11-FIP3 Regulation of Lck Endosomal Traffic Controls TCR Signal Transduction. J. Immunol. 198, 2967-2978. doi: 10.4049/ jimmunol.1600671

Bouchet, J., Mccaffrey, M. W., Graziani, A., and Alcover, A. (2018). The functional interplay of Rab11, FIP3 and Rho proteins on the endosomal recycling pathway controls cell shape and symmetry. Small GTPases 9, 310-315. doi: 10.1080/ 21541248.2016.1224288

Boulch, M., Grandjean, C. L., Cazaux, M., and Bousso, P. (2019). Tumor Immunosurveillance and Immunotherapies: A Fresh Look from Intravital Imaging. Trends Immunol. 40, 1022-1034. doi: 10.1016/j.it.2019.09.002

Bracq, L., Xie, M., Benichou, S., and Bouchet, J. (2018). Mechanisms for Cell-toCell Transmission of HIV-1. Front. Immunol. 9:260. doi: 10.3389/fimmu.2018. 00260

Bretscher, M. S. (1996). Getting membrane flow and the cytoskeleton to cooperate in moving cells. Cell 87, 601-606. doi: 10.1016/s0092-8674(00)81380-x

Bretscher, M. S., and Aguado-Velasco, C. (1998). Membrane traffic during cell locomotion. Curr. Opin. Cell Biol. 10, 537-541. doi: 10.1016/s0955-0674(98) 80070-7

Brown, M. J., Hallam, J. A., Colucci-Guyon, E., and Shaw, S. (2001). Rigidity of circulating lymphocytes is primarily conferred by vimentin intermediate filaments. J. Immunol. 166, 6640-6646. doi: 10.4049/jimmunol.166.11.6640

Brown, M. J., Nijhara, R., Hallam, J. A., Gignac, M., Yamada, K. M., Erlandsen, S. L., et al. (2003). Chemokine stimulation of human peripheral blood T lymphocytes induces rapid dephosphorylation of ERM proteins, which facilitates loss of microvilli and polarization. Blood 102, 3890-3899. doi: 10.1182/blood-200212-3807

Bunnell, S. C., Hong, D. I., Kardon, J. R., Yamazaki, T., Mcglade, C. J., Barr, V. A., et al. (2002). T cell receptor ligation induces the formation of dynamically regulated signaling assemblies. J. Cell Biol. 158, 1263-1275. doi: 10.1083/jcb. 200203043

Bunnell, S. C., Kapoor, V., Trible, R. P., Zhang, W., and Samelson, L. E. (2001). Dynamic actin polymerization drives $\mathrm{T}$ cell receptor-induced spreading: a role for the signal transduction adaptor LAT. Immunity 14, 315-329. doi: 10.1016/ s1074-7613(01)00112-1

Byron, A., Askari, J. A., Humphries, J. D., Jacquemet, G., Koper, E. J., Warwood, S., et al. (2015). A proteomic approach reveals integrin activation state-dependent control of microtubule cortical targeting. Nat. Commun. 6:6135. doi: 10.1038/ ncomms7135

Cai, E., Marchuk, K., Beemiller, P., Beppler, C., Rubashkin, M. G., Weaver, V. M., et al. (2017). Visualizing dynamic microvillar search and stabilization during ligand detection by T cells. Science 356:eaal3118 doi: 10.1126/science.aal3118

Cairo, C. W., Mirchev, R., and David E. G. (2006). Cytoskeletal Regulation Couples LFA-1 Conformational Changes to Receptor Lateral Mobility and Clustering. Immunity 25, 297-308. doi: 10.1016/j.immuni.2006.06.012

Calabia-Linares, C., Robles-Valero, J., De La Fuente, H., Perez-Martinez, M., Martin-Cofreces, N., Alfonso-Perez, M., et al. (2011). Endosomal clathrin drives actin accumulation at the immunological synapse. J. Cell Sci. 124, 820-830. doi: $10.1242 /$ jcs.078832

Campi, G., Varma, R., and Dustin, M. L. (2005). Actin and agonist MHC-peptide complex-dependent $\mathrm{T}$ cell receptor microclusters as scaffolds for signaling. J. Exp. Med. 202, 1031-1036. doi: 10.1084/jem.20051182

Carpier, J. M., Zucchetti, A. E., Bataille, L., Dogniaux, S., Shafaq-Zadah, M., Bardin, S., et al. (2018). Rab6-dependent retrograde traffic of LAT controls immune synapse formation and T cell activation. J. Exp. Med. 215, 1245-1265 doi: 10.1084/jem.20162042

Celli, S., Garcia, Z., and Bousso, P. (2005). CD4 T cells integrate signals delivered during successive DC encounters in vivo. J. Exp. Med. 202, 1271-1278. doi: 10.1084/jem.20051018

Cenciarelli, C., Hou, D., Hsu, K. C., Rellahan, B. L., Wiest, D. L., Smith, H. T., et al. (1992). Activation-induced ubiquitination of the T cell antigen receptor. Science 257, 795-797. doi: 10.1126/science.1323144

Chae, W. J., and Bothwell, A. L. (2015). Spontaneous Intestinal Tumorigenesis in Apc (/Min+) Mice Requires Altered T Cell Development with IL-17A. J. Immunol. Res. 2015:860106. doi: 10.1155/2015/860106

Chae, W. J., Gibson, T. F., Zelterman, D., Hao, L., Henegariu, O., and Bothwell, A. L. (2010). Ablation of IL-17A abrogates progression of spontaneous intestinal tumorigenesis. Proc. Natl. Acad. Sci. U S A. 107, 5540-5544. doi: 10.1073/pnas. 0912675107

Chang, Y. C., Nalbant, P., Birkenfeld, J., Chang, Z. F., and Bokoch, G. M. (2008). GEF-H1 couples nocodazole-induced microtubule disassembly to cell contractility via RhoA. Mol. Biol. Cell 19, 2147-2153. doi: 10.1091/mbc.e0712-1269

Chauveau, A., Le Floc'h, A., Bantilan, N. S., Koretzky, G. A., and Huse, M. (2014). Diacylglycerol kinase alpha establishes $\mathrm{T}$ cell polarity by shaping diacylglycerol accumulation at the immunological synapse. Sci. Signal. 7:ra82. doi: 10.1126/ scisignal.2005287

Chemin, K., Bohineust, A., Dogniaux, S., Tourret, M., Guegan, S., Miro, F., et al. (2012). Cytokine secretion by CD4+ T cells at the immunological synapse requires Cdc42-dependent local actin remodeling but not microtubule organizing center polarity. J. Immunol. 189, 2159-2168. doi: 10.4049/ jimmunol.1200156

Choi, C. K., Vicente-Manzanares, M., Zareno, J., Whitmore, L. A., Mogilner, A., and Horwitz, A. R. (2008). Actin and alpha-actinin orchestrate the assembly and maturation of nascent adhesions in a myosin II motor-independent manner. Nat. Cell Biol. 10, 1039-1050. doi: 10.1038/ncb1763

Choudhuri, K., Llodrá, J., Roth, E. W., Tsai, J., Gordo, S., Wucherpfennig, K. W., et al. (2014). Polarized release of T-cell-receptor-enriched microvesicles at the immunological synapse. Nature 507, 118-123. doi: 10.1038/nature 12951

Combs, J., Kim, S. J., Tan, S., Ligon, L. A., Holzbaur, E. L., Kuhn, J., et al. (2006). Recruitment of dynein to the Jurkat immunological synapse. Proc. Natl. Acad. Sci. U S A. 103, 14883-14888. doi: 10.1073/pnas.0600914103

Comrie, W. A., Babich, A., and Burkhardt, J. K. (2015). F-actin flow drives affinity maturation and spatial organization of LFA-1 at the immunological synapse. J. Cell Biol. 208, 475-491. doi: 10.1083/jcb.201406121

Cordoba, S. P., Choudhuri, K., Zhang, H., Bridge, M., Basat, A. B., Dustin, M. L., et al. (2013). The large ectodomains of CD45 and CD148 regulate their segregation from and inhibition of ligated T-cell receptor. Blood 121, 4295-4302. doi: 10.1182/blood-2012-07-442251

Courtney, A. H., Lo, W. L., and Weiss, A. (2018). TCR Signaling: Mechanisms of Initiation and Propagation. Trends Biochem. Sci. 43, 108-123. doi: 10.1016/j. tibs.2017.11.008

Crespo, C. L., Vernieri, C., Keller, P. J., Garre, M., Bender, J. R., Wittbrodt, J., et al. (2014). The PAR complex controls the spatiotemporal dynamics of F-actin and the MTOC in directionally migrating leukocytes. J. Cell Sci. 127, 4381-4395. doi: $10.1242 /$ jcs. 146217

Das, V., Nal, B., Dujeancourt, A., Thoulouze, M. I., Galli, T., Roux, P., et al. (2004). Activation-induced polarized recycling targets $\mathrm{T}$ cell antigen receptors to the immunological synapse; involvement of SNARE complexes. Immunity 20, 577-588. doi: 10.1016/s1074-7613(04)00106-2

Davis, S. J., and van der Merwe, P. A. (2006). The kinetic-segregation model: TCR triggering and beyond. Nat. Immunol. 7, 803-809. doi: 10.1038/ni1369

De Meester, J., Calvez, R., Valitutti, S., and Dupre, L. (2010). The Wiskott-Aldrich syndrome protein regulates CTL cytotoxicity and is required for efficient killing 
of B cell lymphoma targets. J. Leukoc. Biol. 88, 1031-1040. doi: 10.1189/jlb. 0410197

del Pozo, M. A., Sanchez-Mateos, P., and Sanchez-Madrid, F. (1996). Cellular polarization induced by chemokines: a mechanism for leukocyte recruitment? Immunol. Today 17, 127-131. doi: 10.1016/0167-5699(96)80604-9

Del Rio-Iniguez, I., Vazquez-Chavez, E., Cuche, C., Di Bartolo, V., Bouchet, J., and Alcover, A. (2018). HIV-1 Nef Hijacks Lck and Racl Endosomal Traffic To Dually Modulate Signaling-Mediated and Actin Cytoskeleton-Mediated T Cell Functions. J. Immunol. 201, 2624-2640. doi: 10.4049/jimmunol.1800372

Delon, J., Kaibuchi, K., and Germain, R. N. (2001). Exclusion of CD43 from the immunological synapse is mediated by phosphorylation-regulated relocation of the cytoskeletal adaptor moesin. Immunity 15, 691-701. doi: 10.1016/s10747613(01)00231-x

Depoil, D., Zaru, R., Guiraud, M., Chauveau, A., Harriague, J., Bismuth, G., et al. (2005). Immunological synapses are versatile structures enabling selective $\mathrm{T}$ cell polarization. Immunity 22, 185-194. doi: 10.1016/j.immuni.2004.12.010

D’Oro, U., Munitic, I., Chacko, G., Karpova, T., Mcnally, J., and Ashwell, J. D. (2002). Regulation of constitutive TCR internalization by the zeta-chain. J. Immunol. 169, 6269-6278. doi: 10.4049/jimmunol.169.11.6269

D’Oro, U., Vacchio, M. S., Weissman, A. M., and Ashwell, J. D. (1997). Activation of the Lck tyrosine kinase targets cell surface $\mathrm{T}$ cell antigen receptors for lysosomal degradation. Immunity 7, 619-628. doi: 10.1016/s1074-7613(00)80383-0

Drevot, P., Langlet, C., Guo, X. J., Bernard, A. M., Colard, O., Chauvin, J. P., et al. (2002). TCR signal initiation machinery is pre-assembled and activated in a subset of membrane rafts. EMBO J. 21, 1899-1908. doi: 10.1093/emboj/21.8. 1899

Dupre, L., Houmadi, R., Tang, C., and Rey-Barroso, J. (2015). T Lymphocyte Migration: An Action Movie Starring the Actin and Associated Actors. Front. Immunol. 6:586. doi: 10.3389/fimmu.2015.00586

Dustin, M. L. (2008). Hunter to gatherer and back: immunological synapses and kinapses as variations on the theme of amoeboid locomotion. Annu. Rev. Cell Dev. Biol. 24, 577-596. doi: 10.1146/annurev.cellbio.24.110707.175226

Dustin, M. L., and Choudhuri, K. (2016). Signaling and Polarized Communication Across the T Cell Immunological Synapse. Annu. Rev. Cell Dev. Biol. 32, 303-325. doi: 10.1146/annurev-cellbio-100814-125330

Dustin, M. L., Bivona, T. G., and Philips, M. R. (2004). Membranes as messengers in T cell adhesion signaling. Nat. Immunol. 5, 363-372. doi: 10.1038/ni1057

Ehrlich, L. I., Ebert, P. J., Krummel, M. F., Weiss, A., and Davis, M. M. (2002). Dynamics of p561ck translocation to the T cell immunological synapse following agonist and antagonist stimulation. Immunity 17, 809-822. doi: $10.1016 /$ s1074-7613(02)00481-8

Etienne-Manneville, S. (2004). Actin and microtubules in cell motility: which one is in control? Traffic 5, 470-477. doi: 10.1111/j.1600-0854.2004.00196.x

Etienne-Manneville, S. (2013). Microtubules in cell migration. Annu. Rev. Cell Dev. Biol. 29, 471-499.

Etienne-Manneville, S. (2018). Cytoplasmic Intermediate Filaments in Cell Biology. Annu. Rev. Cell Dev. Biol. 34, 1-28. doi: 10.1146/annurev-cellbio100617-062534

Evnouchidou, I., Chappert, P., Benadda, S., Zucchetti, A., Weimershaus, M., Bens, M., et al. (2020). IRAP-dependent endosomal T cell receptor signalling is essential for T cell responses. Nat. Commun. 11:2779. doi: 10.1038/s41467-02016471-7

Ezratty, E. J., Partridge, M. A., and Gundersen, G. G. (2005). Microtubule-induced focal adhesion disassembly is mediated by dynamin and focal adhesion kinase. Nat. Cell Biol. 7, 581-590. doi: 10.1038/ncb1262

Fabbri, M., Di Meglio, S., Gagliani, M. C., Consonni, E., Molteni, R., Bender, J. R., et al. (2005). Dynamic partitioning into lipid rafts controls the endo-exocytic cycle of the alphaL/beta2 integrin, LFA-1, during leukocyte chemotaxis. Mol. Biol. Cell 16, 5793-5803. doi: 10.1091/mbc.e05-05-0413

Fackler, O. T., Alcover, A., and Schwartz, O. (2007). Modulation of the immunological synapse: a key to HIV-1 pathogenesis? Nat. Rev. Immunol. 7 , 310-317. doi: 10.1038/nri2041

Fackler, O. T., Lu, X., Frost, J. A., Geyer, M., Jiang, B., Luo, W., et al. (2000). p21activated kinase 1 plays a critical role in cellular activation by Nef. Mol. Cell Biol. 20, 2619-2627. doi: 10.1128/mcb.20.7.2619-2627.2000

Fackler, O. T., Luo, W., Geyer, M., Alberts, A. S., and Peterlin, B. M. (1999). Activation of Vav by Nef induces cytoskeletal rearrangements and downstream effector functions. Mol. Cell 3, 729-739. doi: 10.1016/s1097-2765(01)80005-8
Faroudi, M., Utzny, C., Salio, M., Cerundolo, V., Guiraud, M., Muller, S., et al. (2003). Lytic versus stimulatory synapse in cytotoxic T lymphocyte/target cell interaction: manifestation of a dual activation threshold. Proc. Natl. Acad. Sci. US A. 100, 14145-14150. doi: 10.1073/pnas.2334336100

Faure, S., Salazar-Fontana, L. I., Semichon, M., Tybulewicz, V. L., Bismuth, G., Trautmann, A., et al. (2004). ERM proteins regulate cytoskeleton relaxation promoting T cell-APC conjugation. Nat. Immunol. 5, 272-279. doi: 10.1038/ ni1039

Finco, T. S., Kadlecek, T., Zhang, W., Samelson, L. E., and Weiss, A. (1998). LAT is required for TCR-mediated activation of PLCgammal and the Ras pathway. Immunity 9, 617-626. doi: 10.1016/s1074-7613(00)80659-7

Finetti, F., Paccani, S. R., Riparbelli, M. G., Giacomello, E., Perinetti, G., Pazour, G. J., et al. (2009). Intraflagellar transport is required for polarized recycling of the TCR/CD3 complex to the immune synapse. Nat. Cell Biol. 11, 1332-1339. doi: $10.1038 /$ ncb 1977

Finetti, F., Patrussi, L., Galgano, D., Cassioli, C., Perinetti, G., Pazour, G. J., et al. (2015). The small GTPase Rab8 interacts with VAMP-3 to regulate the delivery of recycling T-cell receptors to the immune synapse. J. Cell Sci. 128, 2541-2552. doi: $10.1242 /$ jcs. 171652

Fooksman, D. R., Vardhana, S., Vasiliver-Shamis, G., Liese, J., Blair, D. A., Waite, J., et al. (2010). Functional anatomy of T cell activation and synapse formation. Annu. Rev. Immunol. 28, 79-105. doi: 10.1146/annurev-immunol-030409101308

Garcia-Ortiz, A., and Serrador, J. M. (2020). ERM Proteins at the Crossroad of Leukocyte Polarization, Migration and Intercellular Adhesion. Int. J. Mol. Sci. 21:1502 doi: 10.3390/ijms21041502

Garcia-Ortiz, A., Martin-Cofreces, N. B., Ibiza, S., Ortega, A., IzquierdoAlvarez, A., Trullo, A., et al. (2017). eNOS S-nitrosylates beta-actin on Cys374 and regulates PKC-theta at the immune synapse by impairing actin binding to profilin-1. PLoS Biol. 15:e2000653. doi: 10.1371/journal.pbio.200 0653

Gawden-Bone, C. M., Frazer, G. L., Richard, A. C., Ma, C. Y., Strege, K., and Griffiths, G. M. (2018). PIP5 Kinases Regulate Membrane Phosphoinositide and Actin Composition for Targeted Granule Secretion by Cytotoxic Lymphocytes. Immunity 49, 427-437 e. doi: 10.1016/j.immuni.2018. 08.017

Geiger, B., Rosen, D., and Berke, G. (1982). Spatial relationships of microtubuleorganizing centers and the contact area of cytotoxic $\mathrm{T}$ lymphocytes and target cells. J. Cell Biol. 95, 137-143. doi: 10.1083/jcb.95.1.137

Ghosh, S., Di Bartolo, V., Tubul, L., Shimoni, E., Kartvelishvily, E., Dadosh, T., et al. (2020). ERM-Dependent Assembly of T Cell Receptor Signaling and Costimulatory Molecules on Microvilli prior to Activation. Cell Rep. 30, 3434-3447 e. doi: 10.1016/j.celrep.2020.02.069

Gomez, T. S., Hamann, M. J., Mccarney, S., Savoy, D. N., Lubking, C. M., Heldebrant, M. P., et al. (2005). Dynamin 2 regulates T cell activation by controlling actin polymerization at the immunological synapse. Nat. Immunol. 6, 261-270. doi: 10.1038/ni1168

Gomez, T. S., Kumar, K., Medeiros, R. B., Shimizu, Y., Leibson, P. J., and Billadeau, D. D. (2007). Formins regulate the actin-related protein $2 / 3$ complex-independent polarization of the centrosome to the immunological synapse. Immunity 26, 177-190. doi: 10.1016/j.immuni.2007. 01.008

Gomez, T. S., Mccarney, S. D., Carrizosa, E., Labno, C. M., Comiskey, E. O., Nolz, J. C., et al. (2006). HS1 functions as an essential actin-regulatory adaptor protein at the immune synapse. Immunity 24, 741-752. doi: 10.1016/j.immuni.2006.03. 022

Gomez-Mouton, C., Abad, J. L., Mira, E., Lacalle, R. A., Gallardo, E., JimenezBaranda, S., et al. (2001). Segregation of leading-edge and uropod components into specific lipid rafts during T cell polarization. Proc. Natl. Acad. Sci. U S A. 98, 9642-9647. doi: 10.1073/pnas.171160298

Gonzalez-Granado, J. M., Silvestre-Roig, C., Rocha-Perugini, V., Trigueros-Motos, L., Cibrian, D., Morlino, G., et al. (2014). Nuclear envelope lamin-a couples actin dynamics with immunological synapse architecture and $\mathrm{T}$ cell activation. Sci. Signal 7:ra37. doi: 10.1126/scisignal.2004872

Gorska, M. M., Liang, Q., Karim, Z., and Alam, R. (2009). Uncoordinated 119 protein controls trafficking of Lck via the Rab11 endosome and is critical for immunological synapse formation. J. Immunol. 183, 1675-1684. doi: 10.4049/ jimmunol.0900792 
Gorska, M. M., Stafford, S. J., Cen, O., Sur, S., and Alam, R. (2004). Unc119, a novel activator of Lck/Fyn, is essential for T cell activation. J. Exp. Med. 199, 369-379. doi: 10.1084/jem.20030589

Gounari, F., Chang, R., Cowan, J., Guo, Z., Dose, M., Gounaris, E., et al. (2005). Loss of adenomatous polyposis coli gene function disrupts thymic development. Nat. Immunol. 6, 800-809. doi: 10.1038/ni1228

Gounaris, E., Blatner, N. R., Dennis, K., Magnusson, F., Gurish, M. F., Strom, T. B., et al. (2009). T-regulatory cells shift from a protective anti-inflammatory to a cancer-promoting proinflammatory phenotype in polyposis. Cancer Res. 69, 5490-5497. doi: 10.1158/0008-5472.can-09-0304

Grakoui, A., Bromley, S. K., Sumen, C., Davis, M. M., Shaw, A. S., Allen, P. M., et al. (1999). The immunological synapse: a molecular machine controlling $\mathrm{T}$ cell activation. Science 285, 221-227. doi: 10.1126/science.285.5425.221

Griffiths, G. M., Tsun, A., and Stinchcombe, J. C. (2010). The immunological synapse: a focal point for endocytosis and exocytosis. J. Cell Biol. 189, 399-406. doi: $10.1083 /$ jcb. 201002027

Grigoriev, I., Gouveia, S. M., Van Der Vaart, B., Demmers, J., Smyth, J. T., Honnappa, S., et al. (2008). STIM1 is a MT-plus-end-tracking protein involved in remodeling of the ER. Curr. Biol. 18, 177-182. doi: 10.1016/j.cub.2007.12.050

Gwack, Y., Sharma, S., Nardone, J., Tanasa, B., Iuga, A., Srikanth, S., et al. (2006). A genome-wide Drosophila RNAi screen identifies DYRK-family kinases as regulators of NFAT. Nature 441, 646-650. doi: 10.1038/nature04631

Haller, C., Rauch, S., Michel, N., Hannemann, S., Lehmann, M. J., Keppler, O. T., et al. (2006). The HIV-1 pathogenicity factor Nef interferes with maturation of stimulatory T-lymphocyte contacts by modulation of N-Wasp activity. J. Biol. Chem. 281, 19618-19630. doi: 10.1074/jbc.m513802200

Hao, J. J., Liu, Y., Kruhlak, M., Debell, K. E., Rellahan, B. L., and Shaw, S. (2009). Phospholipase C-mediated hydrolysis of PIP2 releases ERM proteins from lymphocyte membrane. J. Cell Biol. 184, 451-462. doi: 10.1083/jcb.200807047

Hashimoto-Tane, A., Sakuma, M., Ike, H., Yokosuka, T., Kimura, Y., Ohara, O., et al. (2016). Micro-adhesion rings surrounding TCR microclusters are essential for T cell activation. J. Exp. Med. 213, 1609-1625. doi: 10.1084/jem.20151088

Hashimoto-Tane, A., Yokosuka, T., Sakata-Sogawa, K., Sakuma, M., Ishihara, C., Tokunaga, M., et al. (2011). Dynein-driven transport of T cell receptor microclusters regulates immune synapse formation and $\mathrm{T}$ cell activation. Immunity 34, 919-931. doi: 10.1016/j.immuni.2011.05.012

Hivroz, C., Chemin, K., Tourret, M., and Bohineust, A. (2012). Crosstalk between T lymphocytes and dendritic cells. Crit. Rev. Immunol. 32, 139-155. doi: 10. 1615/critrevimmunol.v32.i2.30

Hoekstra, M. E., Bornes, L., Dijkgraaf, F. E., Philips, D., Pardieck, I. N., Toebes, M., et al. (2020). Long-distance modulation of bystander tumor cells by CD8(+) T cell-secreted IFNgamma. Nat. Cancer 1, 291-301. doi: 10.1038/s43018-0200036- 4

Hogan, P. G., Chen, L., Nardone, J., and Rao, A. (2003). Transcriptional regulation by calcium, calcineurin, and NFAT. Genes Dev. 17, 2205-2232. doi: 10.1101/ gad. 1102703

Hogg, N., Laschinger, M., Giles, K., and Mcdowall, A. (2003). T-cell integrins: more than just sticking points. J. Cell Sci. 116, 4695-4705. doi: 10.1242/jcs.00876

Horgan, C. P., and McCaffrey, M. W. (2009). The dynamic Rab11-FIPs. Biochem. Soc. Trans. 37, 1032-1036. doi: 10.1042/bst0371032

Houmadi, R., Guipouy, D., Rey-Barroso, J., Vasconcelos, Z., Cornet, J., Manghi, M., et al. (2018). The Wiskott-Aldrich Syndrome Protein Contributes to the Assembly of the LFA-1 Nanocluster Belt at the Lytic Synapse. Cell Rep. 22, 979-991. doi: 10.1016/j.celrep.2017.12.088

Huang, H., Jeon, M. S., Liao, L., Yang, C., Elly, C., Yates, J. R., 3rd., et al. (2010). K33-linked polyubiquitination of $\mathrm{T}$ cell receptor-zeta regulates proteolysisindependent T cell signaling. Immunity 33, 60-70. doi: 10.1016/j.immuni.2010. 07.002

Hui, K. L., and Upadhyaya, A. (2017). Dynamic microtubules regulate cellular contractility during T-cell activation. Proc. Natl. Acad. Sci. U S A. 114, E4175E4183. doi: 10.1073/pnas.1614291114

Humphries, L. A., Shaffer, M. H., Sacirbegovic, F., Tomassian, T., Mcmahon, K. A., Humbert, P. O., et al. (2012). Characterization of in vivo Dlg1 deletion on T cell development and function. PLoS One 7:e45276. doi: 10.1371/journal.pone. 0045276

Huse, M., Lillemeier, B. F., Kuhns, M. S., Chen, D. S., and Davis, M. M. (2006). $\mathrm{T}$ cells use two directionally distinct pathways for cytokine secretion. Nat. Immunol. 7, 247-255. doi: 10.1038/ni1304
Husson, J., Chemin, K., Bohineust, A., Hivroz, C., and Henry, N. (2011). Force generation upon T cell receptor engagement. PLoS One 6:e19680. doi: 10.1371/ journal.pone.0019680

Hyun, Y. M., Chung, H. L., Mcgrath, J. L., Waugh, R. E., and Kim, M. (2009). Activated integrin VLA-4 localizes to the lamellipodia and mediates T cell migration on VCAM-1. J. Immunol. 183, 359-369. doi: 10.4049/jimmunol. 0803388

Iida, T., Ohno, H., Nakaseko, C., Sakuma, M., Takeda-Ezaki, M., Arase, H., et al. (2000). Regulation of cell surface expression of CTLA-4 by secretion of CTLA4-containing lysosomes upon activation of CD4+ T cells. J. Immunol. 165, 5062-5068. doi: 10.4049/jimmunol.165.9.5062

Ilani, T., Vasiliver-Shamis, G., Vardhana, S., Bretscher, A., and Dustin, M. L. (2009). $\mathrm{T}$ cell antigen receptor signaling and immunological synapse stability require myosin IIA. Nat. Immunol. 10, 531-539. doi: 10.1038/ni.1723

Ishiguro, K., Ando, T., Maeda, O., Watanabe, O., and Goto, H. (2011). Cutting edge: tubulin alpha functions as an adaptor in NFAT-importin beta interaction. J. Immunol. 186, 2710-2713. doi: 10.4049/jimmunol.1003322

Ishii, K., Hirose, K., and Iino, M. (2006). Ca2+ shuttling between endoplasmic reticulum and mitochondria underlying Ca2+ oscillations. EMBO Rep. 7, 390396. doi: 10.1038/sj.embor.7400620

Itoh, K., Sakakibara, M., Yamasaki, S., Takeuchi, A., Arase, H., Miyazaki, M., et al. (2002). Cutting edge: negative regulation of immune synapse formation by anchoring lipid raft to cytoskeleton through Cbp-EBP50-ERM assembly. J. Immunol. 168, 541-544. doi: 10.4049/jimmunol.168.2.541

Ivanova, E., and Carpino, N. (2016). Negative regulation of TCR signaling by ubiquitination of Zap-70 Lys-217. Mol. Immunol. 73, 19-28. doi: 10.1016/j. molimm.2016.03.006

Iwashima, M., Irving, B. A., Van Oers, N. S., Chan, A. C., and Weiss, A. (1994). Sequential interactions of the TCR with two distinct cytoplasmic tyrosine kinases. Science 263, 1136-1139. doi: 10.1126/science.7509083

Jankowska, K. I., Williamson, E. K., Roy, N. H., Blumenthal, D., Chandra, V., Baumgart, T., et al. (2018). Integrins Modulate T Cell Receptor Signaling by Constraining Actin Flow at the Immunological Synapse. Front. Immunol. 9:25. doi: 10.3389/fimmu.2018.00025

Jimbo, T., Kawasaki, Y., Koyama, R., Sato, R., Takada, S., Haraguchi, K., et al. (2002). Identification of a link between the tumour suppressor APC and the kinesin superfamily. Nat. Cell Biol. 4, 323-327. doi: 10.1038/ ncb779

Jung, Y., Riven, I., Feigelson, S. W., Kartvelishvily, E., Tohya, K., Miyasaka, M., et al. (2016). Three-dimensional localization of T-cell receptors in relation to microvilli using a combination of superresolution microscopies. Proc. Natl. Acad. Sci. U S A. 113, E5916-E5924. doi: 10.1073/pnas.160539 9113

Juzans, M., Cuche, C., Rose, T., Mastrogiovanni, M., Di Bartolo, V., and Alcover, A. (2020). Adenomatous polyposis coli modulates actin and micortubule cytoskeleton at the immunological synapse to tune CTL functions. Immuno. Horizons 4, 1-20. doi: 10.4049/immunohorizons.2000044

Kabanova, A., Sanseviero, F., Candi, V., Gamberucci, A., Gozzetti, A., Campoccia, G., et al. (2016). Human Cytotoxic T Lymphocytes Form Dysfunctional Immune Synapses with B Cells Characterized by Non-Polarized Lytic Granule Release. Cell Rep. 15, 9-18. doi: 10.1016/j.celrep.2016.02.084

Kaizuka, Y., Douglass, A. D., Varma, R., Dustin, M. L., and Vale, R. D. (2007). Mechanisms for segregating $\mathrm{T}$ cell receptor and adhesion molecules during immunological synapse formation in Jurkat T cells. Proc. Natl. Acad. Sci. U S A. 104, 20296-20301. doi: 10.1073/pnas.0710258105

Kaverina, I., and Straube, A. (2011). Regulation of cell migration by dynamic microtubules. Semin. Cell Dev. Biol. 22, 968-974. doi: 10.1016/j.semcdb.2011. 09.017

Kaverina, I., Rottner, K., and Small, J. V. (1998). Targeting, capture, and stabilization of microtubules at early focal adhesions. J. Cell Biol. 142, 181-190. doi: $10.1083 /$ jcb.142.1.181

Kawasaki, Y., Senda, T., Ishidate, T., Koyama, R., Morishita, T., Iwayama, Y., et al. (2000). Asef, a link between the tumor suppressor APC and G-protein signaling. Science 289, 1194-1197. doi: 10.1126/science.289.5482.1194

Kim, H. R., Mun, Y., Lee, K. S., Park, Y. J., Park, J. S., Park, J. H., et al. (2018). $\mathrm{T}$ cell microvilli constitute immunological synaptosomes that carry messages to antigen-presenting cells. Nat. Commun. 9:3630. doi: 10.1038/s41467-01806090-8 
Kim, M., Carman, C. V., Yang, W., Salas, A., and Springer, T. A. (2004). The primacy of affinity over clustering in regulation of adhesiveness of the integrin \{alpha\}L $\{$ beta\}2. J. Cell Biol. 167, 1241-1253. doi: 10.1083/jcb.200404160

Koduru, S., Kumar, L., Massaad, M. J., Ramesh, N., Le Bras, S., Ozcan, E., et al. (2010). Cdc42 interacting protein 4 (CIP4) is essential for integrin-dependent T-cell trafficking. Proc. Natl. Acad. Sci. U S A. 107, 16252-16256. doi: 10.1073/ pnas. 1002747107

Krummel, M. F., and Macara, I. (2006). Maintenance and modulation of T cell polarity. Nat. Immunol. 7, 1143-1149. doi: 10.1038/ni1404

Kuhn, J. R., and Poenie, M. (2002). Dynamic polarization of the microtubule cytoskeleton during CTL-mediated killing. Immunity 16, 111-121. doi: 10 . 1016/s1074-7613(02)00262-5

Kuhné, M. R., Lin, J., Yablonski, D., Mollenauer, M. N., Ehrlich, L. I. R., Huppa, J. B., et al. (2003). Linker for activation of T cells, zeta-associated protein-70 and Src homology 2 domain-containing leukocyte protein-76 are required for TCRinduced microtubule-organizing center polarization. J. Immunol. 171, 860-866. doi: 10.4049/jimmunol.171.2.860

Kumari, S., Depoil, D., Martinelli, R., Judokusumo, E., Carmona, G., Gertler, F. B., et al. (2015). Actin foci facilitate activation of the phospholipase C-gamma in primary T lymphocytes via the WASP pathway. Elife 4:e04953. doi: 10.7554/ eLife.04953

Kumari, S., Vardhana, S., Cammer, M., Curado, S., Santos, L., Sheetz, M. P., et al. (2012). T Lymphocyte Myosin IIA is Required for Maturation of the Immunological Synapse. Front. Immunol 3:230. doi: 10.3389/fimmu.2012. 00230

Kupfer, A., and Dennert, G. (1984). Reorientation of the microtubule-organizing center and the Golgi apparatus in cloned cytotoxic lymphocytes triggered by binding to lysable target cells. J. Immunol. 133, 2762-2766.

Kupfer, A., Mosmann, T. R., and Kupfer, H. (1991). Polarized expression of cytokines in cell conjugates of helper T cells and splenic B cells. Proc. Natl. Acad. Sci. US A. 88, 775-779. doi: 10.1073/pnas.88.3.775

Kupfer, A., Swain, S. L., Janeway, C. A., Jr., and Singer, S. J. (1986). The specific direct interaction of helper T cells and antigen-presenting B cells. Proc. Natl. Acad. Sci. U S A. 83, 6080-6083. doi: 10.1073/pnas.83.16.6080

Kupfer, H., Monks, C. R. F., and Kupfer, A. (1994). Small splenic B cells that bind to antigen-specific T helper (Th) cells and face the site of cytokine production in the Th cells selectively proliferate: immunofluorescence microscopic studies of Th-B antigen-presenting cell interactions. J. Exp. Med. 179, 1507-1515. doi: 10.1084/jem.179.5.1507

Kurowska, M., Goudin, N., Nehme, N. T., Court, M., Garin, J., Fischer, A., et al. (2012). Terminal transport of lytic granules to the immune synapse is mediated by the kinesin-1/Slp3/Rab27a complex. Blood 119, 3879-3889. doi: 10.1182/ blood-2011-09-382556

Larghi, P., Williamson, D. J., Carpier, J. M., Dogniaux, S., Chemin, K., Bohineust, A., et al. (2013). VAMP7 controls T cell activation by regulating the recruitment and phosphorylation of vesicular Lat at TCR-activation sites. Nat. Immunol. 14, 723-731. doi: 10.1038/ni.2609

Lassen, L. B., Fuchtbauer, A., Schmitz, A., Sorensen, A. B., Pedersen, F. S., and Fuchtbauer, E. M. (2013). Septin9 is involved in T-cell development and CD8+ T-cell homeostasis. Cell Tissue Res. 352, 695-705. doi: 10.1007/s00441-0131618-6

Lasserre, R., and Alcover, A. (2010). Cytoskeletal cross-talk in the control of T cell antigen receptor signaling. FEBS Lett. 584, 4845-4850. doi: 10.1016/j.febslet. 2010.09.001

Lasserre, R., Charrin, S., Cuche, C., Danckaert, A., Thoulouze, M. I., De Chaumont, F., et al. (2010). Ezrin tunes T-cell activation by controlling Dlg1 and microtubule positioning at the immunological synapse. EMBO J. 29, 2301-2314. doi: 10.1038/emboj.2010.127

Lasserre, R., Cuche, C., Blecher-Gonen, R., Libman, E., Biquand, E., Danckaert, A., et al. (2011). Release of serine/threonine-phosphorylated adaptors from signaling microclusters down-regulates T cell activation. J. Cell Biol. 195, 839-853. doi: $10.1083 /$ jcb.201103105

Lauffenburger, D. A., and Horwitz, A. F. (1996). Cell migration: a physically integrated molecular process. Cell 84, 359-369. doi: 10.1016/s0092-8674(00) 81280-5

Le Floc'h, A., Tanaka, Y., Bantilan, N. S., Voisinne, G., Altan-Bonnet, G., Fukui, Y., et al. (2013). Annular PIP3 accumulation controls actin architecture and modulates cytotoxicity at the immunological synapse. J. Exp. Med. 210, 27212737. doi: 10.1084/jem.20131324

Lee, J. H., Katakai, T., Hara, T., Gonda, H., Sugai, M., and Shimizu, A. (2004). Roles of p-ERM and Rho-ROCK signaling in lymphocyte polarity and uropod formation. J. Cell Biol. 167, 327-337. doi: 10.1083/jcb.20040 3091

Lee, K. H., Dinner, A. R., Tu, C., Campi, G., Raychaudhuri, S., Varma, R., et al. (2003). The immunological synapse balances $\mathrm{T}$ cell receptor signaling and degradation. Science 302, 1218-1222. doi: 10.1126/science.1086507

Lee, K. H., Holdorf, A. D., Dustin, M. L., Chan, A. C., Allen, P. M., and Shaw, A. S. (2002). T cell receptor signaling precedes immunological synapse formation. Science 295, 1539-1542. doi: 10.1126/science.1067710

Lehmann, M., Nikolic, D. S., and Piguet, V. (2011). How HIV-1 takes advantage of the cytoskeleton during replication and cell-to-cell transmission. Viruses 3, 1757-1776. doi: 10.3390/v3091757

Leitinger, B., and Hogg, N. (2002). The involvement of lipid rafts in the regulation of integrin function. J. Cell Sci. 115, 963-972.

Lesko, A. C., Goss, K. H., and Prosperi, J. R. (2014). Exploiting APC function as a novel cancer therapy. Curr. Drug Targets 15, 90-102. doi: 10.2174/ 1389450114666131108155418

Liao, G. J., Nagasaki, T., and Gundersen, G. G. (1995). Low Concentrations of Nocodazole Interfere with Fibroblast Locomotion without Significantly Affecting Microtubule Level - Implications for the Role of Dynamic Microtubules in Cell Locomotion. J. Cell Sci. 108, 3473-3483.

Lillemeier, B. F., Mortelmaier, M. A., Forstner, M. B., Huppa, J. B., Groves, J. T., and Davis, M. M. (2010). TCR and Lat are expressed on separate protein islands on $\mathrm{T}$ cell membranes and concatenate during activation. Nat. Immunol. 11, 90-96. doi: 10.1038/ni.1832

Lillemeier, B. F., Pfeiffer, J. R., Surviladze, Z., Wilson, B. S., and Davis, M. M. (2006). Plasma membrane-associated proteins are clustered into islands attached to the cytoskeleton. Proc. Natl. Acad. Sci. U S A. 103, 18992-18997.

Linsley, P. S., Bradshaw, J., Greene, J., Peach, R., Bennett, K. L., and Mittler, R. S. (1996). Intracellular trafficking of CTLA-4 and focal localization towards sites of TCR engagement. Immunity 4, 535-543. doi: 10.1016/s1074-7613(00) 80480-X

Liu, X., Kapoor, T. M., Chen, J. K., and Huse, M. (2013). Diacylglycerol promotes centrosome polarization in $\mathrm{T}$ cells via reciprocal localization of dynein and myosin II. Proc. Natl. Acad. Sci. U S A. 110, 11976-11981. doi: 10.1073/pnas. 1306180110

Lowin-Kropf, B., Shapiro, V. S., and Weiss, A. (1998). Cytoskeletal polarization of $\mathrm{T}$ cells is regulated by an immunoreceptor tyrosine-based activation motifdependent mechanism. J. Cell Biol. 140, 861-871. doi: 10.1083/jcb.140.4.861

Ludford-Menting, M. J., Oliaro, J., Sacirbegovic, F., Cheah, E. T., Pedersen, N., Thomas, S. J., et al. (2005). A network of PDZ-containing proteins regulates $\mathrm{T}$ cell polarity and morphology during migration and immunological synapse formation. Immunity 22, 737-748. doi: 10.1016/j.immuni.2005.04.009

Luo, B. H., Carman, C. V., Takagi, J., and Springer, T. A. (2005). Disrupting integrin transmembrane domain heterodimerization increases ligand binding affinity, not valency or clustering. Proc. Natl. Acad. Sci. U S A. 102, 3679-3684. doi: 10.1073/pnas.0409440102

Luton, F., Legendre, V., Gorvel, J. P., Schmitt-Verhulst, A. M., and Boyer, C. (1997). Tyrosine and serine protein kinase activities associated with ligand-induced internalized TCR/CD3 complexes. J. Immunol. 158, 3140-3147.

Lyakh, L., Ghosh, P., and Rice, N. R. (1997). Expression of NFAT-family proteins in normal human T cells. Mol. Cell Biol. 17, 2475-2484. doi: $10.1128 / \mathrm{mcb} .17 .5$. 2475

Macian, F., Lopez-Rodriguez, C., and Rao, A. (2001). Partners in transcription: NFAT and AP-1. Oncogene 20, 2476-2489. doi: 10.1038/sj.onc. 1204386

Mackenzie, G. G., and Oteiza, P. I. (2007). Zinc and the cytoskeleton in the neuronal modulation of transcription factor NFAT. J. Cell Physiol. 210, 246-256. doi: 10.1002/jcp.20861

Maiuri, P., Rupprecht, J. F., Wieser, S., Ruprecht, V., Bénichou, O., Carpi, N., et al. (2015). Actin flows mediate a universal coupling between cell speed and cell persistence. Cell 161, 374-386. doi: 10.1016/j.cell.2015.01.056

Manes, S., and Viola, A. (2006). Lipid rafts in lymphocyte activation and migration. Mol. Membr. Biol. 23, 59-69. doi: 10.1080/09687860500430069 
Markle, T. J., Philip, M., and Brockman, M. A. (2013). HIV-1 Nef and T-cell activation: a history of contradictions. Future Virol. 8:fvl.2213. doi: 10.2217/fvl. 13.20

Martin-Belmonte, F., Martinez-Menarguez, J. A., Aranda, F. J., Ballesta, J., De Marco, M. C., and Alonso, M. A. (2003). MAL regulates clathrin-mediated endocytosis at the apical surface of Madin-Darby canine kidney cells. J. Cell Biol. 163, 155-164. doi: 10.1083/jcb.200304053

Martin-Cofreces, N. B., and Sanchez-Madrid, F. (2018). Sailing to and Docking at the Immune Synapse: Role of Tubulin Dynamics and Molecular Motors. Front. Immunol. 9:1174. doi: 10.3389/fimmu.2018.01174

Martin-Cofreces, N. B., Baixauli, F., Lopez, M. J., Gil, D., Monjas, A., Alarcon, B., et al. (2012). End-binding protein 1 controls signal propagation from the $\mathrm{T}$ cell receptor. EMBO J. 31, 4140-4152. doi: 10.1038/emboj.2012.242

Martin-Cofreces, N. B., Robles-Valero, J., Cabrero, J. R., Mittelbrunn, M., GordonAlonso, M., Sung, C. H., et al. (2008). MTOC translocation modulates IS formation and controls sustained T cell signaling. J. Cell Biol. 182, 951-962. doi: $10.1083 /$ jcb. 200801014

Martinelli, S., Chen, E. J., Clarke, F., Lyck, R., Affentranger, S., Burkhardt, J. K., et al. (2013). Ezrin/Radixin/Moesin proteins and flotillins cooperate to promote uropod formation in T cells. Front. Immunol. 4:84. doi: 10.3389/fimmu.2013. 00084

Martinez, G. J., Pereira, R. M., Aijo, T., Kim, E. Y., Marangoni, F., Pipkin, M. E., et al. (2015). The transcription factor NFAT promotes exhaustion of activated CD8(+) T cells. Immunity 42, 265-278. doi: 10.1016/j.immuni.2015.01.006

Mayya, V., Judokusumo, E., Abu Shah, E., Peel, C. G., Neiswanger, W., Depoil, D., et al. (2018). Durable Interactions of T Cells with T Cell Receptor Stimuli in the Absence of a Stable Immunological Synapse. Cell Rep. 22, 340-349. doi: 10.1016/j.celrep.2017.12.052

McDonald-Hyman, C., Muller, J. T., Loschi, M., Thangavelu, G., Saha, A., Kumari, S., et al. (2018). The vimentin intermediate filament network restrains regulatory $\mathrm{T}$ cell suppression of graft-versus-host disease. J. Clin. Invest. 128, 4604-4621. doi: 10.1172/jci95713

Meiri, D., Marshall, C. B., Greeve, M. A., Kim, B., Balan, M., Suarez, F., et al. (2012). Mechanistic Insight into the Microtubule and Actin Cytoskeleton Coupling through Dynein-Dependent RhoGEF Inhibition. Mole. Cell 45, 642-655. doi: 10.1016/j.molcel.2012.01.027

Mittelbrunn, M., Gutierrez-Vazquez, C., Villarroya-Beltri, C., Gonzalez, S., Sanchez-Cabo, F., Gonzalez, M. A., et al. (2011). Unidirectional transfer of microRNA-loaded exosomes from $\mathrm{T}$ cells to antigen-presenting cells. Nat. Commun. 2:282. doi: 10.1038/ncomms 1285

Monks, C. R., Freiberg, B. A., Kupfer, H., Sciaky, N., and Kupfer, A. (1998). Threedimensional segregation of supramolecular activation clusters in T cells. Nature 395, 82-86. doi: 10.1038/25764

Monticelli, S., Solymar, D. C., and Rao, A. (2004). Role of NFAT proteins in IL13 gene transcription in mast cells. J. Biol. Chem. 279, 36210-36218. doi: 10.1074/jbc.m406354200

Morales-Tirado, V., Johannson, S., Hanson, E., Howell, A., Zhang, J., Siminovitch, K. A., et al. (2004). Cutting edge: selective requirement for the Wiskott-Aldrich syndrome protein in cytokine, but not chemokine, secretion by CD4+ T cells. J. Immunol. 173, 726-730. doi: 10.4049/jimmunol.173.2.726

Moreau, H. D., Lemaitre, F., Garrod, K. R., Garcia, Z., Lennon-Dumenil, A. M., and Bousso, P. (2015). Signal strength regulates antigen-mediated T-cell deceleration by distinct mechanisms to promote local exploration or arrest. Proc. Natl. Acad. Sci. U S A. 112, 12151-12156. doi: 10.1073/pnas.1506654112

Moreau, H. D., Lemaitre, F., Terriac, E., Azar, G., Piel, M., Lennon-Dumenil, A. M., et al. (2012). Dynamic in situ cytometry uncovers $\mathrm{T}$ cell receptor signaling during immunological synapses and kinapses in vivo. Immunity 37, 351-363. doi: 10.1016/j.immuni.2012.05.014

Moreau, H. D., Piel, M., Voituriez, R., and Lennon-Dumenil, A. M. (2018). Integrating Physical and Molecular Insights on Immune Cell Migration. Trends Immunol. 39, 632-643. doi: 10.1016/j.it.2018.04.007

Moseley, J. B., Bartolini, F., Okada, K., Wen, Y., Gundersen, G. G., and Goode, B. L. (2007). Regulated binding of adenomatous polyposis coli protein to actin. J. Biol. Chem. 282, 12661-12668. doi: 10.1074/jbc.m61061 5200

Mossman, K. D., Campi, G., Groves, J. T., and Dustin, M. L. (2005). Altered TCR signaling from geometrically repatterned immunological synapses. Science 310, 1191-1193. doi: $10.1126 /$ science. 1119238
Mostowy, S., and Cossart, P. (2012). Septins: the fourth component of the cytoskeleton. Nat. Rev. Mol. Cell Biol. 13, 183-194. doi: 10.1038/nrm3284

Mujal, A. M., Gilden, J. K., Gerard, A., Kinoshita, M., and Krummel, M. F. (2016). A septin requirement differentiates autonomous and contact-facilitated $\mathrm{T}$ cell proliferation. Nat. Immunol. 17, 315-322. doi: 10.1038/ni.3330

Muller, M. R., and Rao, A. (2010). NFAT, immunity and cancer: a transcription factor comes of age. Nat. Rev. Immunol. 10, 645-656. doi: 10.1038/nri2818

Munemitsu, S., Souza, B., Muller, O., Albert, I., Rubinfeld, B., and Polakis, P. (1994). The Apc Gene-Product Associates with Microtubules in-Vivo and Promotes Their Assembly in-Vitro. Cancer Res. 54, 3676-3681.

Murugesan, S., Hong, J., Yi, J., Li, D., Beach, J. R., Shao, L., et al. (2016). Formingenerated actomyosin arcs propel $\mathrm{T}$ cell receptor microcluster movement at the immune synapse. J. Cell Biol. 215, 383-399. doi: 10.1083/jcb.201603080

Nakamura, M., Zhou, X. Z., and Lu, K. P. (2001). Critical role for the EB1 and APC interaction in the regulation of microtubule polymerization. Curr. Biol. 11, 1062-1067. doi: 10.1016/s0960-9822(01)00297-4

Nelson, S., and Nathke, I. S. (2013). Interactions and functions of the adenomatous polyposis coli (APC) protein at a glance. J. Cell Sci. 126, 873-877. doi: 10.1242/ jcs.100479

Nguyen, K., Sylvain, N. R., and Bunnell, S. C. (2008). T cell costimulation via the integrin VLA-4 inhibits the actin-dependent centralization of signaling microclusters containing the adaptor SLP-76. Immunity 28, 810-821. doi: 10.1016/j.immuni.2008.04.019

Nicolson, G. L. (2014). The Fluid-Mosaic Model of Membrane Structure: still relevant to understanding the structure, function and dynamics of biological membranes after more than 40 years. Biochim. Biophys. Acta 1838, 1451-1466. doi: 10.1016/j.bbamem.2013.10.019

Niedergang, F., Di Bartolo, V., and Alcover, A. (2016). Comparative Anatomy of Phagocytic and Immunological Synapses. Front. Immunol. 7:18. doi: 10.3389/ fimmu.2016.00018

Nieminen, M., Henttinen, T., Merinen, M., Marttila-Ichihara, F., Eriksson, J. E., and Jalkanen, S. (2006). Vimentin function in lymphocyte adhesion and transcellular migration. Nat. Cell Biol. 8, 156-162. doi: 10.1038/ncb1355

Nijhara, R., Van Hennik, P. B., Gignac, M. L., Kruhlak, M. J., Hordijk, P. L., Delon, J., et al. (2004). Racl mediates collapse of microvilli on chemokine-activated T lymphocytes. J. Immunol. 173, 4985-4993. doi: 10.4049/jimmunol.173.8.4985

Nishikimi, A., Ishihara, S., Ozawa, M., Etoh, K., Fukuda, M., Kinashi, T., et al. (2014). Rab13 acts downstream of the kinase Mst1 to deliver the integrin LFA-1 to the cell surface for lymphocyte trafficking. Sci. Signal 7:ra72. doi: 10.1126/ scisignal.2005199

Nobile, C., Rudnicka, D., Hasan, M., Aulner, N., Porrot, F., Machu, C., et al. (2010). HIV-1 Nef inhibits ruffles, induces filopodia, and modulates migration of infected lymphocytes. J. Virol. 84, 2282-2293. doi: 10.1128/jvi.02230-09

Nolz, J. C., Fernandez-Zapico, M. E., and Billadeau, D. D. (2007). TCR/CD28stimulated actin dynamics are required for NFAT1-mediated transcription of c-rel leading to CD28 response element activation. J. Immunol. 179, 1104-1112. doi: 10.4049/jimmunol.179.2.1104

Nolz, J. C., Gomez, T. S., Zhu, P., Li, S., Medeiros, R. B., Shimizu, Y., et al. (2006). The WAVE2 complex regulates actin cytoskeletal reorganization and CRAC-mediated calcium entry during T cell activation. Curr. Biol. 16, 24-34. doi: 10.1016/j.cub.2005.11.036

Nordenfelt, P., Elliott, H. L., and Springer, T. A. (2016). Coordinated integrin activation by actin-dependent force during T-cell migration. Nat. Commun. 7:13119. doi: 10.1038/ncomms13119

Northrop, J. P., Ho, S. N., Chen, L., Thomas, D. J., Timmerman, L. A., Nolan, G. P., et al. (1994). NF-AT components define a family of transcription factors targeted in T-cell activation. Nature 369, 497-502. doi: 10.1038/369497a0

Obeidy, P., Ju, L. A., Oehlers, S. H., Zulkhernain, N. S., Lee, Q., Galeano Nino, J. L., et al. (2020). Partial loss of actin nucleator actin-related protein $2 / 3$ activity triggers blebbing in primary T lymphocytes. Immunol. Cell Biol. 98, 93-113. doi: $10.1111 /$ imcb. 12304

Obino, D., Farina, F., Malbec, O., Saez, P. J., Maurin, M., Gaillard, J., et al. (2016). Actin nucleation at the centrosome controls lymphocyte polarity. Nat. Commun. 7:10969. doi: 10.1038/ncomms10969

Okada, K., Bartolini, F., Deaconescu, A. M., Moseley, J. B., Dogic, Z., Grigorieff, N., et al. (2010). Adenomatous polyposis coli protein nucleates actin assembly and synergizes with the formin mDia1. J. Cell Biol. 189, 1087-1096. doi: 10.1083/ jcb.201001016 
Okamura, H., Aramburu, J., Garcia-Rodriguez, C., Viola, J. P., Raghavan, A., Tahiliani, M., et al. (2000). Concerted dephosphorylation of the transcription factor NFAT1 induces a conformational switch that regulates transcriptional activity. Mol. Cell 6, 539-550. doi: 10.1016/s1097-2765(00)00053-8

Okamura, H., Garcia-Rodriguez, C., Martinson, H., Qin, J., Virshup, D. M., and Rao, A. (2004). A conserved docking motif for CK1 binding controls the nuclear localization of NFAT1. Mol. Cell Biol. 24, 4184-4195. doi: 10.1128/mcb.24.10. 4184-4195.2004

O'Keefe, J. P., and Gajewski, T. F. (2005). Cutting edge: cytotoxic granule polarization and cytolysis can occur without central supramolecular activation cluster formation in CD8+ effector T cells. J. Immunol. 175, 5581-5585. doi: 10.4049/jimmunol.175.9.5581

Onnis, A., Finetti, F., Patrussi, L., Gottardo, M., Cassioli, C., Spano, S., et al. (2015). The small GTPase Rab29 is a common regulator of immune synapse assembly and ciliogenesis. Cell Death Differ. 22, 1687-1699. doi: 10.1038/cdd.2015.17

Otomo, T., Otomo, C., Tomchick, D. R., Machius, M., and Rosen, M. K. (2005). Structural basis of Rho GTPase-mediated activation of the formin mDia1. Mol. Cell 18, 273-281. doi: 10.1016/j.molcel.2005.04.002

Oukka, M., Ho, I. C., De La Brousse, F. C., Hoey, T., Grusby, M. J., and Glimcher, L. H. (1998). The transcription factor NFAT4 is involved in the generation and survival of T cells. Immunity 9, 295-304. doi: 10.1016/s1074-7613(00)80612-3

Pageon, S. V., Tabarin, T., Yamamoto, Y., Ma, Y., Nicovich, P. R., Bridgeman, J. S., et al. (2016). Functional role of T-cell receptor nanoclusters in signal initiation and antigen discrimination. Proc. Natl. Acad. Sci. U S A. 113, E5454-E5463. doi: $10.1073 /$ pnas.1607436113

Pan, X., Rudolph, J. M., Abraham, L., Habermann, A., Haller, C., Krijnse-Locker, J., et al. (2012). HIV-1 Nef compensates for disorganization of the immunological synapse by inducing trans-Golgi network-associated Lck signaling. Blood 119, 786-797. doi: 10.1182/blood-2011-08-373209

Park, H., and Doh, J. (2015). Study on the role of microtubules on T cell migration under confined environments. Biomed. Eng. Lett. 5, 188-193. doi: 10.1007/ s13534-015-0197-8

Patino-Lopez, G., Dong, X., Ben-Aissa, K., Bernot, K. M., Itoh, T., Fukuda, M., et al. (2008). Rab35 and its GAP EPI64C in T cells regulate receptor recycling and immunological synapse formation. J. Biol. Chem. 283, 18323-18330. doi: 10.1074/jbc.m800056200

Paul, N. R., Jacquemet, G., and Caswell, P. T. (2015). Endocytic Trafficking of Integrins in Cell Migration. Curr. Biol. 25, R1092-R1105. doi: 10.1016/j.cub. 2015.09.049

Penna, A., Demuro, A., Yeromin, A. V., Zhang, S. L., Safrina, O., Parker, I., et al. (2008). The CRAC channel consists of a tetramer formed by Stim-induced dimerization of Orai dimers. Nature 456, 116-120. doi: 10.1038/nature07338

Pereira, E. A., and Dasilva, L. L. (2016). HIV-1 Nef: Taking Control of Protein Trafficking. Traffic 17, 976-996. doi: 10.1111/tra.12412

Pfisterer, K., Forster, F., Paster, W., Supper, V., Ohradanova-Repic, A., Eckerstorfer, P., et al. (2014). The late endosomal transporter CD222 directs the spatial distribution and activity of Lck. J. Immunol. 193, 2718-2732. doi: 10.4049/ jimmunol.1303349

Phuyal, S., and Farhan, H. (2019). Multifaceted Rho GTPase Signaling at the Endomembranes. Front. Cell Dev. Biol. 7:127. doi: 10.3389/fcell.2019.00127

Piotrowski, J. T., Gomez, T. S., Schoon, R. A., Mangalam, A. K., and Billadeau, D. D. (2013). WASH knockout $\mathrm{T}$ cells demonstrate defective receptor trafficking, proliferation, and effector function. Mol. Cell Biol. 33, 958-973. doi: 10.1128/ mcb.01288-12

Prakriya, M., Feske, S., Gwack, Y., Srikanth, S., Rao, A., and Hogan, P. G. (2006). Orail is an essential pore subunit of the CRAC channel. Nature 443, 230-233. doi: 10.1038/nature05122

Purbhoo, M. A., Irvine, D. J., Huppa, J. B., and Davis, M. M. (2004). T cell killing does not require the formation of a stable mature immunological synapse. Nat. Immunol. 5, 524-530. doi: 10.1038/ni1058

Quann, E. J., Merino, E., Furuta, T., and Huse, M. (2009). Localized diacylglycerol drives the polarization of the microtubule-organizing center in T cells. Nat. Immunol. 10, 627-635. doi: 10.1038/ni.1734

Quintana, A., and Hoth, M. (2012). Mitochondrial dynamics and their impact on T cell function. Cell Calc. 52, 57-63. doi: 10.1016/j.ceca.2012.02.005

Quintana, A., Pasche, M., Junker, C., Al-Ansary, D., Rieger, H., Kummerow, C., et al. (2011). Calcium microdomains at the immunological synapse: how ORAI channels, mitochondria and calcium pumps generate local calcium signals for efficient T-cell activation. EMBO J. 30, 3895-3912. doi: 10.1038/emboj.2011.289 Randzavola, L. O., Strege, K., Juzans, M., Asano, Y., Stinchcombe, J. C., GawdenBone, C. M., et al. (2019). Loss of ARPC1B impairs cytotoxic T lymphocyte maintenance and cytolytic activity. J. Clin. Invest. 129, 5600-5614. doi: 10.1172/ jci129388

Ratner, S., Sherrod, W. S., and Lichlyter, D. (1997). Microtubule retraction into the uropod and its role in T cell polarization and motility. J. Immunol. 159, 1063-1067.

Rauch, S., Pulkkinen, K., Saksela, K., and Fackler, O. T. (2008). Human immunodeficiency virus type 1 Nef recruits the guanine exchange factor Vav1 via an unexpected interface into plasma membrane microdomains for association with p21-activated kinase 2 activity. J. Virol. 82, 2918-2929. doi: 10.1128/jvi.02185-07

Razvag, Y., Neve-Oz, Y., Sajman, J., Reches, M., and Sherman, E. (2018). Nanoscale kinetic segregation of TCR and CD45 in engaged microvilli facilitates early T cell activation. Nat. Commun. 9:732. doi: 10.1038/s41467-018-03127-w

Real, E., Faure, S., Donnadieu, E., and Delon, J. (2007). Cutting edge: Atypical PKCs regulate T lymphocyte polarity and scanning behavior. J. Immunol. 179, 5649-5652. doi: 10.4049/jimmunol.179.9.5649

Ren, C., Yuan, Q., Braun, M., Zhang, X., Petri, B., Zhang, J., et al. (2019). Leukocyte Cytoskeleton Polarization Is Initiated by Plasma Membrane Curvature from Cell Attachment. Dev. Cell 49, 206-219e. doi: 10.1016/j.devcel.2019.02.023

Reth, M. (1989). Antigen receptor tail clue. Nature 338, 383-384. doi: 10.1038/ 338383b0

Ridley, A. J., Schwartz, M. A., Burridge, K., Firtel, R. A., Ginsberg, M. H., Borisy, G., et al. (2003). Cell migration: integrating signals from front to back. Science 302, 1704-1709. doi: 10.1126/science.1092053

Ritter, A. T., Asano, Y., Stinchcombe, J. C., Dieckmann, N. M., Chen, B. C., Gawden-Bone, C., et al. (2015). Actin depletion initiates events leading to granule secretion at the immunological synapse. Immunity 42, 864-876. doi: 10.1016/j.immuni.2015.04.013

Ritter, A. T., Kapnick, S. M., Murugesan, S., Schwartzberg, P. L., Griffiths, G. M., and Lippincott-Schwartz, J. (2017). Cortical actin recovery at the immunological synapse leads to termination of lytic granule secretion in cytotoxic T lymphocytes. Proc. Natl. Acad. Sci. U S A. 114, E6585-E6594. doi: 10.1073/pnas.1710751114

Rivas, F. V., O'keefe, J. P., Alegre, M. L., and Gajewski, T. F. (2004). Actin cytoskeleton regulates calcium dynamics and NFAT nuclear duration. Mol. Cell Biol. 24, 1628-1639. doi: 10.1128/mcb.24.4.1628-1639.2004

Rodgers, W., and Rose, J. K. (1996). Exclusion of CD45 inhibits activity of p56lck associated with glycolipid-enriched membrane domains. J. Cell Biol. 135, 1515-1523. doi: 10.1083/jcb.135.6.1515

Rodriguez-Fernandez, J. L., Sanchez-Martin, L., Rey, M., Vicente-Manzanares, M., Narumiya, S., Teixido, J., et al. (2001). Rho and Rho-associated kinase modulate the tyrosine kinase PYK2 in T-cells through regulation of the activity of the integrin LFA-1. J. Biol. Chem. 276, 40518-40527. doi: 10.1074/jbc.m102896200

Rougerie, P., and Delon, J. (2012). Rho GTPases: masters of T lymphocyte migration and activation. Immunol. Lett. 142, 1-13. doi: 10.1016/j.imlet.2011. 12.003

Roumier, A., Olivo-Marin, J. C., Arpin, M., Michel, F., Martin, M., Mangeat, P., et al. (2001). The membrane-microfilament linker ezrin is involved in the formation of the immunological synapse and in T cell activation. Immunity 15, 715-728. doi: 10.1016/s1074-7613(01)00225-4

Round, J. L., Humphries, L. A., Tomassian, T., Mittelstadt, P., Zhang, M., and Miceli, M. C. (2007). Scaffold protein Dlgh1 coordinates alternative p38 kinase activation, directing $\mathrm{T}$ cell receptor signals toward NFAT but not NF-kappaB transcription factors. Nat. Immunol. 8, 154-161. doi: 10.1038/ni1422

Round, J. L., Tomassian, T., Zhang, M., Patel, V., Schoenberger, S. P., and Miceli, M. C. (2005). Dlgh1 coordinates actin polymerization, synaptic T cell receptor and lipid raft aggregation, and effector function in T cells. J. Exp. Med. 201, 419-430. doi: 10.1084/jem.20041428

Rubinfeld, B., Souza, B., Albert, I., Muller, O., Chamberlain, S. H., Masiarz, F. R., et al. (1993). Association of the APC gene product with beta-catenin. Science 262, 1731-1734. doi: 10.1126/science.8259518

Sako, Y., and Kusumi, A. (1995). Barriers for lateral diffusion of transferrin receptor in the plasma membrane as characterized by receptor dragging by laser 
tweezers: fence versus tether. J. Cell Biol. 129, 1559-1574. doi: 10.1083/jcb.129. 6.1559

Saliba, D. G., Cespedes-Donoso, P. F., Balint, S., Compeer, E. B., Korobchevskaya, K., Valvo, S., et al. (2019). Composition and structure of synaptic ectosomes exporting antigen receptor linked to functional CD40 ligand from helper T cells. Elife 8:e47528. doi: 10.7554/eLife.47528

Sánchez-Madrid, F., and del Pozo, M. A. (1999). Leukocyte polarization in cell migration and immune interactions. EMBO J. 18, 501-511. doi: 10.1093/emboj/ 18.3.501

Sanderson, N. S., Puntel, M., Kroeger, K. M., Bondale, N. S., Swerdlow, M., Iranmanesh, N., et al. (2012). Cytotoxic immunological synapses do not restrict the action of interferon-gamma to antigenic target cells. Proc. Natl. Acad. Sci. U S A. 109, 7835-7840. doi: 10.1073/pnas.1116058109

Saoudi, A., Kassem, S., Dejean, A., and Gaud, G. (2014). Rho-GTPases as key regulators of T lymphocyte biology. Small GTPases 5:e28208. doi: 10.4161/sgtp. 28208

Saveanu, L., Zucchetti, A. E., Evnouchidou, I., Ardouin, L., and Hivroz, C. (2019). Is there a place and role for endocytic TCR signaling? Immunol. Rev. 291, 57-74. doi: 10.1111/imr.12764

Schwartz, M. A. (2010). Integrins and extracellular matrix in mechanotransduction. Cold Spring Harb. Perspect. Biol. 2:a005066. doi: 10.1101/cshperspect.a005066

Serrador, J. M., Alonso-Lebrero, J. L., Del Pozo, M. A., Furthmayr, H., SchwartzAlbiez, R., Calvo, J., et al. (1997). Moesin interacts with the cytoplasmic region of intercellular adhesion molecule- 3 and is redistributed to the uropod of $\mathrm{T}$ lymphocytes during cell polarization. J. Cell .Biol 138, 1409-1423. doi: 10.1083/ jcb.138.6.1409

Serrador, J. M., Nieto, M., Alonso-Lebrero, J. L., Del Pozo, M. A., Calvo, J., Furthmayr, H., et al. (1998). CD43 interacts with moesin and ezrin and regulates its redistribution to the uropods of T lymphocytes at the cell-cell contacts. Blood 91, 4632-4644. doi: 10.1182/blood.v91.12.4632.412k17_4632_4644

Serrador, J. M., Urzainqui, A., Alonso-Lebrero, J. L., Cabrero, J. R., Montoya, M. C., Vicente-Manzanares, M., et al. (2002). A juxta-membrane amino acid sequence of P-selectin glycoprotein ligand-1 is involved in moesin binding and ezrin/radixin/moesin-directed targeting at the trailing edge of migrating lymphocytes. Eur. J. Immunol. 32, 1560-1566. doi: 10.1002/1521-4141(200206) 32:6<1560::aid-immu1560>3.0.co;2-u

Shaffer, M. H., Dupree, R. S., Zhu, P., Saotome, I., Schmidt, R. F., Mcclatchey, A. I., et al. (2009). Ezrin and moesin function together to promote T cell activation. J. Immunol. 182, 1021-1032. doi: 10.4049/jimmunol.182.2.1021

Sharma, S., Findlay, G. M., Bandukwala, H. S., Oberdoerffer, S., Baust, B., Li, Z., et al. (2011). Dephosphorylation of the nuclear factor of activated T cells (NFAT) transcription factor is regulated by an RNA-protein scaffold complex. Proc. Natl. Acad. Sci. U S A. 108, 11381-11386. doi: 10.1073/pnas.1019711108

Sharma, S., Quintana, A., Findlay, G. M., Mettlen, M., Baust, B., Jain, M., et al. (2013). An siRNA screen for NFAT activation identifies septins as coordinators of store-operated Ca2+ entry. Nature 499, 238-242. doi: 10.1038/nature12229

Shiratori, T., Miyatake, S., Ohno, H., Nakaseko, C., Isono, K., Bonifacino, J. S., et al. (1997). Tyrosine phosphorylation controls internalization of CTLA-4 by regulating its interaction with clathrin-associated adaptor complex AP-2. Immunity 6, 583-589. doi: 10.1016/s1074-7613(00)80346-5

Silva, O., Crocetti, J., Humphries, L. A., Burkhardt, J. K., and Miceli, M. C. (2015). Discs Large Homolog 1 Splice Variants Regulate p38-Dependent and -Independent Effector Functions in CD8+ T Cells. PLoS One 10:e133353. doi: 10.1371 /journal.pone. 0133353

Silvin, C., Belisle, B., and Abo, A. (2001). A role for Wiskott-Aldrich syndrome protein in T-cell receptor-mediated transcriptional activation independent of actin polymerization. J. Biol. Chem. 276, 21450-21457. doi: 10.1074/jbc. m010729200

Simons, K., and Gerl, M. J. (2010). Revitalizing membrane rafts: new tools and insights. Nat. Rev. Mol. Cell Biol. 11, 688-699. doi: 10.1038/nrm2977

Sims, T. N., Soos, T. J., Xenias, H. S., Dubin-Thaler, B., Hofman, J. M., Waite, J. C., et al. (2007). Opposing effects of PKCtheta and WASp on symmetry breaking and relocation of the immunological synapse. Cell 129, 773-785. doi: 10.1016/j.cell.2007.03.037

Singer, I. I, Scott, S., Kawka, D. W., Chin, J., Daugherty, B. L., Demartino, J. A., Disalvo, J., et al. (2001). CCR5, CXCR4, and CD4 are clustered and closely apposed on microvilli of human macrophages and T cells. J. Virol. 75 , 3779-3790. doi: 10.1128/jvi.75.8.3779-3790.2001

Skokos, D., Shakhar, G., Varma, R., Waite, J. C., Cameron, T. O., Lindquist, R. L., et al. (2007). Peptide-MHC potency governs dynamic interactions between $\mathrm{T}$ cells and dendritic cells in lymph nodes. Nat. Immunol. 8, 835-844. doi: 10.1038/ni1490

Smith, A., Carrasco, Y. R., Stanley, P., Kieffer, N., Batista, F. D., and Hogg, N. (2005). A talin-dependent LFA-1 focal zone is formed by rapidly migrating $\mathrm{T}$ lymphocytes. J. Cell Biol. 170, 141-151. doi: 10.1083/jcb.200412032

Soares, H., Henriques, R., Sachse, M., Ventimiglia, L., Alonso, M. A., Zimmer, C., et al. (2013). Regulated vesicle fusion generates signaling nanoterritories that control T cell activation at the immunological synapse. J. Exp. Med. 210, 2415-2433. doi: 10.1084/jem.20130150

Stephen, L. A., Elmaghloob, Y., Mcilwraith, M. J., Yelland, T., Castro Sanchez, P., Roda-Navarro, P., et al. (2018). The Ciliary Machinery Is Repurposed for T Cell Immune Synapse Trafficking of LCK. Dev. Cell 47, 122-132 e124. doi: 10.1016/j.devcel.2018.08.012

Stewart, M. P., Mcdowall, A., and Hogg, N. (1998). LFA-1-mediated adhesion is regulated by cytoskeletal restraint and by a $\mathrm{Ca} 2+-$ dependent protease, calpain. J. Cell Biol. 140, 699-707. doi: 10.1083/jcb.140.3.699

Stewart, M., and Hogg, N. (1996). Regulation of Leukocyte Integrin Function: Affinity vs. Avidity. 61, 554-561. doi: 10.1002/(sici)1097-4644(19960616)61: $4<554::$ aid-jcb8 $>3.0 . c 0 ; 2-n$

Stinchcombe, J. C., Bossi, G., Booth, S., and Griffiths, G. M. (2001). The immunological synapse of CTL contains a secretory domain and membrane bridges. Immunity 15, 751-761. doi: 10.1016/s1074-7613(01)00234-5

Stinchcombe, J. C., Majorovits, E., Bossi, G., Fuller, S., and Griffiths, G. M. (2006). Centrosome polarization delivers secretory granules to the immunological synapse. Nature 443, 462-465. doi: 10.1038/nature05071

Stolp, B., Abraham, L., Rudolph, J. M., and Fackler, O. T. (2010). Lentiviral Nef proteins utilize PAK2-mediated deregulation of cofilin as a general strategy to interfere with actin remodeling. J. Virol. 84, 3935-3948. doi: 10.1128/jvi.0246709

Stolp, B., and Fackler, O. T. (2011). How HIV takes advantage of the cytoskeleton in entry and replication. Viruses 3, 293-311. doi: 10.3390/v3040293

Stolp, B., Imle, A., Coelho, F. M., Hons, M., Gorina, R., Lyck, R., et al. (2012). HIV1 Nef interferes with T-lymphocyte circulation through confined environments in vivo. Proc. Natl. Acad. Sci. U S A. 109, 18541-18546. doi: 10.1073/pnas. 1204322109

Su, L., Pan, P., Yan, P., Long, Y., Zhou, X., Wang, X., et al. (2019). Role of vimentin in modulating immune cell apoptosis and inflammatory responses in sepsis. Sci. Rep. 9:5747. doi: 10.1038/s41598-019-42287-7

Sudhaharan, T., Goh, W. I., Sem, K. P., Lim, K. B., Bu, W., and Ahmed, S. (2011). Rho GTPase Cdc42 is a direct interacting partner of Adenomatous Polyposis Coli protein and can alter its cellular localization. PLoS One 6:e16603. doi: 10.1371/journal.pone.0016603

Sudhof, T. C., and Rizo, J. (2011). Synaptic vesicle exocytosis. Cold Spr. Harb. Perspect. Biol. 3:a005637. doi: 10.1101/cshperspect.a005637

Svensson, L., Stanley, P., Willenbrock, F., and Hogg, N. (2012). The Galphaq/11 proteins contribute to $\mathrm{T}$ lymphocyte migration by promoting turnover of integrin LFA-1 through recycling. PLoS One 7:e38517. doi: 10.1371/journal. pone. 0038517

Swamy, M., Beck-Garcia, K., Beck-Garcia, E., Hartl, F. A., Morath, A., Yousefi, O. S., et al. (2016). A Cholesterol-Based Allostery Model of T Cell Receptor Phosphorylation. Immunity 44, 1091-1101. doi: 10.1016/j.immuni.2016. 04.011

Takesono, A., Heasman, S. J., Wojciak-Stothard, B., Garg, R., and Ridley, A. J. (2010). Microtubules regulate migratory polarity through Rho/ROCK signaling in T cells. PLoS One 5:e8774. doi: 10.1371/journal.pone.0008774

Tamzalit, F., Tran, D., Jin, W., Boyko, V., Bazzi, H., Kepecs, A., et al. (2020). Centrioles control the capacity, but not the specificity, of cytotoxic $\mathrm{T}$ cell killing. Proc. Natl. Acad. Sci. U S A. 117, 4310-4319. doi: 10.1073/pnas.1913220117

Tamzalit, F., Wang, M. S., Jin, W., Tello-Lafoz, M., Boyko, V., Heddleston, J. M., et al. (2019). Interfacial actin protrusions mechanically enhance killing by cytotoxic T cells. Sci. Immunol. 4:eaav5445. doi: 10.1126/sciimmunol.aav5445

Thauland, T. J., and Parker, D. C. (2010). Diversity in immunological synapse structure. Immunology 131, 466-472. doi: 10.1111/j.1365-2567.2010.03366.x 
Thibaut, R., Bost, P., Milo, I., Cazaux, M., Lemaître, F., Garcia, Z., et al. (2020). Bystander IFN- $\gamma$ activity promotes widespread and sustained cytokine signaling altering the tumor microenvironment. Nat. Cancer 1, 302-314. doi: 10.1038/ s43018-020-0038-2

Thoulouze, M. I., Sol-Foulon, N., Blanchet, F., Dautry-Varsat, A., Schwartz, O., and Alcover, A. (2006). Human immunodeficiency virus type-1 infection impairs the formation of the immunological synapse. Immunity 24, 547-561. doi: 10.1016/j.immuni.2006.02.016

Tooley, A. J., Gilden, J., Jacobelli, J., Beemiller, P., Trimble, W. S., Kinoshita, M., et al. (2009). Amoeboid T lymphocytes require the septin cytoskeleton for cortical integrity and persistent motility. Nat. Cell Biol. 11, 17-26. doi: $10.1038 /$ ncb 1808

Torralba, D., Baixauli, F., Villarroya-Beltri, C., Fernandez-Delgado, I., LatorrePellicer, A., Acin-Perez, R., et al. (2018). Priming of dendritic cells by DNAcontaining extracellular vesicles from activated $\mathrm{T}$ cells through antigen-driven contacts. Nat. Commun. 9:2658. doi: 10.1038/s41467-018-05077-9

Tsun, A., Qureshi, I., Stinchcombe, J. C., Jenkins, M. R., De La Roche, M., Kleczkowska, J., et al. (2011). Centrosome docking at the immunological synapse is controlled by Lck signaling. J. Cell Biol. 192, 663-674. doi: 10.1083/ jcb. 201008140

Ueda, H., Morphew, M. K., Mcintosh, J. R., and Davis, M. M. (2011). CD4+ T-cell synapses involve multiple distinct stages. Proc. Natl. Acad. Sci. U S A. 108, 17099-17104. doi: 10.1073/pnas.1113703108

Ueda, H., Zhou, J., Xie, J., and Davis, M. M. (2015). Distinct Roles of Cytoskeletal Components in Immunological Synapse Formation and Directed Secretion. J. Immunol. 195, 4117-4125. doi: 10.4049/jimmunol.1402175

Upla, P., Marjomaki, V., Kankaanpaa, P., Ivaska, J., Hyypia, T., Van Der Goot, F. G., et al. (2004). Clustering induces a lateral redistribution of alpha 2 beta 1 integrin from membrane rafts to caveolae and subsequent protein kinase C-dependent internalization. Mol. Biol. Cell 15, 625-636. doi: 10.1091/mbc.e03-080588

Valitutti, S., Muller, S., Dessing, M., and Lanzavecchia, A. (1996). Different responses are elicited in cytotoxic $\mathrm{T}$ lymphocytes by different levels of $\mathrm{T}$ cell receptor occupancy. J. Exp. Med. 183, 1917-1921. doi: 10.1084/jem.183.4.1917

Valitutti, S., Müller, S., Salio, M., and Lanzavecchia, A. (1997). Degradation of T cell receptor (TCR)-CD3-z complexes after antigenic stimulation. J. Exp. Med. 185, 1859-1864. doi: 10.1084/jem.185.10.1859

van Kooyk, Y., Van Vliet, S. J., and Figdor, C. G. (1999). The actin cytoskeleton regulates LFA-1 ligand binding through avidity rather than affinity changes. J. Biol. Chem. 274, 26869-26877. doi: 10.1074/jbc.274.38.26869

van Zanten, T. S., Cambi, A., Koopman, M., Joosten, B., Figdor, C. G., and Garcia-Parajo, M. F. (2009). Hotspots of GPI-anchored proteins and integrin nanoclusters function as nucleation sites for cell adhesion. Proc. Natl. Acad. Sci. U S A. 106, 18557-18562. doi: 10.1073/pnas.0905217106

Vardhana, S., Choudhuri, K., Varma, R., and Dustin, M. L. (2010). Essential role of ubiquitin and TSG101 protein in formation and function of the central supramolecular activation cluster. Immunity 32, 531-540. doi: 10.1016/j. immuni.2010.04.005

Varma, R., Campi, G., Yokosuka, T., Saito, T., and Dustin, M. L. (2006). T cell receptor-proximal signals are sustained in peripheral microclusters and terminated in the central supramolecular activation cluster. Immunity 25, 117-127. doi: 10.1016/j.immuni.2006.04.010

Vicente-Manzanares, M., and Sanchez-Madrid, F. (2004). Role of the cytoskeleton during leukocyte responses. Nat. Rev. Immunol. 4, 110-122. doi: 10.1038/ nri1268

Vicente-Manzanares, M., Choi, C. K., and Horwitz, A. R. (2009). Integrins in cell migration-the actin connection. J. Cell Sci. 122, 199-206. doi: 10.1242/jcs. 018564

Vigorito, E., Billadeu, D. D., Savoy, D., Mcadam, S., Doody, G., Fort, P., et al. (2003). RhoG regulates gene expression and the actin cytoskeleton in lymphocytes. Oncogene 22, 330-342. doi: 10.1038/sj.onc.1206116

Villarroya-Beltri, C., Gutierrez-Vazquez, C., Sanchez-Cabo, F., Perez-Hernandez, D., Vazquez, J., Martin-Cofreces, N., et al. (2013). Sumoylated hnRNPA2B1 controls the sorting of miRNAs into exosomes through binding to specific motifs. Nat. Commun. 4:2980. doi: 10.1038/ncomms3980

Viola, A., and Gupta, N. (2007). Tether and trap: regulation of membrane-raft dynamics by actin-binding proteins. Nat. Rev. Immunol. 7, 889-896. doi: 10 . $1038 /$ nri2193
Vivar, O. I., Masi, G., Carpier, J. M., Magalhaes, J. G., Galgano, D., Pazour, G. J., et al. (2016). IFT20 controls LAT recruitment to the immune synapse and T-cell activation in vivo. Proc. Natl. Acad. Sci. U S A. 113, 386-391. doi: 10.1073/pnas. 1513601113

Wang, H. Y., Altman, Y., Fang, D., Elly, C., Dai, Y., Shao, Y., et al. (2001). Cbl promotes ubiquitination of the $\mathrm{T}$ cell receptor zeta through an adaptor function of Zap-70. J. Biol. Chem. 276, 26004-26011. doi: 10.1074/jbc.m010738200

Watanabe, T., Wang, S., Noritake, J., Sato, K., Fukata, M., Takefuji, M., et al. (2004). Interaction with IQGAP1 links APC to Rac1, Cdc42, and actin filaments during cell polarization and migration. Dev. Cell 7, 871-883. doi: 10.1016/j.devcel. 2004.10.017

Waterman-Storer, C. M., Worthylake, R. A., Liu, B. P., Burridge, K., and Salmon, E. D. (1999). Microtubule growth activates Racl to promote lamellipodial protrusion in fibroblasts. Nat. Cell Biol. 1, 45-50. doi: 10.1038/9018

Wiedemann, A., Depoil, D., Faroudi, M., and Valitutti, S. (2006). Cytotoxic T lymphocytes kill multiple targets simultaneously via spatiotemporal uncoupling of lytic and stimulatory synapses. Proc. Natl. Acad. Sci. U S A. 103, 10985-10990. doi: 10.1073/pnas.0600651103

Wittmann, T., Bokoch, G. M., and Waterman-Storer, C. M. (2004). Regulation of microtubule destabilizing activity of Op18/stathmin downstream of Rac1. J. Biol. Chem 279, 6196-6203. doi: 10.1074/jbc.m307261200

Wong, C., Chen, C., Wu, Q., Liu, Y., and Zheng, P. (2015). A critical role for the regulated wnt-myc pathway in naive T cell survival. J. Immunol. 194, 158-167. doi: 10.4049/jimmunol.1401238

Wu, J., Motto, D. G., Koretzky, G. A., and Weiss, A. (1996). Vav and SLP-76 interact and functionally cooperate in IL2 gene activation. Immunity 4, 593-602. doi: 10.1016/s1074-7613(00)80485-9

Wu, Y., Borde, M., Heissmeyer, V., Feuerer, M., Lapan, A. D., Stroud, J. C., et al. (2006). FOXP3 controls regulatory $\mathrm{T}$ cell function through cooperation with NFAT. Cell 126, 375-387. doi: 10.1016/j.cell.2006.05.042

Wunderlich, L., Farago, A., Downward, J., and Buday, L. (1999). Association of Nck with tyrosine-phosphorylated SLP-76 in activated T lymphocytes. Eur. J. Immunol. 29, 1068-1075. doi: 10.1002/(sici)1521-4141(199904)29:04<1068:: aid-immu1068>3.0.co;2-p

Xavier, R., Rabizadeh, S., Ishiguro, K., Andre, N., Ortiz, J. B., Wachtel, H., et al. (2004). Discs large (Dlg1) complexes in lymphocyte activation. J. Cell Biol. 166, 173-178. doi: 10.1083/jcb.200309044

Yablonski, D., Kane, L. P., Qian, D., and Weiss, A. (1998a). A Nck-Pak1 signaling module is required for T-cell receptor-mediated activation of NFAT, but not of JNK. EMBO J. 17, 5647-5657. doi: 10.1093/emboj/17.19.5647

Yablonski, D., Kuhne, M. R., Kadlecek, T., and Weiss, A. (1998b). Uncoupling of nonreceptor tyrosine kinases from PLC-gammal in an SLP-76-deficient T cell. Science 281, 413-416. doi: 10.1126/science.281.5375.413

Yanez-Mo, M., Siljander, P. R., Andreu, Z., Zavec, A. B., Borras, F. E., Buzas, E. I., et al. (2015). Biological properties of extracellular vesicles and their physiological functions. J. Extr. Ves. 4:27066. doi: 10.3402/jev.v4.27066

Yi, J., Wu, X. S., Crites, T., and Hammer, J. A. 3rd.,. (2012). Actin retrograde flow and actomyosin II arc contraction drive receptor cluster dynamics at the immunological synapse in Jurkat T cells. Mol. Biol. Cell 23, 834-852. doi: 10.1091/mbc.e11-08-0731

Yokosuka, T., Sakata-Sogawa, K., Kobayashi, W., Hiroshima, M., Hashimoto-Tane, A., Tokunaga, M., et al. (2005). Newly generated T cell receptor microclusters initiate and sustain T cell activation by recruitment of Zap70 and SLP-76. Nat. Immunol. 6, 1253-1262. doi: 10.1038/ni1272

Yoo, S. K., Lam, P. Y., Eichelberg, M. R., Zasadil, L., Bement, W. M., and Huttenlocher, A. (2012). The role of microtubules in neutrophil polarity and migration in live zebrafish. J. Cell Sci. 125, 5702-5710. doi: 10.1242/jcs.108324

Yudushkin, I. A., and Vale, R. D. (2010). Imaging T-cell receptor activation reveals accumulation of tyrosine-phosphorylated CD3zeta in the endosomal compartment. Proc. Natl. Acad. Sci. U S A. 107, 22128-22133. doi: 10.1073/ pnas. 1016388108

Zhang, S. L., Yu, Y., Roos, J., Kozak, J. A., Deerinck, T. J., Ellisman, M. H., et al. (2005). STIM1 is a Ca2+ sensor that activates CRAC channels and migrates from the $\mathrm{Ca} 2+$ store to the plasma membrane. Nature 437, 902-905. doi: 10.1038 /nature04147

Zhang, W., Sloan-Lancaster, J., Kitchen, J., Trible, R. P., and Samelson, L. E. (1998). LAT: the ZAP-70 tyrosine kinase substrate that links $\mathrm{T}$ cell receptor to cellular activation. Cell 92, 83-92. doi: 10.1016/s0092-8674(00)80901-0 
Zhang, Y., Shen, H., Liu, H., Feng, H., Liu, Y., Zhu, X., et al. (2017). Arp2/3 complex controls $\mathrm{T}$ cell homeostasis by maintaining surface TCR levels via regulating TCR. Sci. Rep. 7:8952. doi: 10.1038/s41598-017-08357-4

Zucchetti, A. E., Bataille, L., Carpier, J. M., Dogniaux, S., San Roman-Jouve, M., Maurin, M., et al. (2019). Tethering of vesicles to the Golgi by GMAP210 controls LAT delivery to the immune synapse. Nat. Commun. $10: 2864$.

Zurli, V., Montecchi, T., Heilig, R., Poschke, I., Volkmar, M., Wimmer, G., et al. (2020). Phosphoproteomics of CD2 signaling reveals AMPK-dependent regulation of lytic granule polarization in cytotoxic T cells. Sci. Signal. 13:eaaz1965. doi: 10.1126/scisignal.aaz1965
Conflict of Interest: The authors declare that the research was conducted in the absence of any commercial or financial relationships that could be construed as a potential conflict of interest.

Copyright (c) 2020 Mastrogiovanni, Juzans, Alcover and Di Bartolo. This is an openaccess article distributed under the terms of the Creative Commons Attribution License (CC BY). The use, distribution or reproduction in other forums is permitted, provided the original author(s) and the copyright owner(s) are credited and that the original publication in this journal is cited, in accordance with accepted academic practice. No use, distribution or reproduction is permitted which does not comply with these terms. 